\title{
BC-TOP-4-A
}

Revision 3

November 1974

\section{TOPICAL REPORT \\ SEISMIC ANALYSES OF \\ STRUCTURES AND EQUIPMENT \\ FOR NUCLEAR POWER PLANTS}

Bechtel Power Corporation

San Francisco, California

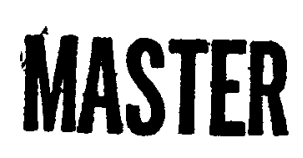


BC-TOP -4

Rev. 2

CAVEAT: THIS REPORT HAS BEEN PREPARED BY AND FOR THE USE OF BECHTEL POWER CORPORATION AND ITS RELATED ENTITIES. ITS USE BY OTHERS IS PERMITTED ONLY ON THE UNDERSTANDING THAT THERE ARE NO REPRESENTATIONS OR WARRANTIES, EXPRESS OR IMPLIED, AS TO THE VALIDITY OF THE INFORMATION OR CONCLUSIONS CONTAINED HEREIN. 


\section{DISCLAIMER}

This report was prepared as an account of work sponsored by an agency of the United States Government. Neither the United States Government nor any agency Thereof, nor any of their employees, makes any warranty, express or implied, or assumes any legal liability or responsibility for the accuracy, completeness, or usefulness of any information, apparatus, product, or process disclosed, or represents that its use would not infringe privately owned rights. Reference herein to any specific commercial product, process, or service by trade name, trademark, manufacturer, or otherwise does not necessarily constitute or imply its endorsement, recommendation, or favoring by the United States Government or any agency thereof. The views and opinions of authors expressed herein do not necessarily state or reflect those of the United States Government or any agency thereof. 


\section{DISCLAIMER}

Portions of this document may be illegible in electronic image products. Images are produced from the best available original document. 


\author{
TOPICAL REPORT \\ BC-TOP $-4-A$ \\ Revision 3 \\ SEISMIC ANALYSES \\ OF \\ STRUCTURES AND EQUIPMENT \\ FOR \\ NUCLEAR POWER PLANTS
}

Prepared By:

N. C. Tsai

A. H. Hadjian

P. T. Kuo

M. J. Adair

W. M. Morrow

G. C. K. Yeh

S. L. Sobkowski

Approved By:

H. W. Wahl

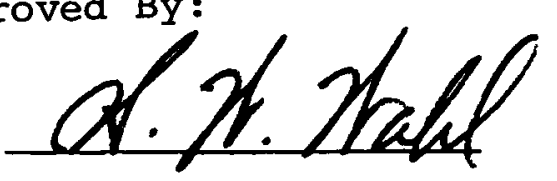

Bechtel Power Corporation

Issue Date: September 1974

San Francisco, California 


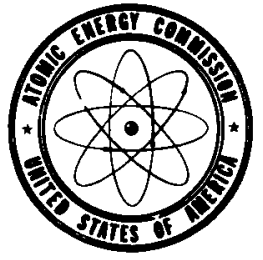

\author{
UNITED STATES \\ ATOMIC ENERGY COMMISSION \\ WASHINGTON, D.C. 20545
}

OCT 3 I 1974

Mr. John V. Morowski

Vice President-Engineering

Bechtel Power Corporation

Fifty Beale Street

San Francisco, California 94119

Dear Mr. Morowski:

The Regulatory staff has completed its review of Bechtel Power Corporation's Topical Report, BC-TOP-4, Revision 3, dated September 1974 and entitled "Seismic Analyses of Structures and Equipment for Nuclear Power Plants". We conclude that the design criterla and procedures described by this report are acceptable to the Regulatory staff and that BC-TOP -4 , Revision 3, is acceptable by reference in applications for construction permits and operating licenses. A summary of our evaluation is enclosed.

BC-TOP-4 does not provide all of the pertinent information required by the Regulatory staff in its review of specific applications. Therefore, the appropriate supplementary information identified in the Regulatory Position of the enclosed Topical Report Evaluation will have to be provided in individual Safety Analysis Reports.

The staff does not intend to repeat its review of BC-TOP-4, Revision 3 , when it appears as a reference in a particular license application. Should Regulatory criteria or regulations change, such that our conclusions concerning $\mathrm{BC}-\mathrm{TOP}-4$, Revision 3, are invalidated, you will be notified and given the opportunity to revise and resubmit your topical report for review, should you do desire. 
We request that you reissue $\mathrm{BC}-\mathrm{TOP}-4$, Revision 3, dated September 1974 in accordance with the provisions of the "Elements of the Regulatory Staff Topical Report Review Program" which was forwarded to you on August 26, 1974. If you have any questions in this regard, please let us know.

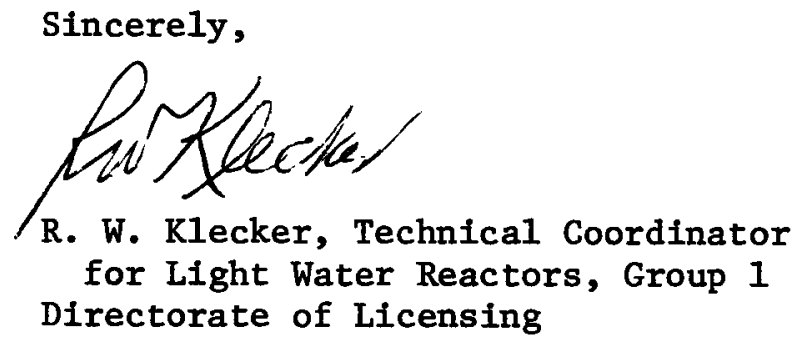

Enclosure:

Topical Report Evaluation 


\section{TOPICAL REPORT EVALUATION}

Report No.: BC-TOP-4 Rev. 3

Report Title: Seismic Analyses of Structures and Equipment for Nuclear Power Plants

Report Date: September 1974

Originating Organization: Bechtel Power Corporation

Reviewed by: Structural Engineering Branch

\section{SUMMARY OF REPORT}

This topical report contains the current general practice used by Bechtel Power Corporation for the seismic analysis of nuclear power plant structures and components. This includes the specification of design earthquakes, the establishment of mathematical models for structures and components, and the various applicable methods of computing seismic responses such as floor accelerations, shears, moments and displacements.

Evaluation of regional geology and seismicity has been discussed for background information. Design earthquake motions are described and are in general accordance with Appendix A to 10 CFR 100 and Reguiatory Guide 1.60 .

To predict the seismic response of Category I structures subjected to design earthquakes, mathematical models are established and the equations of motion for the models are formulated. Structural deformations are assumed to be small and linearly elastic. Equivalent linear properties of soils are used to represent the nonlinear stressstrain relationship of foundation soils. Modal damping values associated with the energy dissipations of the structural system are determined by applying a proper weighting matrix to the 
associated damping values adopted from Regulatory Guide 1.61

Lumped parameter and finite element representations for soil-structure interaction analysis will be used where considered necessary and are described.

Analytical techniques for computing structural response are described including the following:

1. Method of modal superposition

a. Response spectrum technique

b. Time history technique

2. Method of direct integration.

Methods of combining modal responses and responses to the three components of earthquake motions have also been discussed. Procedures of generating floor or in-structure response spectra with appropriate consideration of frequency interval and frequency variation are also described.

Procedures for analysis of long, buried structures for seismic motions are described and are based on the theory of seismic wave propagation. Effects of soil-structure differential movements have been considered.

In Appendix A, a cross-reference list of subjects covered by this report is provided to enable identification with the AEC Standard Format and Content of Safety Analysis Reports. Appendices B, C, $D$, and $E$ contain a discussion of minimum number of lumped masses, lateral torsional motion, structure-foundation analysis and modeling 
of cylindrical containment structures respectively. Appendix $G$ contains a list of computer codes used by Bechtel in seismic analysis, and Appendix $\mathrm{H}$ contains a commentary on soil-structure interaction. SUMMARY OF THE REGULATORY EVALUATION

The Structural Engineering Branch, Directorate of Licensing, has reviewed the subject report including Appendices $A, B, C, D, E, G$, and $H$, with the exception of certain portions that are provided solely for information purposes including Sections 2.1 thru 2.4 which discuss geology, soil conditions and seismology. These subjects are not within the review responsibility of the Structural Engineering Branch. Appendix $G$ contains a list of computer codes used by Bechtel Corporation for seismic analysis. The Structural Engineering Branch has neither reviewed nor certified these computer programs.

The seismic analysis procedures covered by this report, as augmented by pertinent referenced information to be provided in individual plants SARs, have been reviewed and are judged to represent the present "state of the art" in the field of seismic analysis of structures and components. If properly utilized in nuclear power plant structural design work, the procedures and criteria contained in the report should provide conservative and acceptable bases for seismic design.

REGULATORY POSITION

The design criteria and procedures described by this report are acceptable to the Regulatory Staff. The report may be referenced in 
all case applications docketed prior to the issuance of the forthcoming AEC Regulatory Standard Review Plans, provided that the following specific information reviewed and accepted by the Regulatory Staff is included in individual SAR:

a. The bases for a site dependent analys is if used to develop the shape of the design response spectra from bedrock time history of response spectra input.

b. A list of all soil-supported Category I structures and the corresponding depth of soil over bedrock.

c. Parameters that governs use of analytical methods to investigate soil-structure interaction such as depth of structural embedment in soil, non-homogeneity of soil properties and geometry of structural foundation.

d. Selection of soil-structure interaction analysis methods (lumped spring, finite element or others) to be used for Category I structures.

e. A summary of natural frequencies and response loads determined by the seismic system analysis. (FSAR)

f. Comparison of responses obtained from both response spectrum and time history methods. (FSAR)

g. Methods for seismic analysis of dams, if any.

h. Basis for selection of forcing frequencies to preclude resonance, if applicable. 
no. $: 52674$

$-5-$

i. Procedures for field location of supports and restraints. (FSAR)

j. Seismic analyses for fuel elements, control rod assemblies and control rod drives.

This topical report does not include seismic analysis of piping systems which forms the subject of another Bechtel Power Corporation's Topical Report, BP-TOP-1. All items concerning seismic analysis of piping systems should therefore be either referred to BP-TOP-1 which is being reviewed by the Regulatory Staff, or provided in individual SAR. 
BC-TOP-4-A

Rev. 3

\section{ABSTRACT}

This topical report presents the current, general practice within Bechtel Power Corporation for the seismic analysis of nuclear power plant structures and components. This includes the specification of design earthquakes, the establishment of the mathematical models for structures and components, and the various applicable methods of computing seismic responses. This topical does not include criteria on the use of the computed seismic response in conjunction with other applicable loads for the structural design. 
$\mathrm{BC}-\mathrm{TOP}-4-\mathrm{A}$

Rev. 3

NOTATIONS

TABLE OF CONTENTS

1.0 INTRODUCTION

2.0 SITE EVALUATION AND DESIGN EARTHQUAKE

2.1 Summary

2.2 Evaluation of Geology

2.3 Stability Evaluation of Subsurface Materials and Slopes

2.4 Evaluation of Seismicity

2.5 Specification of Safe Shutdown Earthquake

3.0 MODELING TECHNIQUES FOR STRUCTURES AND FOUNDATIONS

3.1 Summary

3.2 Mathematic Modeling of Structures

3.3 Structure-Foundation Interaction

3.4 Example - Pressurized Water Reactor

4.0 STRUCTURAL RESPONSE

4.1 Summary

4.2 Response Analysis

4.3 Total Structural Response from Separate Lateral and Vertical Analyses

4.4 Structural Overturning and Soil Pressure

4.5 Example - Pressurized Water Reactor

5.0 ANALYSIS OF PLANT COMPONENTS

5.1 Summary

5.2 Generation of Floor Response Spectrum

5.3 Dynamic Analysis

6.0 ANALYSIS OF LONG, BURIED STRUCTURES

6.1 Summary

6.2 Stresses Due to Free Field Seismic Wave Propagation

6.3 Stresses Due to Soil Building Differential Movements

\section{APPENDICES}

A Cross Reference Listing to AEC Format

B Minimum Number of Lumped Masses Versus Number of Modes Used

C Lateral-Torsional Motion Due to Lateral Excitation

D Analysis of Structure-Foundation Systems

E Validity of Modeling a Cylindrical Containment structure by Cantilever Beam

F (Deleted)

$G$ Computer Codes for Seismic Analysis

$\mathrm{H}$ Commentary on Soil-Structure Interaction 


\section{NOTATIONS}

The following notations were used in the text:

A

b

B

$c_{p}, c_{s}$

$c_{x}, c_{\psi}, c_{z}$

$c_{x}^{\prime}, c_{\psi}^{\prime}, c_{z}^{\prime}$

C

[C]

d, $d^{\prime}$

E

E

$\mathbf{E}_{\mathbf{S}}$
Cross section area.

Effective width of structure normal to the plane of horizontal vibration.

Width of rectangular base slab in the plane of horizontal vibration.

Compressional and shear wave velocities.

Total, equivalent interaction damping for horizontal translation, rocking and vertical translation for lumped parameter soil-structure interaction analysis.

Equivalent interaction damping due to foundation medium below the base slab.

Circumference of structural cross section. Damping matrix.

Depth of the base slab below grade and below ground water table, respectively.

Young's modulus.

Kinetic energy of structure in the overturning evaluation.

Energy required to overturn the structure. 
Friction coefficient between soil and structure.

$f_{e}$

$\mathbf{f}_{j}$

$\Delta \mathrm{f}_{\mathrm{j}}$

F

g

G

$\mathrm{h}$

$h_{i}, h_{j}$

$\Delta \mathrm{h}$

$\mathrm{H}$

I

$I_{0}$

k
Fundamental equipment frequency in cps.

Structural frequency in cps.

Variation in structural frequency.

Friction force per unit length for buried structure, along the structural axis.

Gravity constant.

Shear modulus.

Embedment depth (same as d).

Layer thickness.

Vertical distance for which the center of mass of structure must be lifted to overturn the structure.

Depth of buried structure from the grade.

Moment of inertia of a cross section, or mass moment of inertia.

Total mass moment of inertia of structure about the base rotation center.

Spring constant of the soil perpendicular to the axis of buried structures in the elastic foundation representation $\left(=\mathrm{Bk}_{\mathrm{s}}\right)$. 


$$
\begin{aligned}
& k_{p} \\
& k_{s}
\end{aligned}
$$$$
k_{x}, k_{\psi}, k_{z}
$$$$
k_{x}^{\prime}, k_{\psi}^{\prime}, k_{z}^{\prime}
$$$$
k_{x}^{\prime \prime}, k_{\psi}^{\prime \prime}, k_{z}^{\prime \prime}
$$

L

$$
\mathrm{m}_{\mathrm{i}}
$$$$
\mathrm{m}_{\mathrm{o}}
$$$$
\bar{m}_{j}
$$$$
\mathrm{M}_{\mathrm{x}}, \mathrm{M}_{\mathrm{y}}
$$$$
M(x)
$$

Coefficient for passive soil pressure.

Coefficient of subgrade reaction of soil for a beam.

Total equivalent interaction springs for horizontal translation, rocking and vertical translation at the base.

Contributions from the foundation medium below base slab, to the total equivalent interaction springs.

Contributions due to embedment, to the total equivalent interaction springs.

Sitffness matrix.

Dimension of rectangular base slab perpendicular to plane of horizontal vibration.

Mass.

Total mass of structure and base slab.

Generalized mass.

Maximum values of base moments.

Bending moment distribution along buried structures.

Mass matrix.

Operating Basis Earthquake. 
BC-TOP-4-A

Rev. 3

$P_{d r y} P_{s u b}$

$q_{j}(t)$

$Q(x)$

$r_{v}$

R

$\mathrm{S}$

Sa, sd

SAR

SSE

$t$

$\Delta t$

$\ddot{u}(t)$

$\mathrm{v}$

$v_{p}, v_{s}$

$\mathrm{v}_{\mathrm{H}}, \mathrm{v}_{\mathrm{V}}$

$\mathbf{v}_{\mathbf{x}}$
Passive soil pressures above and below ground water table.

Generalized coordinates.

Shear distribution along buried structures.

Shear wave velocity ratio.

Base radius; radius of buried structures.

Section modulus.

Acceleration and displacement spectra.

Safety Analysis Report.

Safe Shutdown Earthquake.

Time.

Time interval for digitized earthquake or response time histories.

Earthquake ground motion.

Maximum ground velocity during earthquake.

Maximum ground particle velocity due to compressional and shear waves, respectively.

Maximum horizontal and vertical velocity at structural center of mass.

Maximum horizontal relative velocity at structural center of mass. 
V

$v_{i}, v_{s}$

$w_{b}, w_{p}$

$x_{i},\{x\}$

$x_{i j}$

$\alpha$

$\beta, \beta_{j}$

$\gamma$

$\gamma_{\text {soil }} \gamma_{\text {water }}$

$\epsilon$

$\sigma$

v

$\rho$

$\tau$

${ }^{\omega} \mathbf{j}$
Maximum vertical inertia force at base slab.

Shear wave velocity.

Work done against overturning by embedment, and work done by buoyancy to increase overturning potential.

Coordinates.

Contribution to $x_{i}$ from mode $j$.

Shape factor for structural cross section.

Material damping per mode of fixed base structures or components.

Shear strain in soil.

Unit weights of soil and water.

Strain in buried structures.

Stress in buried structures.

Poisson's ratio.

Density of soil.

Shear stress in buried strucutres.

Circular natural frequency (rad/sec). 


\subsection{INTRODUCTION}

The integrity of the safety-related components of nuclear power plants must be assured in the event that earthquakes occur at nuclear plant sites. This assurance is provided by designing the plant to withstand the seismic responses that would be experienced during a postulated earthquake. This topical report presents the methods generally used within Bechtel Power Corporation to compute the various seismic responses such as floor accelerations, shears, moments and displacements. Use of the seismic responses in conjunction with other applicable loads for the final design is covered in the project Safety Analysis Report (SAR).

AEC's Seismic and Geology Siting Criteria (10 CFR Part 100, Appendix A) requires that, for the purposes of analysis and design, two design earthquakes be specified for each site, i.e., the Safe Shutdown Earthquake (SSE), and the Operating Basis Earthquake(OBE). The same document provides the definitions of both design earthquakes.

A different degree of importance to seismic safety is assigned to the various facility structures, components, and equipment of the nuclear power plant. Based upon their function in plant operation and their potential hazard to the operating personnel and the public, the structures, systems and components are divided into two categories in accordance with AEC Regulatory Guide 1.29 (1-1)* and the AEC Standard Format and Content of Safety Analysis Reports for Nuclear Power Plants (1-2). They are the Seismic Category I (referred to as Category I hereafter) and the Seismic Non-Category I. A list of all Category I

* The numbers in parentheses are the references listed at the end of each section. 
structures for each license application is included in Section 3.2 of the Safety Analysis Report.

The seismic responses of structures, systems and components to the postulated design earthquakes are predicted by a detailed dynamic analysis or by equivalent testing procedures. This topical report reflects present practice for dynamic analysis within Bechtel Power Corporation. However, deviations from this report may be made for particular projects because of unique siting and foundation considerations. Such deviations will be explicitly included in SAR submittals for those particular plants. The methods of dynamic analysis presented herein are continuously being reviewed and updated, if necessary. Such updating will be reported in future revisions to this report.

Seismic qualification of plant components, systems and equipment, by dynamic testing, is not covered in this topical report. Seismic qualification of piping systems, by analysis, is addressed exclusively in a separate Bechtel Power Corporation Topical Report, BP-TOP-1, (1-3). 
BC-TOP-4-A

Rev. 3

\section{SECTION 1.0 REFERENCES}

(1-1) Seismic Design Classification, Regulatory Guide 1.29, Directorate of Regulatory Standards, U.S. Atomic Energy Commission, August, 1973.

(1-2) Standard Format and Content of Safety Analysis Reports for Nuclear Power Plants, prepared by the Regulatory Staff of U.S. Atomic Energy Commission, October, 1972.

(1-3) Seismic Analysis of Piping Systems, Topical Report BPTOP-1, Revision 1, Bechtel Power Corporation, San Francisco, California, February, 1974. 
BC-TOP-4-A

Rev. 3

\subsection{SITE EVALUATION AND DESIGN EARTHQUAKES}

\subsection{Summary}

An evaluation of the geologic and seismic characteristics of the site and its surrounding region is essential to ensuring that the nuclear power plant will not produce undue risk to the health and safety of the public during earthquakes. This section summarizes the principal geologic and seismic evaluations made to assess the seismicity of the region, to evaluate the effect of the earthquake motion on the foundation materials, and to determine the Safe Shutdown Earthquake (SSE) for the site. The Operating Basis Earthquake (OBE) is then taken as a fraction, but not less than one half, of the SSE.

Seismic criteria for some sites are developed by independent consultants to the utilities. The following discussion therefore applies only to Bechtel practice.

\subsection{Evaluation of Geology}

Geologic evaluation of the site and the region surrounding it is essential to assessing the seismic characteristics of the site. Information on regional geology, tectonic structures, site geology, and foundation conditions is necessary for each evaluation. Basic information, of the kind outlined in Section 2.5.1 of the AEC Format for SAR's (1-2), is also evaluated.

Preliminary geologic information is obtained by thoroughly searching the pertinent available literature and documents and from consultations with authorities from universities, private organizations, and local, state, and federal agencies. More detailed information is obtained from field exploration and laboratory testing. Field exploration, which is especially directed toward evaluating faulting, includes 
surface geologic mapping, subsurface investigations (including test borings and trenches) and various geophysical surveys. The test boring and laboratory testing programs serve to identify the soil and rock types and to determine their strengths, densities, water contents, consolidation characteristics, and other properties significant to foundation design. These data are necessary for the evaluation of liquefaction potential and the determination of foundation conditions and soil damping values (damping inherent to the soil material). The geophysical surveys, on the other hand, provide data on shear wave and compressional wave velocities for the determination of the in-situ values of shear modulus, modulus of elasticity, and Poisson's ratio of the subsurface materials. Results of both in-situ and laboratory tests of soils are strain dependent. Figure 2-1 shows a typical stress-strain curve, in which both the equivalent linear shear modulus, $G$, and the damping ratio are defined. It is important to correlate these test results with the expected strains during the specified seismic events. Figure 2-2 shows the strain levels associated with different types of tests in comparison with the strain levels attained during actual earthquakes $(2-1)$.

By compiling actual test data on soils, Seed and Idriss (2-2) have developed idealized relationships between strains and both shear moduli and damping. Figures 2-3 and 2-4 show such curves for saturated clays. Similar curves for sands are shown in Figures 2-5 and 2-6. The effect of relative density, $D_{r}$, and mean principal effective stress, $\sigma_{m}^{\prime}$ on the shear modulus of sands is shown in Figure 2-7. This figure can be used to obtain values of shear modulus with depth of soil profiles. These idealized relationships can be used together with some corrections appropriate for the individual sites. 


\subsection{Stability Evaluation of Subsurface Materials and Slopes}

To help assess the conditions of the foundation materials and the possible seismically induced effects, the following evaluations are made:

\subsubsection{Safety Related Criteria of Foundation Materials}

The bearing capacity of soil foundations is computed by the procedures recommended by Terzaghi and Peck (2-3). A factor of safety against shear failure of 3 is used for static conditions, and 2 for dynamic conditions. The bearing capacity of rock foundations is determined by laboratory and, if necessary, field tests, using factors of safety consistent with existing mineralogy, rock types and geologic conditions.

\subsubsection{Liquefaction Potential of Subsurface Materials}

An investigation is made of the potential for seismically induced liquefaction at the site using, initially, the simplified procedure established by seed and Idriss (2-4). If conditions are such that a more exact analysis is required, the procedure as outlined by seed and Idriss (2-5) is used. The factor of safety against liquefaction is 1.2 .

\subsubsection{Slope Stability}

The stability of soil slopes and embankments under static conditions is evaluated using Bechtel computer code CE 533, which is a modification of the method of slices (2-6), and CE 576, which is the method of slices that takes into consideration the interaction between the slices (2-7). Under seismic conditions, the same methods are used with the inclusion of an additional equivalent static force for each slice equal to the peak ground acceleration times the total weight of soil and water in each slice. 
The stability of rock slopes is analyzed by geologic mapping of discontinuities in the slopes, and computations of factors of safety against sliding, under both static and dynamic conditions, along these discontinuities. Rock slopes are made stable either by excavation or reinforcement.

\subsubsection{Subsidence Potential}

The geologic features which could affect the foundations of proposed structures are examined for potential subsidence, uplift, or collapse. The physical properties of the materials underlying the site are evaluated with consideration of:

- Area of actual subsidence, uplift or collapse.

- Natural features such as tectonic depressions, karst terrain or areas underlain by soluable deposits.

- Man's activities such as withdrawal or addition of gas, oil, brine or ground water, or mineral extraction.

- Rocks or soils that might be unstable due to mineralogy, lack of consolidation, water conditions or potential undesirable response to seismic events.

- Regional warping or residual stresses in bedrock.

\subsection{Evaluation of Seismicity}

The evaluation is carried out by a review of the pertinent literature and consultations with authorities from universities and various state and federal agencies. This generally provides the information needed to determine the maximum vibratory ground motion that has occurred at the site, but in some cases field investigations are required 
to more precisely estimate the intensities experienced at particular areas during past earthquakes.

Earthquake histories and epicentral maps are prepared showing all historically reported significant earthquakes that have occurred within 200 miles of the site. Epicenters or regions of highest intensity of historically reported earthquakes are correlated with tectonic structures. Where such correlation is not feasible, the epicenters or regions of highest intensity are identified with geologic provinces.

Earthquake intensities are rated according to the Modified Mercalli Intensity Scales (MM). Figures 2-8 and 2-9 are sample epicenter maps compiled for a site in South Carolina in the United States, which correlates with the tectonic structures and the geologic provinces, respectively. In both figures, the radius of the outer circle is 200 miles.

Evaluation is also made of those faults which may be of significance in establishing the SSE, to determine if they are to be considered active faults. The definition of active fault and the criteria for fault evaluation follow those outlined in Appendix A of 10 CFR Part 100.

\subsection{Specification of Safe Shutdown Earthquake}

\subsubsection{Horizontal Motion}

The design basis for the maximum vibratory ground motion is estimated through evaluation of the geology and the seismic history of the site and its surrounding region. The most significant earthquakes in the region surrounding the site are identified by considering those historically reported earthquakes that could have been felt at the site. 
If active faults exist in the region, the most severe earthquakes that could be felt along these faults are determined by considering the geologic history of faults, their length, and other significant features. The maximum vibratory ground motion is then estimated by assuming that the epicenters or regions of highest intensity of such earthquakes are situated at the point on the tectonic structures or provinces nearest to the site.

(a) Maximum Ground Acceleration - Based on the seismicity evaluation, a judgment is made to estimate the maximum intensity that could occur at the site. When deemed appropriate, this estimate may also make use of the statistical correlation between intensity, magnitude, and epicentral distance, as presented by Richter (2-8), Cloud and Perez (2-9), and seed, Idriss and Kiefer (2-10). After the maximum intensity is established, the oorresponding value of the maximum horizontal ground acceleration for design is then obtained from the Neumann curve (2-11). Figure 2-10 shows the Neumann curve derived from the data of ten earthquakes varying in intensity from $V$ to VIII (MM) at locations where peak accelerations were recorded. Above intensity VIII, the upper branch $\mathrm{Ja}$ is extrapolated in a straight line due to lack of data; the lower branch, Jb, is a modification based on more recent data and is adopted in place of the upper branch for intensities higher than VIII. In all cases, the minimum value of the horizontal ground acceleration for the site is $0.1 \mathrm{~g}$ for the SSE.

(b) Design Spectra - The SSE is specified by a suitable set of idealized, smooth curves, known as the "design spectra", and a compatible time history of motion. The design spectra presently used are adopted from the AEC Regulatory Guide 1.60 (2-12). They are obtained based on a statistical evaluation of the actual response spectra of many strong-motion earthquakes recorded at sites underlain by various geologic materials in the Western United States. Hence, in using these 
curves, the variations in site conditions and foundation properties and the effects of distant and nearby earthquakes have been taken into account. Figure 2-11 shows the design spectra for damping values ranging from 0.5 to 10 percent of critical, for a peak horizontal ground acceleration of $1.0 \mathrm{~g}$. The 1 percent damping spectrum is obtained from Ref. (2-13). Table 2-l(a) lists the spectral amplification factors at the control point frequencies: 0.25 , 2.5, 9 and 33 cps. For sites with an SSE horizontal ground acceleration other than $1.0 \mathrm{~g}$, the design spectra in Figure 2-1l are linearly scaled to the applicable level.

(c) Time History - The response spectra of the time history are such that they envelop the design spectra at a sufficient number of frequencies, although only the specific structural frequencies are of engineering significance in the seismic analysis. Since no recorded earthquake motions would fulfill this criterion, synthetic time history moticns are generated by modifying actual records or other digitally simulated motions according to the techniques proposed by Tsai (2-14). Figure 2-12 shows one such synthetic time history motion, which was generated by modifying the 1952 Taft earthquake and has a total duration of 24 seconds. The maximum integrated velocity of the time history is about $5 \mathrm{ft} / \mathrm{sec}$ for a peak ground acceleration of $1.0 \mathrm{~g}$. Its response spectra generally envelop the design spectra for damping values equal to or greater than one percent of critical. Figures 2-13 and 2-14 show the comparison of the time history response spectra and the design spectra for $2,5,10,1$ and 7 percent of critical, respectively. The spectra were computed at the following 71 frequencies (in cycles per second): 
$0.2, \ldots$ (increment $=0.1 \mathrm{cps}$ ) $\ldots 3.0$,

$3.15,3.3,3.45,3.6,3.8,4.0,4.2,4.4$,

$4.7,5.0,5.25,5.5,5.75,6.0,6.25,6.5$,

$6.75,7.0,7.3,7.6,8.0,8.5,9.0,9.5$,

$10,10.5,11,11.5,12,12.5,13,13.5$,

$14,14.5,15,16.5,18,20,22,25,28,33$.

These frequencies are so chosen that most of the increments do not exceed 5 percent within the range of 1 to $15 \mathrm{cps}$, which is the usual range of power plant structure frequencies. The response spectra occasionally fall below the corresponding design spectra, but the amount is always less than 10 percent.

(d) Engineering Application - Unless otherwise stated in the SAR, the design earthquake is, for engineering design, assumed to be the free-field motion at the structural basement level, without the effect of structure.

\subsubsection{Vertical Motion}

(a) Maximum Ground Acceleration - According to the AEC Regulatory Guide 1.60 (2-12), the maximum vertical ground acceleration of the SSE is equal to the maximum horizontal ground acceleration of the SSE specified for the same site.

(b) Design Spectra - The design spectra of the vertical component of the SSE are also adopted from Refs. (2-12, 2-13). Figure 2-15 shows the 0.5 percent to 10 percent damping design spectra for the case of a peak vertical ground acceleration of $1.0 \mathrm{~g}$. They are linearly scaled to the proper level for sites with an SSE peak ground acceleration other than $1.0 \mathrm{~g}$.

Table 2-1(b) lists the spectral amplification factors at the control point frequencies: $0.25,3.5,9$ and $33 \mathrm{cps}$ $(2-12)$. 
(c) Time History - A synthetic time history motion of 24second duration was generated for the vertical component of the SSE (Figure 2-16). The maximum integrated velocity of this time history is about $3.8 \mathrm{ft} / \mathrm{sec}$ for a peak vertical ground acceleration of $1.0 \mathrm{~g}$. Its response spectra are compared with the corresponding design spectra for 2 percent, 5 percent, 10 percent damping (Figure 2-17) and 1 percent and 7 percent damping (Figure 2-18). 


\section{SECTION 2.0 REFERENCES}

(2-1) Soil Behaviors Under Earthquake Loading Conditions, prepared for the U.S. Atomic Energy Commission by a Joint Venture of Shannon and Wilson, Inc., (Seattle) and Agbabian-Jacobsen Associates (Los Angeles), 1972.

(2-2) Seed, H.B. and Idriss, I.M., "Soil Moduli and Damping Factor For Dynamic Response Analysis", Earthquake Engineering Research Center, Report No. 70-10, University of California, Berkeley, California, December 1970.

(2-3) Terzaghi, K. and Peck, R.B., Soil Mechanics in Engineering Practice, Second Edition, John Wiley and Sons, New York, 1967, p. 729.

(2-4) Seed, H.B. and Idriss, I.M., "Simplified Procedure for Evaluating Soil Liquefaction", Journal of Soil Mechanics and Foundations Division, ASCE, Vol. 97, No. SM9, Proceedings Paper 8371, September 1971, pp. 1249-1273.

(2-5) Seed, H.B. and Idriss, I.M., "Analysis of Soil Liquefaction: Niigata Earthquake", Journal of Soil Mechanics and Foundations Division, ASCE, Vo1. 93, No. SM3, Proceedings Paper 5233, May 1967, pp. 83-98.

(2-6) "The Method of Slices", Civil Works Engineering Manual, Corps of Engineers, SM1110-2-190Z.

(2-7) Whitman, R.V. and Bailey, A., "Use of Computers for Slope Stability Analysis", Journal of Soil Mechanics and Foundations Division, ASCE, Vol. 93, No. SM4, Proceèdings Paper 5327, July 1967, pp. 475-528. 
(2-8) Richter, C.F., Elementary Seismology, W.H. Freeman and Co., 1958 .

(2-9) Cloud, W.K. and Perez, V., "Strong Motion Records and Acceleration", Proceedings of the Fourth World Conference on Earthquake Engineering, Santiago, Chile, Vol. 1, January 13-18, 1969, pp. A2-119 - A2-132.

(2-10) Seed, H.B., Idriss, I.M., and Kiefer, F.W., "Characteristics of Rock Motions During Earthquakes", Journal of Soil Mechanics and Foundation Engineering Division, ASCE, Vo1. 95, No. SM5, Proceedings Paper 6873, September 1969, pp. 1199-1215.

(2-11) Neumann F., Earthquake Intensity and Related Ground Motion, University of Washington Press, Seattle, 1954.

(2-12) Design Response Spectra for Seismic Design of Nuclear Power Plants, Regulatory Guide 1.60, Rev. 1, Directorate of Regulatory Standards, U.S. Atomic Energy Commission, December 1973.

(2-13) Newmark, N.M., Blume, J.A., and Kapur, K.K., "Design Response Spectra for Nuclear Power Plants", paper presented at the ASCE Annual Meeting, San Francisco, CA., April 1973.

(2-14) Tsai, N.C., "Spectrum-Compatible Motions for Design Purposes", Journal of Engineering Mechanics Division, ASCE, Vol. 98, No. EM2, Proceedings Paper 8807, April 1972, pp. 345-356. 
TABLE 2-1(a) AMPLIFICATION FACTORS FOR

HORIZONTAL DESIGN SPECTRA

\begin{tabular}{|c|c|c|c|c|}
\hline \multirow{2}{*}{$\begin{array}{l}\text { Damping } \\
(\% \text { Critica1) } \\
\end{array}$} & \multirow{2}{*}{$\begin{array}{c}\text { Displacement Amplificationt } \\
0.25 \mathrm{cps}\end{array}$} & \multicolumn{3}{|c|}{ Acceleration Amplification } \\
\hline & & $2.5 \mathrm{cps}$ & 9 cps & $33 \mathrm{cps}$ \\
\hline 0.5 & 3.20 & 5.95 & 4.96 & 1.0 \\
\hline 1 & 2.83 & 5.05 & 4.25 & 1.0 \\
\hline 2 & 2.50 & 4.25 & 3.54 & 1.0 \\
\hline 5 & 2.05 & 3.13 & 2.61 & 1.0 \\
\hline 7 & 1.88 & 2.72 & 2.27 & 1.0 \\
\hline 10 & 1.70 & 2.28 & 1.90 & 1.0 \\
\hline
\end{tabular}

+Note: Maximum horizontal ground displacement is specified as 36 inches for $1 \mathrm{~g}$ peak ground acceleration.

TABLE 2-1(b) AMPLIFICATION FACTORS FOR

VERTICAL DESIGN SPECTRA

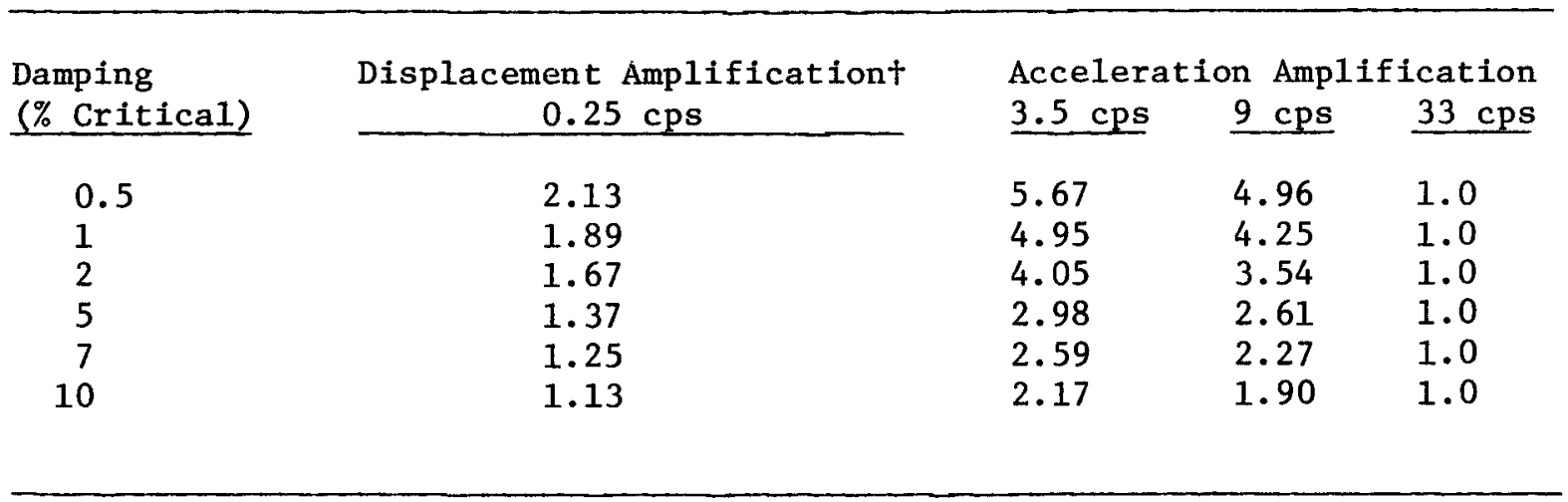

†Note: Maximum vertical ground displacement is specified as 36 inches for Ig peak vertical ground acceleration. 


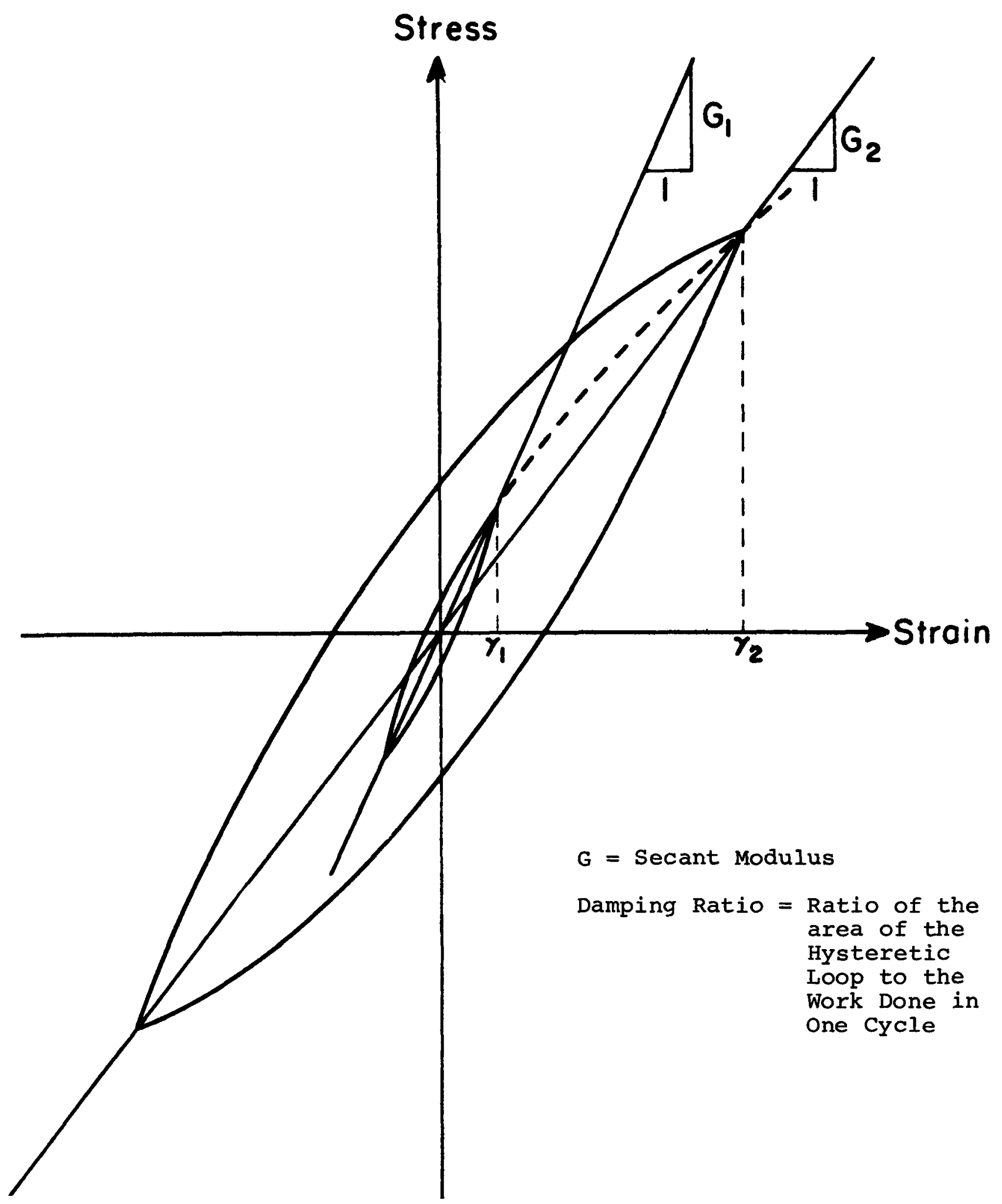

Fig. 2-1. Representation of Shear Modulus, G, and Damping Ratio for Soils, as Obtained from Stress Strain Curves 


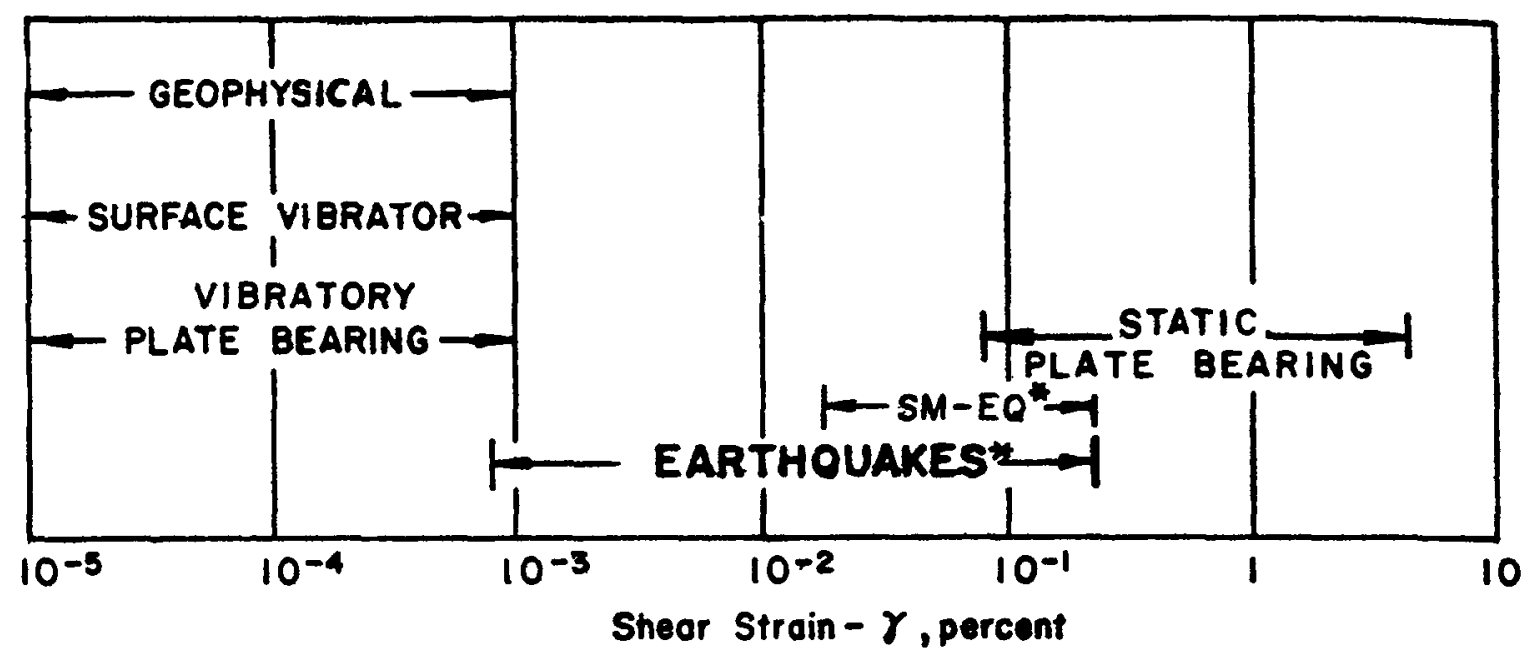

a. FIELD TESTS

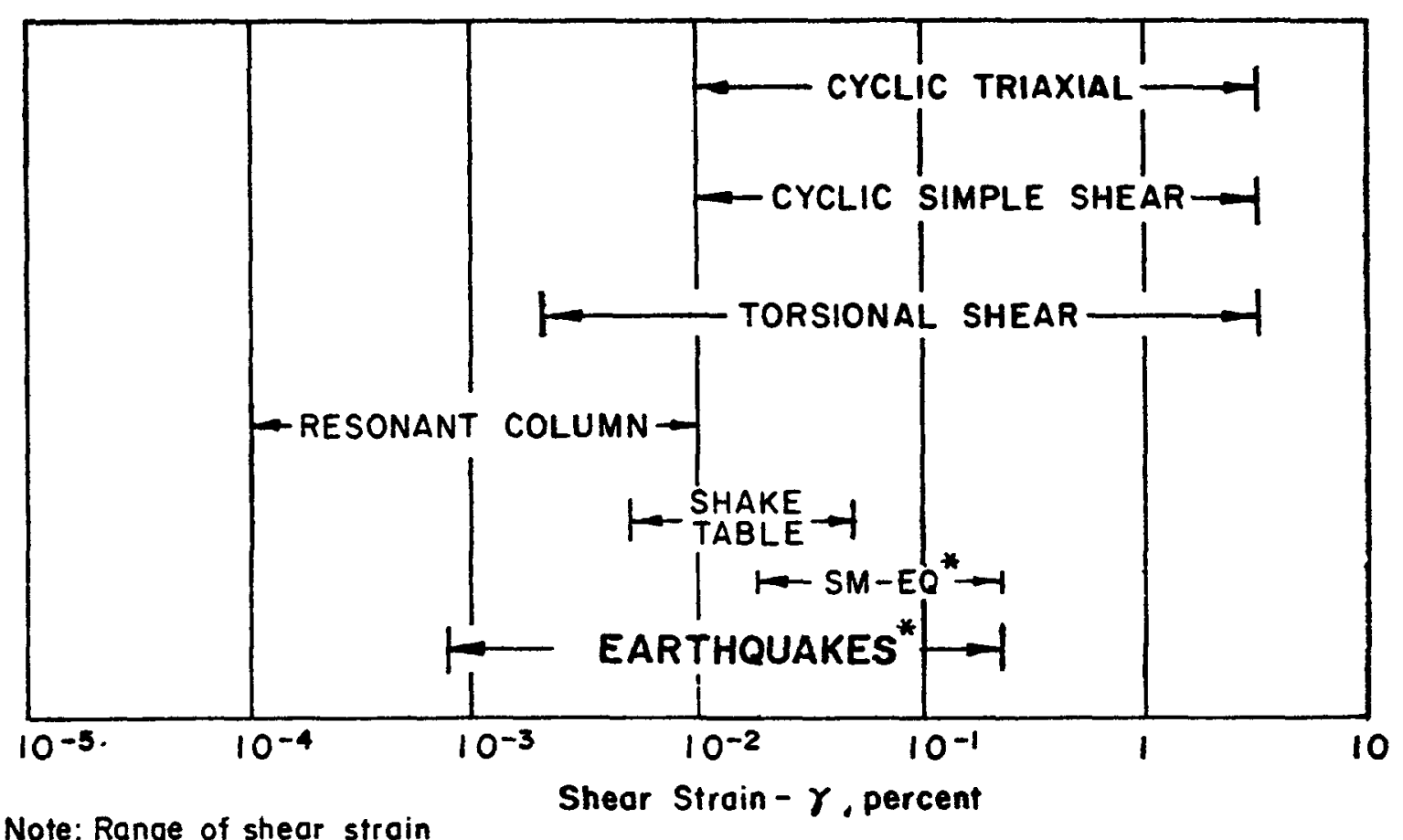

* Note: Range of shear strain denoted as "Eorthquakes" represents an extreme b. LABORATORY TESTS range for most earthquakes.

"SM-EQ" denotes strains induced by strong motion earthquakes.

Fig. 2-2. Field and Laboratory Tests Showing Approximate Strain Ranges of Test Procedures for Soils (Ref. 2-I) 


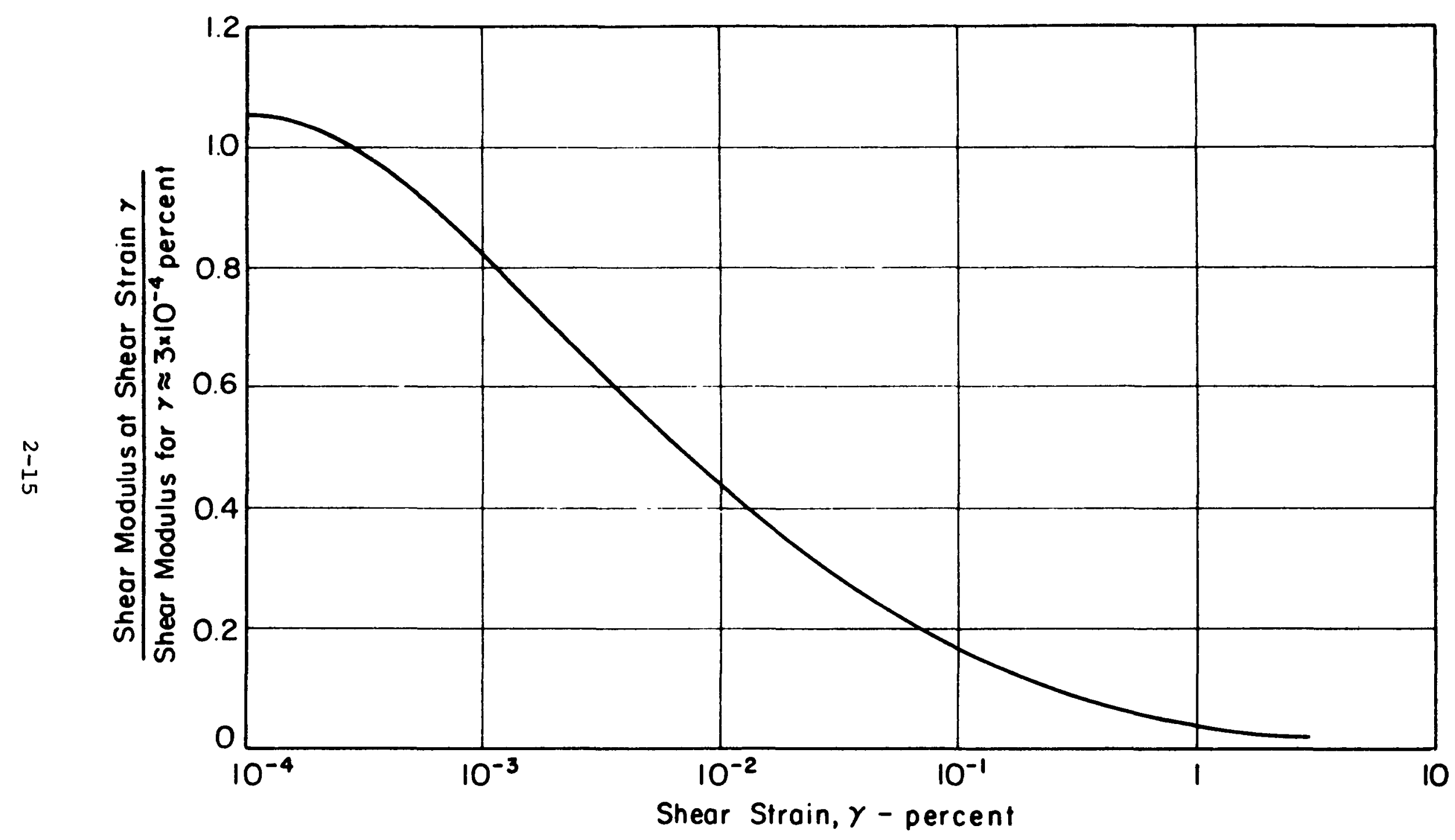

Fig. 2-3. Typical Reduction of Shear Modulus with Shear Strain for Saturated Clays (after Seed \& Idriss, Ref. 2-2) 


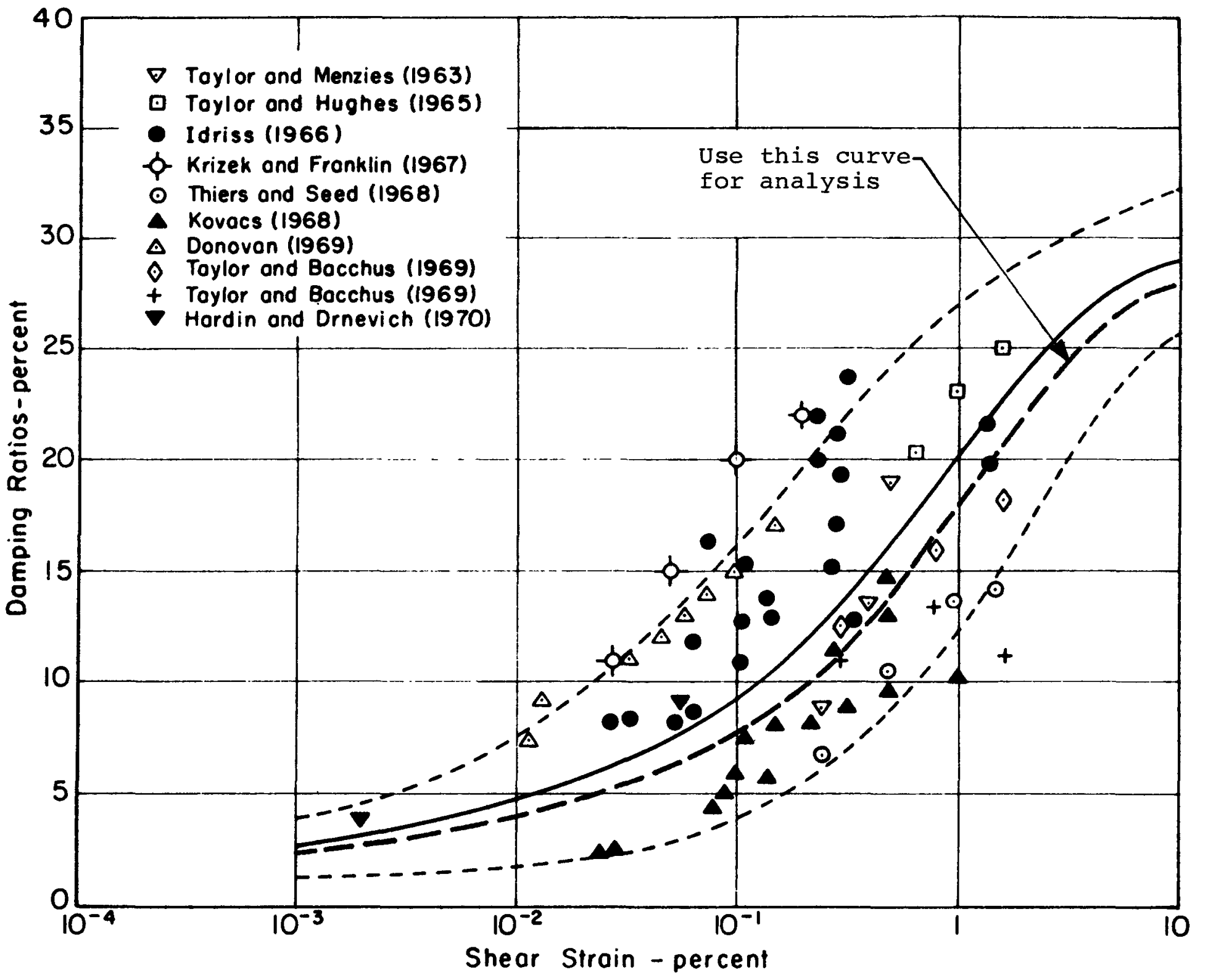

Fig.2-4. Damping Ratios for Saturated Clays (after seed \& Idriss, Ref. 2-2) 


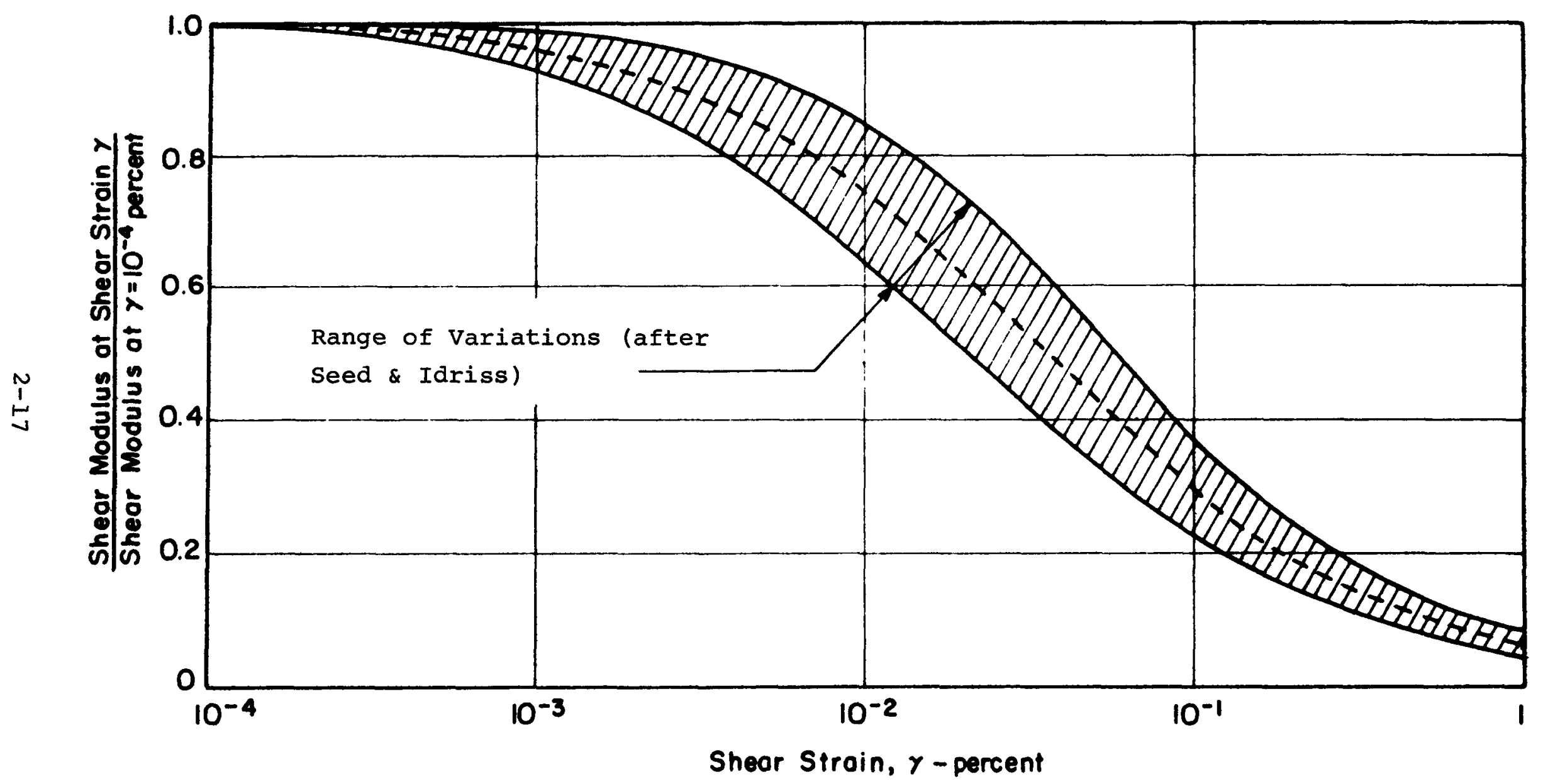

Fig. 2-5. Variation of Shear Modulus with Shear Strain for Sands (after Seed \& Idriss, Ref. 2-2) 


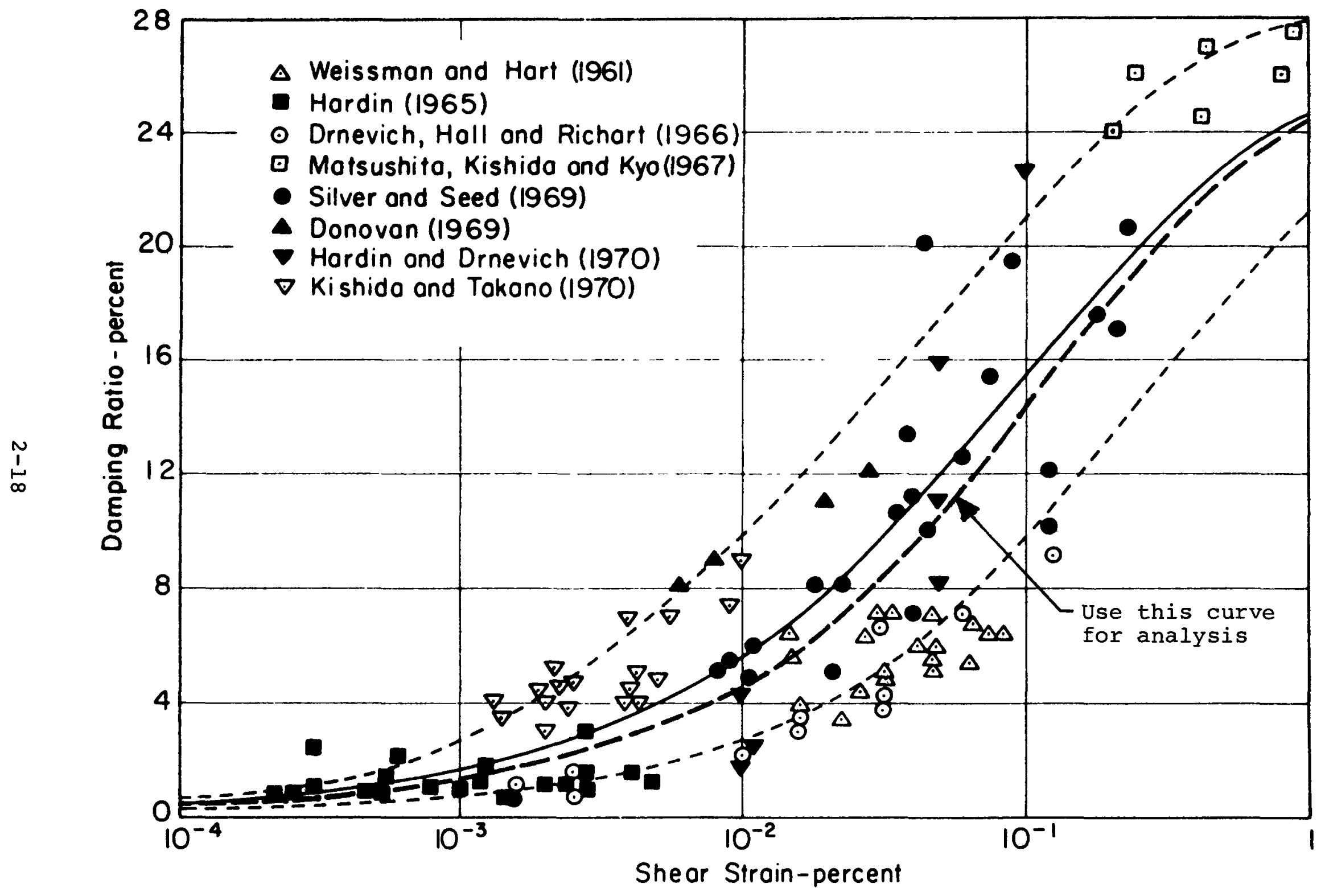

Fig. 2-6. Damping Ratios for Sands (after Seed \& Idriss, Ref. 2-2) 


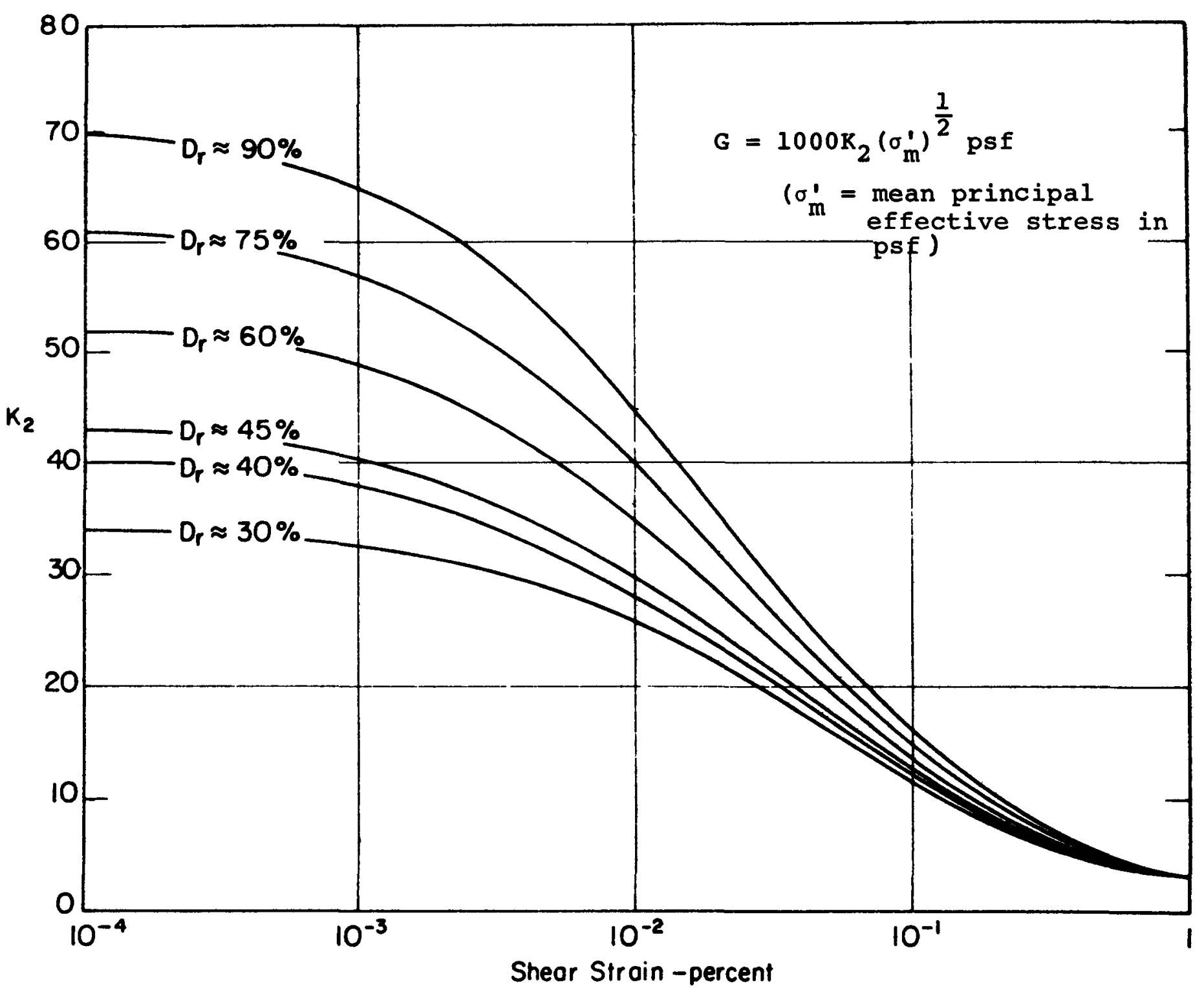

Fig. 2-7. Shear Moduli of Sands at Different Relative Densities, $D_{r}$ (after Seed \& Idriss, Ref. 2-2) 

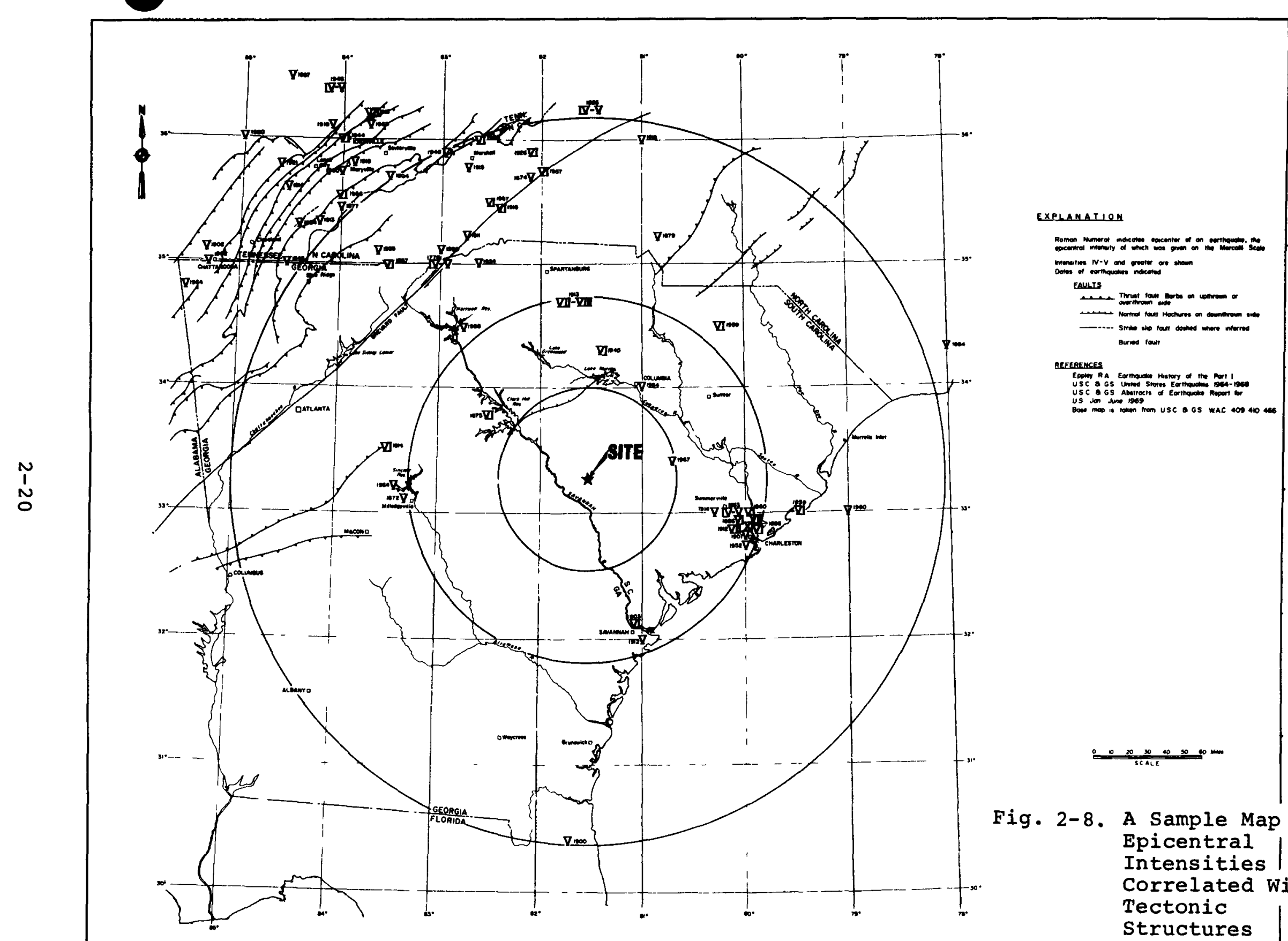

Fig. 2-8. A Sample Map of 喵 Epicentral Intensities Correlated with $\omega$ \% Tectonic Structures 


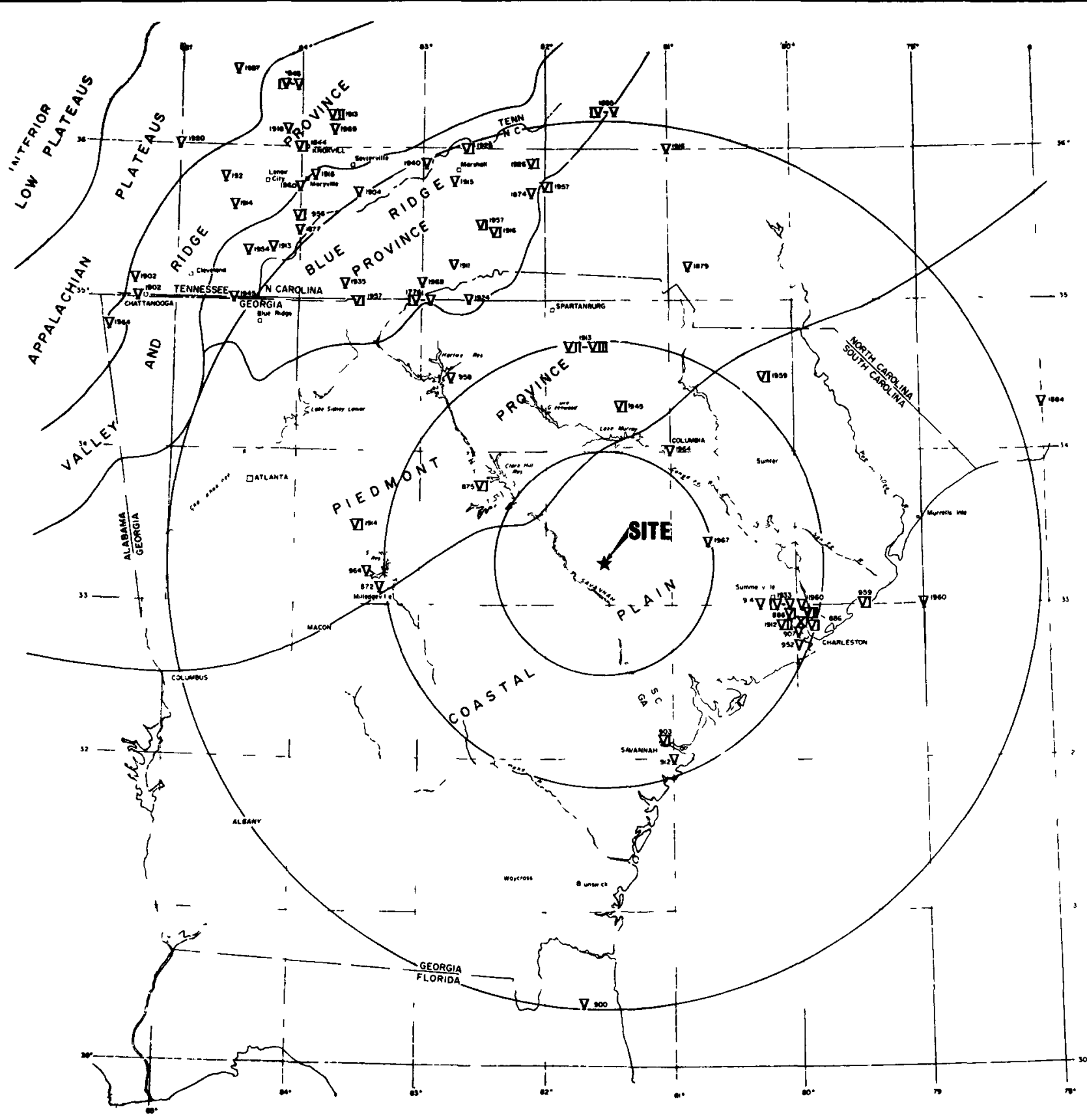

EXPLANATION

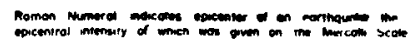

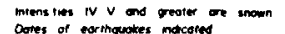

REFERENCES
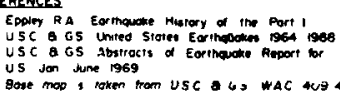


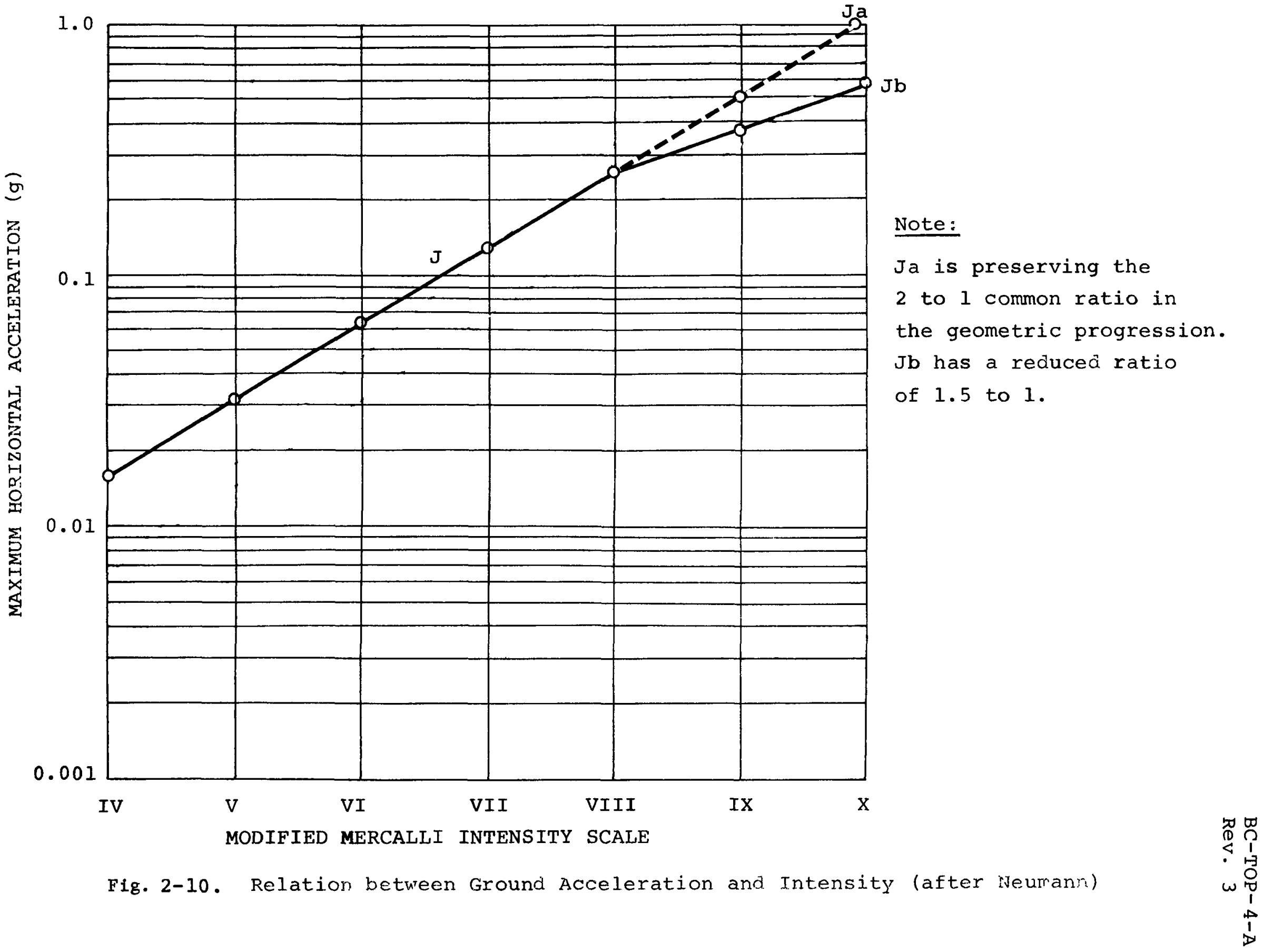


BC-TOP-4-A

Rev. 3

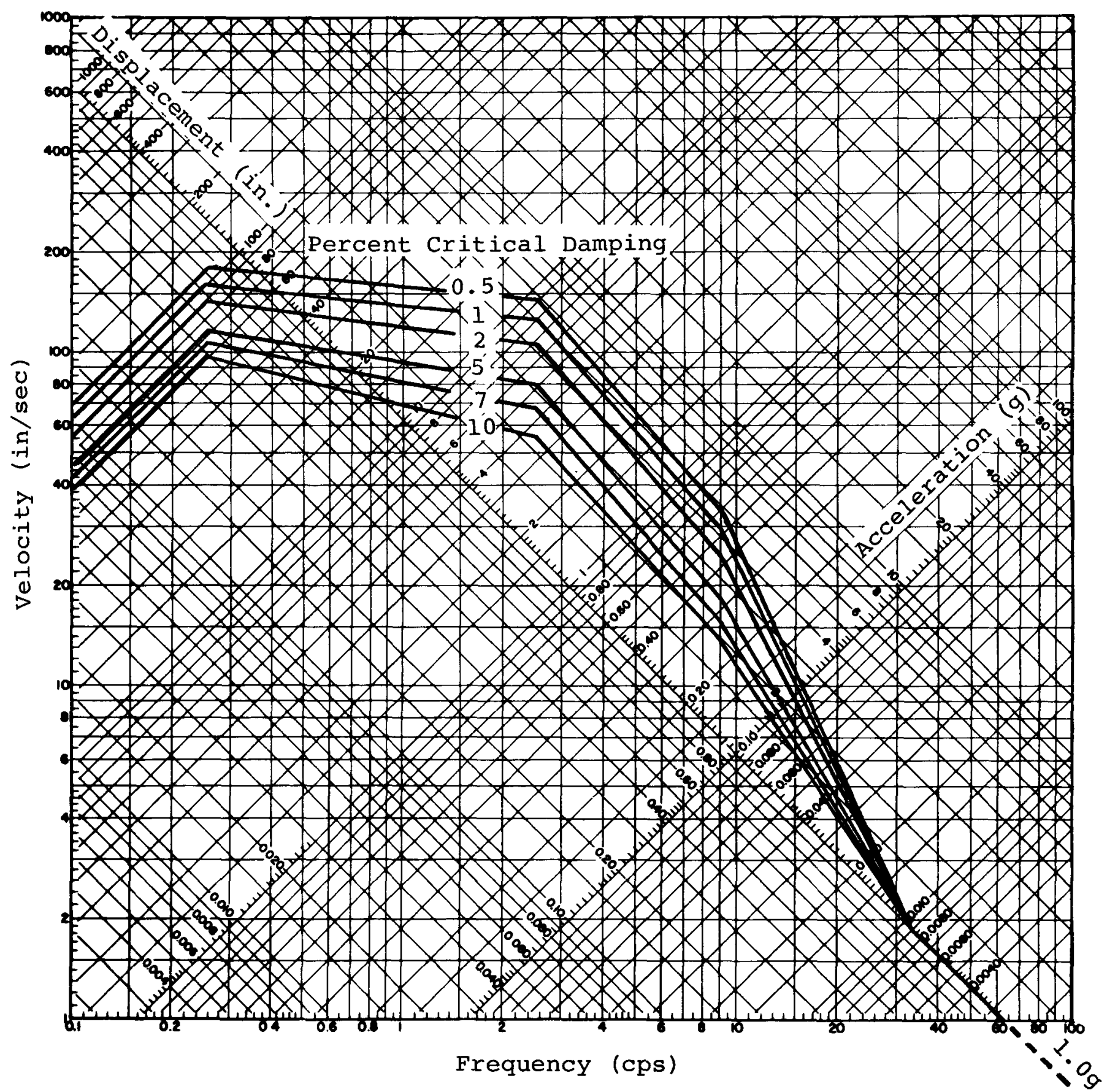

Fig. 2-1l Horizontal Design Spectra For Peak Horizontal Ground Acceleration of $1.0 \mathrm{~g}$ 


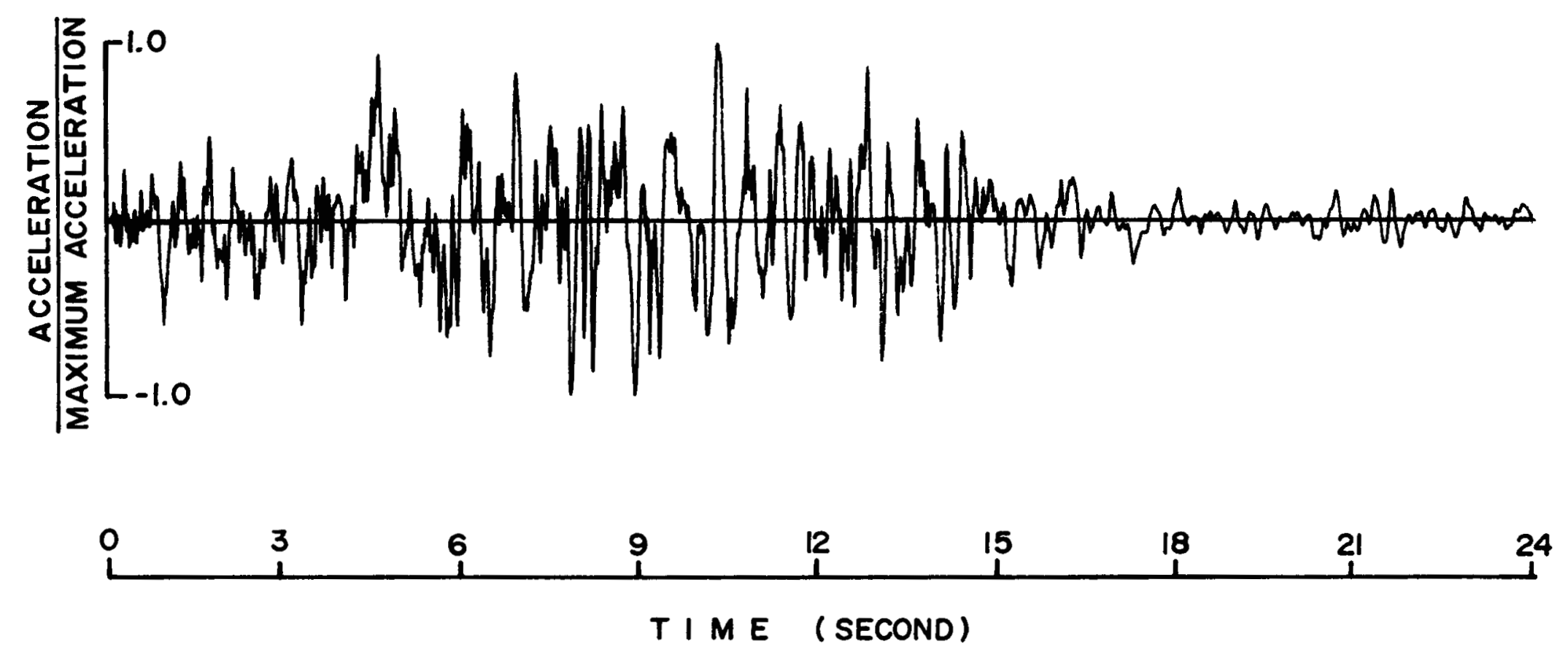

Fig. 2-12 Synthetic Time History Motion of The Horizontal Component of The Design Earthquake 


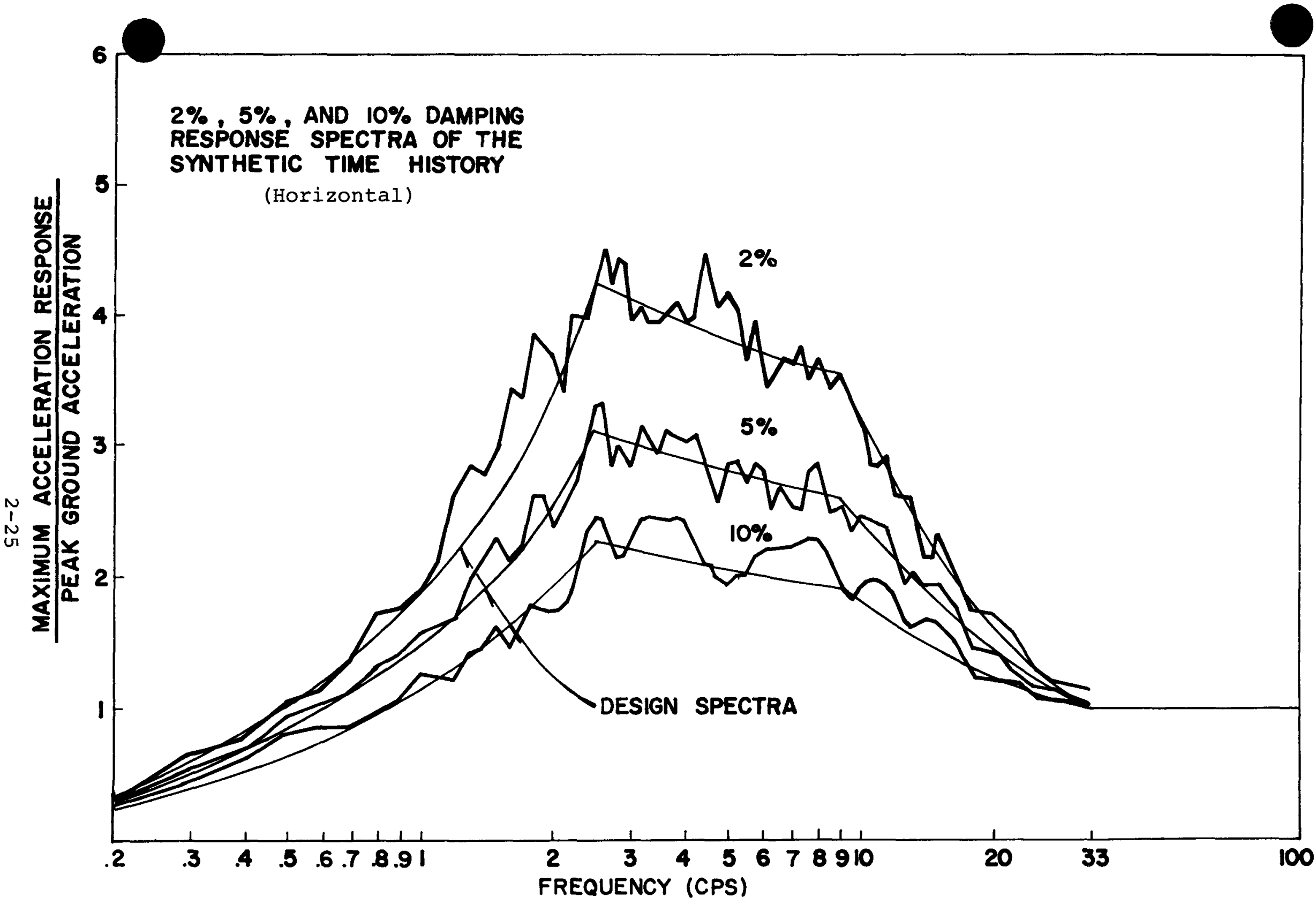

Fig. 2-13 Comparison of The Acceleration Response Spectra of The Horizontal Synthetic Time History With the Horizontal Design Spectra For 2\%, 5\%, and 10\% Damping 


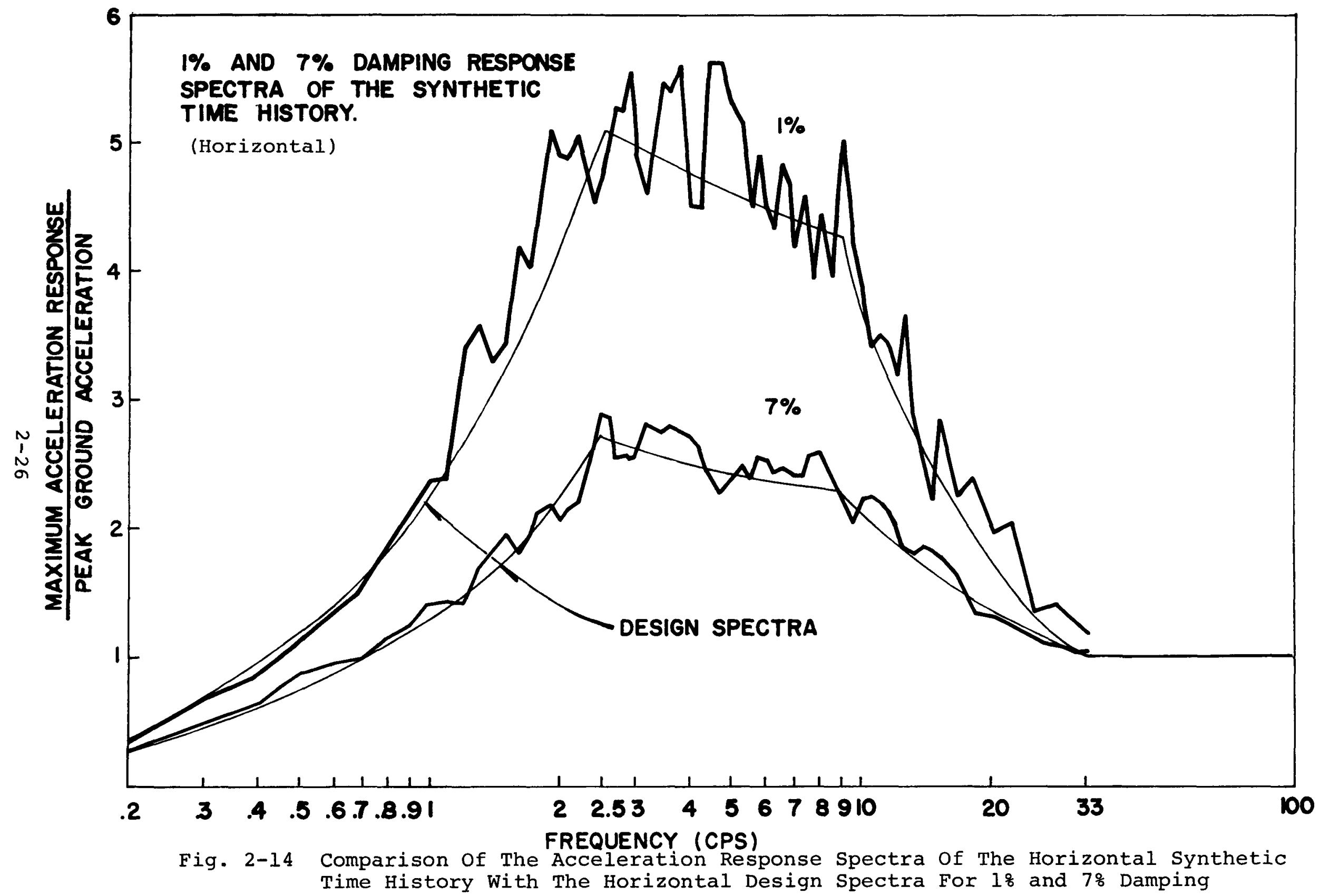


BC-TOP-4-A

Rev. 3

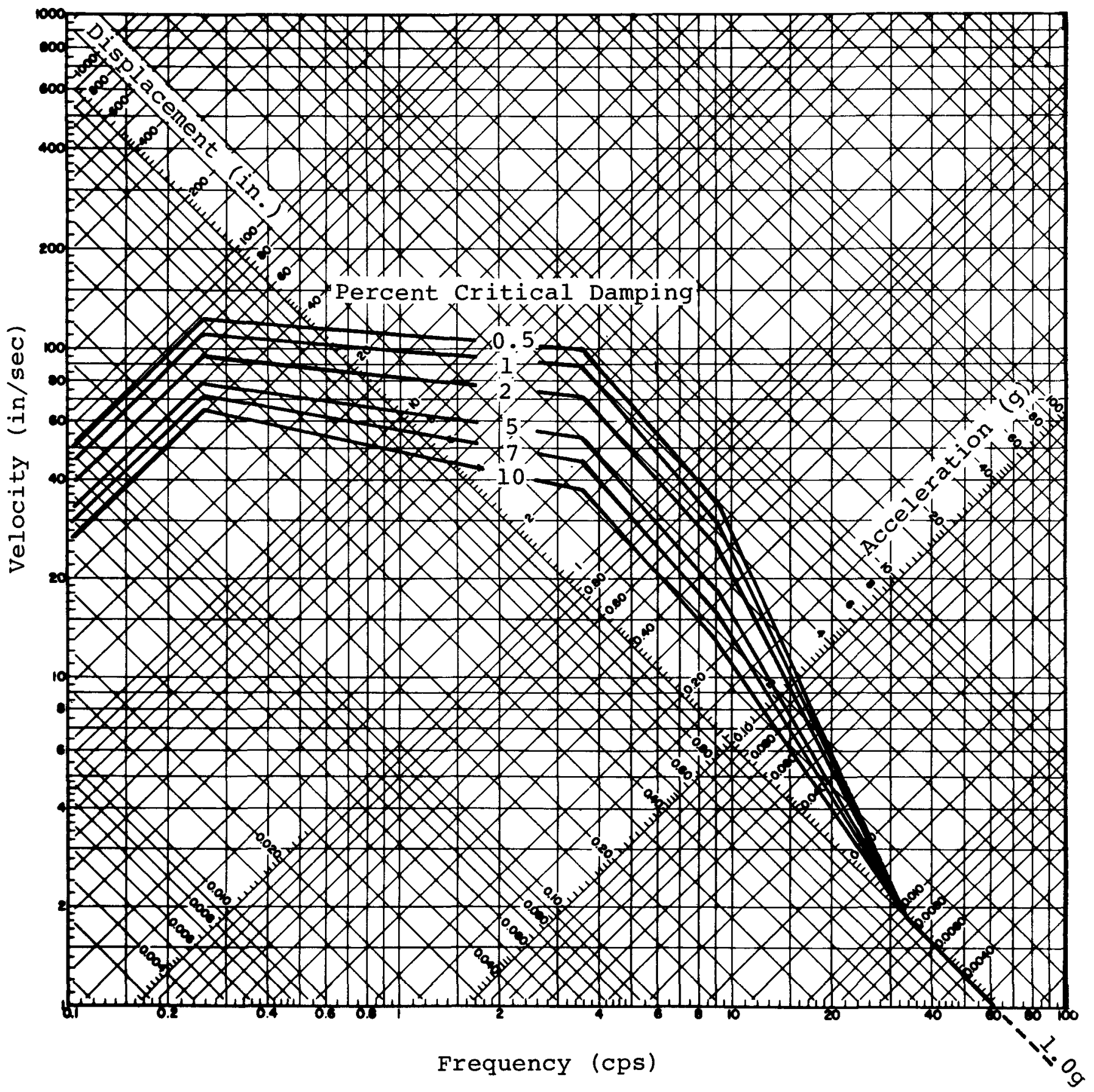

Fig. 2-15 Vertical Design Spectra For Peak Vertical Ground Acceleration of $\mathrm{l} .0 \mathrm{~g}$ 
SYNTHETIC TIME HISTORY (VERTICAL)
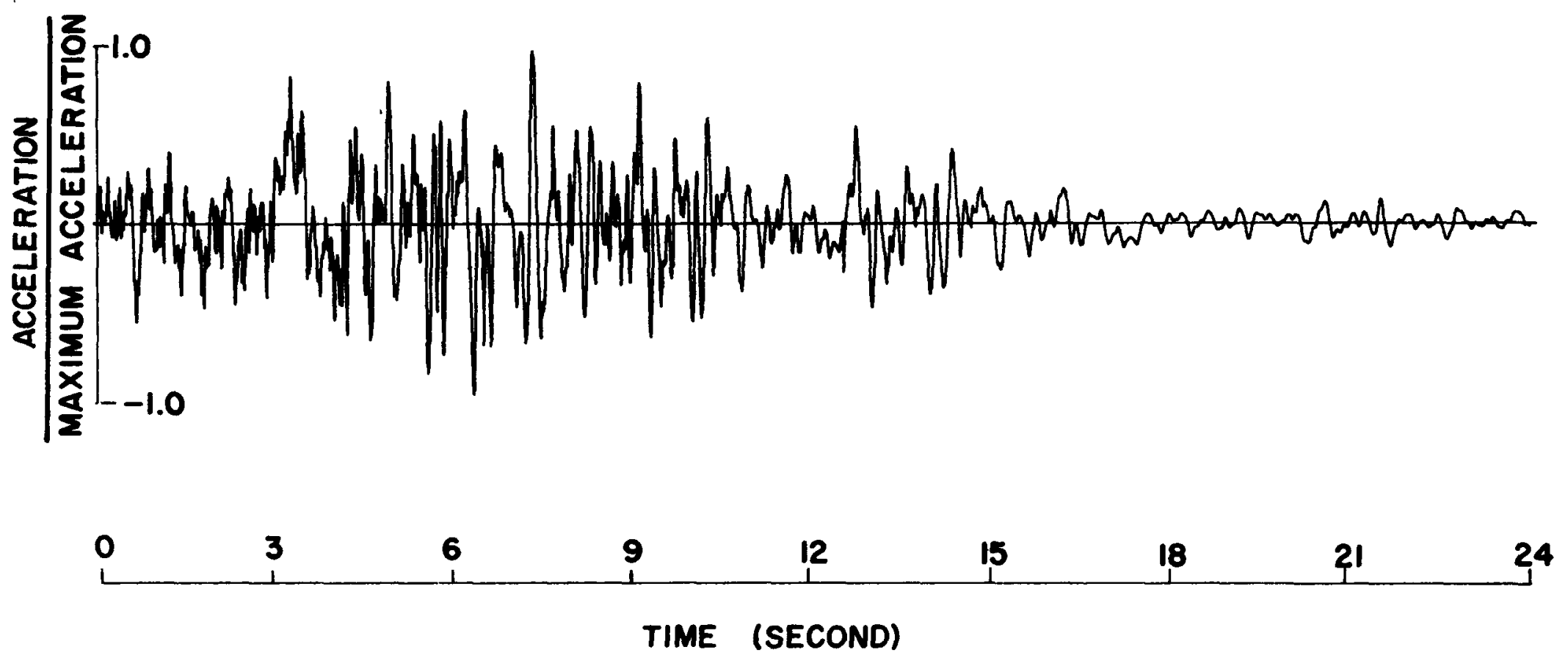

Fig. 2-16 Synthetic Time History of The Vertical Component of The Design Earthquake 


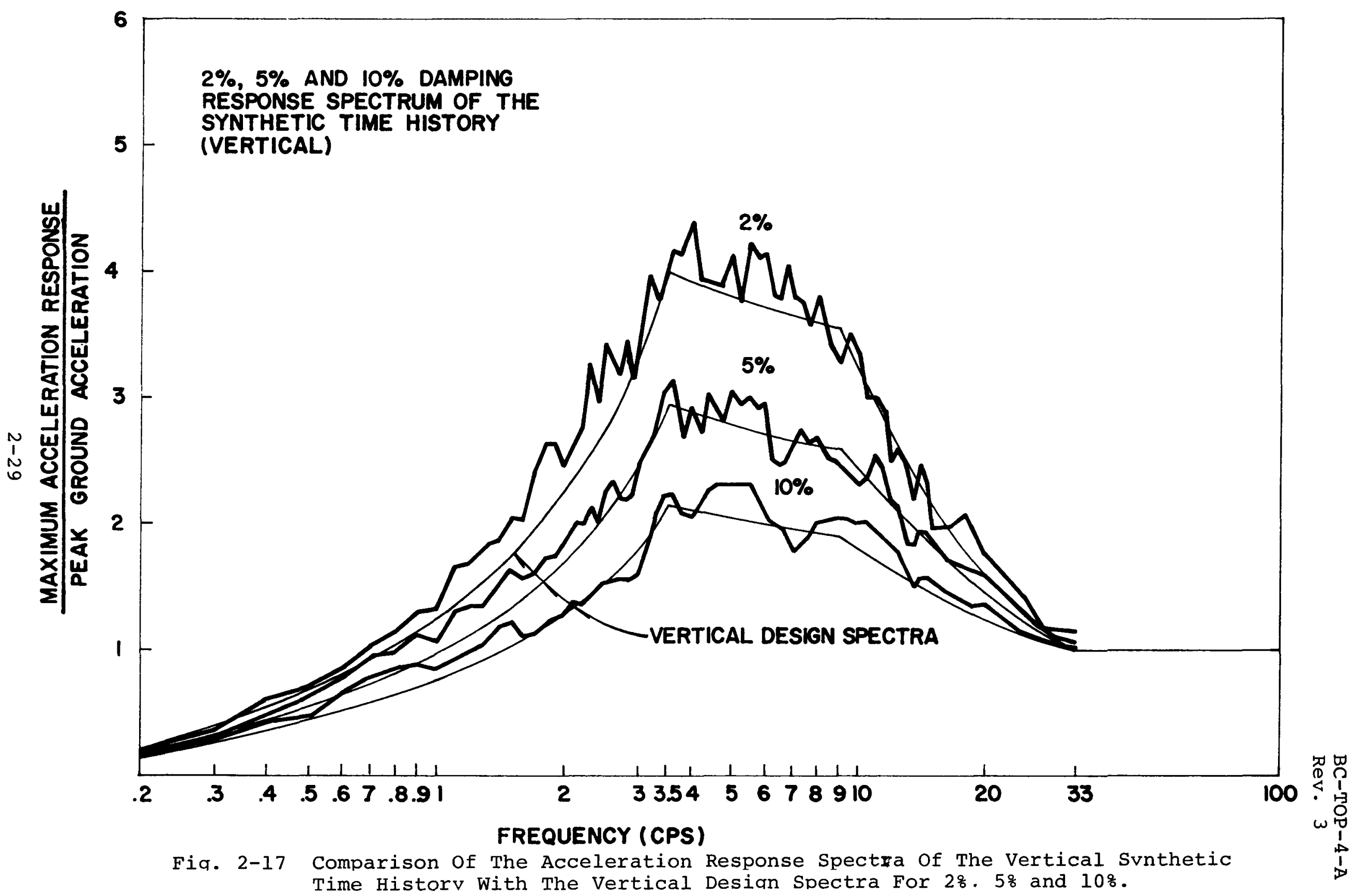




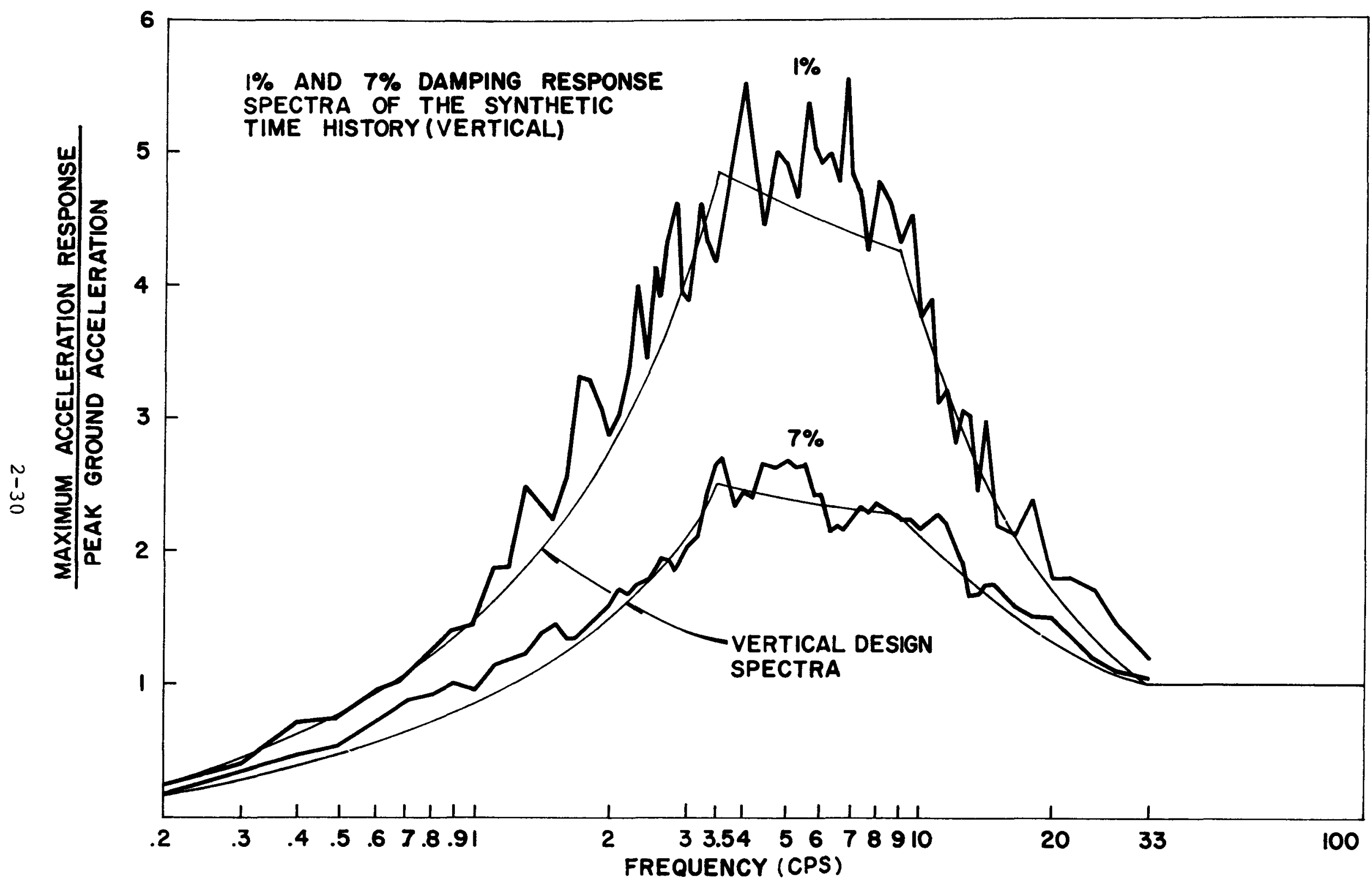

Fia. 2-18 Comparison of The Acceleration Response Spectra of The Vertical Synthetic Time History with The Vertical Design Spectra For $1 \%$ and $7 \%$ Damping. 
BC-TOP $-4-A$

Rev. 3

\subsection{MODELING TECHNIQUES FOR STRUCTURES AND FOUNDATIONS}

\section{1 SUMMARY}

To predict the seismic response of Category I structures subjected to the design earthquakes, mathematical models are first established to represent the structures and foundations. The equations of motion for the models are then solved for the structural response. Because the structures are designed to remain essentially elastic under seismic loading, the techniques of structural analysis assume the structural deformation to be small and linearly elastic. Foundation soils usually exhibit nonlinear stress-strain relationships. To facilitate the analysis, the equivalent linear properties of the soils are used, but are selected based on the strain levels obtained by an iterative procedure (3-1). With these assumptions and assuming that the structural damping is viscous, the equations of motion take the following general form:

$$
[M]\{\ddot{x}\}+[C]\{\dot{x}\}+[K]\{x\}=-[M]\{\ddot{u}\}
$$

in which [M] is the mass matrix associated with the inertia forces, [C] is the damping matrix associated with the energy dissipations, [K] is the stiffness matrix associated with the restoring forces, $\{x\}$ is the displacement vector, and $\{\ddot{u}\}$ is the vector of ground acceleration inputs. The solution of these equations yields the structural displacements, accelerations, and velocities, which in turn allow determination of the shears, moments, and other response. 
This section describes the techniques used to develop the mathematical models from which the mass, damping, and stiffness matrices in Eq. (3-1) can be formulated. For practical purposes, the mathematical models of the structures are usually represented by normal modes, and the structural damping is specified in terms of the percentage of critical damping per mode.

With the design earthquakes specified for horizontal and vertical directions, the dynamic analysis is performed separately for the horizontal and vertical inputs. A minimum amount of torsion is accounted for by applying an equivalent eccentricity in design equal to 5 percent of the width of the structure normal to the direction of the input motion. In the lateral analysis, the horizontal design earthquake is applied along each of the two major horizontal axes of the structures, one at a time. The methods for solving Eq. (3-1), which include the spectral response analysis and the time history analysis, are presented in section 4.0 .

\subsection{MATHEMATIC MODELING OF STRUCTURES}

The details of the mathematical model depend on the complexity of the actual structure. The information required from the analysis is a primary consideration in developing the mathematical model. Besides predicting the forces in the structure, it is often necessary to check the clearance provided between major internal components. Thus, enough points on the structure are considered to account properly for the required clearances. Also, locations of Category I equipment are taken into consideration. Buildings may be mathematically modeled as a system of lumped masses located 
at elevations of mass concentrations, such as floors. For structures such as concrete stacks and containment structures having continuous mass distributions, a sufficient number of mass points are chosen so that the vibration modes of interest can be adequately defined. In general, to adequately define the frequency of the highest mode to be used in the analysis, the minimum number of lumped masses is to be twice this mode number. This criterion applies to each of the major components and/or systems. Appendix B provides a justification of this criterion.

An equipment, component, or system is usually lumped into the supporting structure mass if its estimated mass is less than one-tenth that of the supporting mass or, for supporting structures having continuous mass distributions, 0.03 of the fundamental mode effective mass (3-1). This equipment, component, or system is later analyzed using the response spectrum generated at the supporting level.

After the locations of the mass points have been established, the number of dynamic degrees of freedom associated with each mass is considered. In all structures, six degrees of freedom exist for all mass points, i.e., three translational and three rotational. However, in most structures some of the dynamic degrees of freedom can be neglected, or can be uncoupled from each other so that separate analyses can be performed for different types of motions. For example, rotatory inertia can be neglected because its contribution to the total kinetic energy of the system is small compared to the contribution from translational inertia.

Coupling between the two horizontal motions occurs because the center of mass and center of resistance do 
not coincide. The degree of coupling depends on the amount of eccentricity and the ratio of the uncoupled torsional frequency to the uncoupled lateral frequency. If the uncoupled torsional frequency is high, with respect to the uncoupled lateral frequency, and if the eccentricities are small, the coupling between translation and torsion can be neglected (see Appendix C) .

Since lateral-torsional coupling and torsional response can significantly influence floor accelerations, structures are in general designed to keep minimum eccentricities. However, for analysis of structures that possess unusual eccentricities, a model is developed to include the effect of lateral-torsional coupling. Appendix $C$ outlines one method of establishing the model for the coupled analysis. It also shows the effect of coupling on the frequencies of a single story structure with different eccentricities.

The derivation of the stiffness matrix associated with the dynamic degrees of freedom is accomplished by modeling the assembly of structural members as elastic elements between the mass points. Various basic structural elements -- beams, plates, shells and solid elements -are available to mathematically model the structural complexity. The element stiffness matrices are assembled to form the total structural stiffness matrix. A number of computer codes are available to develop the stiffness matrix, such as STRESS, STRUDL, Bechtel plane frame program (CE 917), STARDYNE, MARC, ASHSD (CE 771), SAP (CE 779), and SUPERSMIS. The stiffness matrix associated with the specified dynamic degrees of freedom is obtained from the total stiffness matrix by a standard reduction process (3-2). As an alternative practice, 
a flexibility matrix is sometimes formulated first and then inverted to give the stiffness matrix.

Normally, the mass matrix is a diagonal matrix representing the mass of the structure lumped at the mass point locations. However, this depends on the choice of coordinates and the mass matrix may contain off-diagonal terms representing inertia coupling. For example, if the structure is continuous and not physically lumped at node points, a mass matrix consistent with the displacements of the system will contain offdiagonal terms $(3=3)$. However, in this case it is often sufficient to use a lumped (diagonal) mass matrix.

\subsubsection{Damping}

Energy dissipation in structures is generally represented by equivalent viscous damping. Evaluation of the damping coefficients is based on the material, the predicted stress and strain level, and the type of connections used in the structural system. Table 3-1 summarizes the damping values generally used, which are adopted from the AEC Regulatory Guide 1.61 (3-4). They are expressed as a percentage of critical damping, and are used for modal representation of the fixed base structure or equipment. For those fixed base structures where a single material is dominant as shown by the mode shape, the damping value associated with that material is adopted from Table 3-1. This modal damping value is assumed the same for all modes, that is,

$$
\beta_{1}=\beta_{2}=\ldots=\beta
$$


For fixed base structures composed of major subsystems that are made of different materials, the composite modal damping is computed by first constructing the following matrix:

$$
[B]=[\Phi]^{T}\left[\backslash \beta_{m} \backslash\right][M][\Phi]
$$

where $[\Phi]$ is the modal matrix, and $\left[\backslash \beta_{m}\right\rangle$ ] is a diagonal matrix made up of the damping values specified for the subsystems. The composite modal damping is then obtained from [B] by using the diagonal terms after they are divided by the generalized mass of the corresponding mode, where the generalized mass is defined by $\overline{\mathrm{m}}_{j}$, as follows :

$$
\left.\backslash \backslash \overline{\mathrm{m}}_{j} \backslash\right]=[\Phi]^{\mathrm{T}}[M][\Phi]
$$

For flexible base structures represented by lumped parameter models, see section 3.3 for the consideration of the structure-foundation interaction damping.

\subsection{STRUCTURE-FOUNDATION INTERACTION}

The techniques for modeling the structures have been presented in the preceding section. When a structure is supported on a flexible foundation, structure-foundation interaction is taken into account by coupling the structural model with the foundation medium.

The two methods used for representing the structurefoundation interaction are the lumped parameter representation and the finite element representation, depending upon the degree of structural embedment. The lumped parameter representation is used generally for 
structures supported at or near the ground surface. on the other hand, the finite element representation is generally used for deeply embedded structures. Reference (3-5) and Appendix $H$ discuss the distinction between, and the applicability of, these two methods for interaction representation. The method of representation to be used for each plant is stated in the individual SAR's.

Layering of the foundation material is usually present at the plant sites. The layering effect will be addressed in the individual SAR's.

\subsubsection{Lumped Parameter Representation}

In using the lumped parameter representation, the effect of the foundation medium is represented by the foundation impedances. In general, the foundation impedances are complex functions of the base mat, embedment depth, elastic properties of the foundation medium and forcing frequencies. Whether or not frequency dependent, they can always be represented by a mechanical analog composed of equivalent springs and dampers. The equivalent dampers represent the radiation effect of the seismic wave energy away from the structural base. The material damping of the foundation medium is neqlected in the lumped parameter representation if it is small compared with the radiation damping.

Figure 3-1 shows a schematic lumped parameter model of the structure-foundation system, with the equivalent foundation springs, $k_{x}$ and $k_{\psi}$, and radiation dampers, $c_{x}$ and $c_{\psi}$, representing the foundation impedances for horizontal seismic excitation. The foundation is represented by $\mathrm{k}_{z}$ and $\mathrm{c}_{\mathrm{z}}$ for vertical motion, and $\mathrm{k}_{t}$ and $\mathrm{c}_{t}$ for torsion. 
When the material below the base slab elevation is considered uniform, the impedance functions can be adequately represented by frequency-independent ones (3-5, $3-6,3-7)$. Table 3-2 shows the expressions of the equivalent spring stiffnesses and radiation damping coefficients, $k_{x}, \ldots, c_{z}$, for both circular and rectangular bases. If the material properties below the base slab vary in a continuous manner, without well-defined boundaries, use Table 3-2 and an established average property for the material within one base dimension from the base slab.

When significant layering condition exists at the plant site, its effect will be addressed in the individual SAR's.

With the foundation impedances specified, the structurefoundation system is formulated by coupling the fixedbase structure with the foundation medium through the base mat. The method of coupling, in terms of the equations of motion, is described in Appendix D; the structure being represented by its fixed base normal modes. The interaction system is based on the engineering judgment that the interaction effect out of the plane of the input ground motion is negligible.

The equations of motion for the interaction system represent a coupled system, mathematically. However, when frequency independent impedances are used, it is usually sufficient to represent this coupled system by normal modes. Appendix D shows one technique to determine the composite modal damping of the interaction system in this case. This is accomplished by requiring that 
at selected locations of the structural model, the dynamic amplification functions of both the coupled and uncoupled systems match each other at the natural frequencies (3-8). For conservatism, however, any computed composite damping exceeding 108 of critical will be replaced by a maximum of $10 \%$ of critical except for those modes that are clearly associated with rigid body translation or rotation of the structure. The adequacy of this exception is discussed in Appendix $\mathrm{H}$ and Refs. $(3-9)$ and $(3-10)$.

\subsubsection{Finite Element Representation}

The finite element method is used for more complex conditions such as structures having deep embedment. To minimize the effect of wave reflection from the boundaries, a minimum dimension is taken to be $8 \mathrm{~B}$ to $10 \mathrm{~B}$ in width, and $3 \mathrm{~B}(3-11)$ in depth (B is the effective width of the structural base), unless a firm rock boundary is encountered within this prescribed region. Figure 3-2 shows an example of a plane strain finite element model that may be used to evaluate the soilstructure interaction. In this figure, the base input motion $y(t)$ for the finite element model is computed based on the design earthquake time history specified at the elevation of the structural base. The method of such computation is described in Ref. (3-13). The vertical dimension of each finite soil element is equal to or less than $\lambda / 4$ or $c_{s} / 4 f$, where $\lambda$ is the shear wave length associated with the highest frequency of interest if this frequency is to be transmitted through the soil profile, and $c_{s}$ is the shear wave velocity of the soil. 
BC-TOP $-4-A$

Revision 3

The material damping of the foundation soil is included in the finite element analysis. In general, the foundation soil elements have nonlinear stress-strain characteristics. However, an iterative process is used to obtain equivalent linear properties which are strain dependent (2-2). References (3-12) and (3-13) describe the methods generally used for such an analysis.

\subsection{Example - Pressurized Water Reactor}

To illustrate the first method of the lumped representation of a structure-foundation system, the containment structure and internal components of a typical pressurized water reactor building are considered. The containment structure consists essentially of a post-tensioned concrete cylinder, a dome, and a reinforced concrete circular base slab. The internal system is composed of a network of concrete walls providing the radiation shielding and is normally designed to act independently of the containment structure except at the base connection. Figure 3-3 shows the cross-section of both structures, which are modeled as cantilever beams. In modeling the containment structure, it has been assumed that plane sections remain plane during bending for horizontal seismic analysis, and any ovaling action is omitted because of its nebligible contribution to the total stress response. A justification of the validity of this assumption is given in Appendix E.

\subsubsection{Fixed Base}

Both the containment structure and internal system are modeled by lumped masses. Torsion was excluded from the dynamic analysis in this example. Figure 3-3 shows the lumped structural model with 11 masses for the containment structure and 6 masses for the internal system. Table 3-3 shows the fixed base structural 
frequencies of the containment structure and the internal system. Figure 3-4(a) shows the fixed base structural mode shapes.

\subsubsection{Flexible Foundation}

The base mat is assumed to be supported on a uniform, flexible soil characterized by a unit weight of 130 $1 \mathrm{~b} / \mathrm{ft}^{3}$, a Poisson's ratio of $1 / 3$, and a shear modulus of $1.4 \times 10^{4} \mathrm{ksf}$ (corresponding to a shear wave velocity of about $2000 \mathrm{ft} / \mathrm{sec}$ ). Figure $3-3$ shows the frequency independent foundation impedances computed according to Table 3-2 for the case of a circular base on a uniform half space. The soil-structure system was formulated according to Eq. (D-13) of Appendix D. Four fixed base containment structure modes and three internal structure modes were included in the analysis. Table 3-4 shows the frequencies of the first eight soil-structure modes. Figure 3-4(b) shows the mode shapes, with the dashed lines representing the relative magnitude of base mat rocking in each mode.

A damping value of 2 percent of critical was used for each of the fixed base structural modes in this example. The damping determination technique described in Appendix $D$ was then used to calculate the composite modal damping for the soil-structure system. The results shown in Table 3-4 were obtained on the basis of the dynamic amplification functions at mass points 11 and 18 , as the responses at these two locations appear to be most sensitive to the damping.

The seismic response of both the fixed base and interaction models are presented in section 4.6 . 
(3-1) sadjian, A.H., "Some Problems with the Calculations of Seismic Forces on Equipment", Specialty Conference on Structural Design of Nuclear Plant Facilities, Vol. II, Chicago, Illinois, December 17-18, 1973, pp. 1-34.

(3-2) Weaver, W., Computer Programs for Structural Analysis, D. Van Norstrand Co., Princeton, New Jersey, 1967, pp. 189-198.

(3-3) Archer, J. S., "Consistent Mass Matrix for Distributed Mass System", Journal of Structural Division, ASCE, Vol. 89, No. ST4, Part 1, Proc. Paper 3391, August, 1963, pp. 161-178.

(3-4) Damping Values for Seismic Design of Nuclear Power Plants, Regulatory Guide 1.61, Directorate of Regulatory Standards, U. S. Atomic Energy Commission, October, 1973.

(3-5) Hadjian, A. H. (Editor), A Comparative study in SoilStructure Interaction, Technical Report, Bechtel Power Corporation, November, 1973.

(3-6) Richart, Jr., F. E., Hall, Jr., J. R., and Woods, R. D., Vibrations of Soils and Foundation, Prentice-Hall, Inc., New Jersey, 1970, pp. 347 and 382 .

(3-7) Parmelee, R. A., Perelman, D. S., and Lee, S. L., "Seismic Response of Multiple-Story Structures on Flexible Foundations", Bulletin of the Seismological society of America, Vol. 59, No. 3, June, 1976, pp. 1061-1070. 
(3-8) Tsai, N. C., Soil-Structure Interaction During Earthquakes, Technical Report, Power and Industrial Division, Bechtel Corporation, San Francisco, California, May 1, 1972 .

(3-9) Whitman, R. V., Protonotarios, J. N., and Nelson, M. F., "Case Study of Soil-Structure Interaction", paper presented at the ASCE Annual and National Environmental Engineering Meeting, Houston, Texas, Meeting Pring 1816, October 16-22, 1972 .

(3-10) Tsai, N. C., A Discussion of Agrawal's Paper: "Comparative Study for Soil-Structure Interaction Effect by the Soil Spring and Finite Element Model", Technical Report, Bechtel Power Corporation, San Francisco, California, October, 1973.

(3-11) Hwang, R. N., Seismic Response of Embedded Structures, Ph.D. Thesis, University of California, Berkeley, California, 1973, pp. 66-69.

(3-12) Idriss, I. M., Dezfulian, H., and Seed, H. B., Computer Programs for Evaluating the Seismic Response of Soil Deposits with Nonlinear Characteristics Using Equivalent Linear Procedures, Department of Civil Engineering, University of California, Berkeley, California, April, 1969.

(3-13) Lysmer, J., Soil Dynamic Analysis for the Alvin W. Vogtle Nuclear Power Plant, In Preparation for Bechtel Corporation, Los Angeles, California. 
1. Equipment and large-diameter piping systems (pipe diameter in excess of 12 inches) ${ }^{3}$

2. Small-diameter piping systems (pipe diameter equal to or less than 12 inches)

3. Welded steel structures

4. Bolted steel structures

5. Prestressed concrete structures

6. Reinforced concrete structures

Note: I Damping values for foundation material and for foundation-structure interaction analysis are not included in this table.

2 For dynamic analysis of active components as defined by Regulatory Guide 1.48, these values should also be used for SSE.

3 This includes both material and structural damping. If the piping system consists of only one or two spans with little structural damping, use the values for small-diameter piping. 
BC-TOP $-4-\mathrm{A}$

Rev. 3

TABLE 3-2

\section{LUMPED REPRESENTATION OF STRUCTURE-FOUNDATION INTERACTION}

\section{(a) Circular Base}

Motion

Horizontal

Rocking

Vertical

Torsion

$$
k_{t}=16 \mathrm{GR}^{3} / 3
$$

Equivalent Damping Coefficient

$$
c _ { x } = 0 . 5 7 6 k _ { x } R \longdiv { \rho / G }
$$$$
c_{\psi}=\frac{0.30}{1+B_{\psi}} k_{\psi} R \sqrt{\rho / G}
$$$$
c_{z}=0.85 k_{z} R \sqrt{\rho / G}
$$

$c_{t}=\frac{\sqrt{k_{t} I_{t}}}{1+2 I_{t} / \rho R^{5}}$

in which

$$
\begin{aligned}
& \nu=\text { Poisson's ratio of foundation medium, } \\
& G=\text { shear modulus of foundation medium, } \\
& R=\text { radius of the circular base mat, } \\
& \rho=\text { density of foundation medium, }
\end{aligned}
$$$$
B_{\psi}=\frac{3(1-\nu) I_{0}}{8 \rho R^{5}},
$$$$
I_{0}=\text { total mass moment of inertia of structure }
$$
and base mat about the rocking axis at the base.

$I_{t}=$ polar mass moment of inertia of structure and base mat. 


\section{(b) Rectangular Base}

Motion

Horizontal

Rocking

Vertical

Torsion
Equivalent

\section{Spring Constant}

$k_{x}=2(1+v) G \beta_{x} \sqrt{B L}$

$\mathrm{k}_{\psi}=\frac{\mathrm{G}}{1-\mathrm{v}_{\psi}} \mathrm{B}^{2} \mathrm{~L}$

$k_{z}=\frac{G}{1-v} \quad z_{z} \sqrt{B L}$
Equivalent Damping Coefficient

Use the formulas for circular base having an equivalent radius $R$ defined by Table 3-2(c) .

in which $\nu$ and $G$ are as defined previously, and

$B=$ width of the base mat in the plane of horizontal excitation;

$L=$ length of the base mat perpendicular to the plane of horizontal excitation;

$\beta_{x}, \beta_{\psi}, \beta_{z}=$ constants that are functions of the dimensional ratio, B/L. (After Fig. 10-16 in Ref. 3-6.)

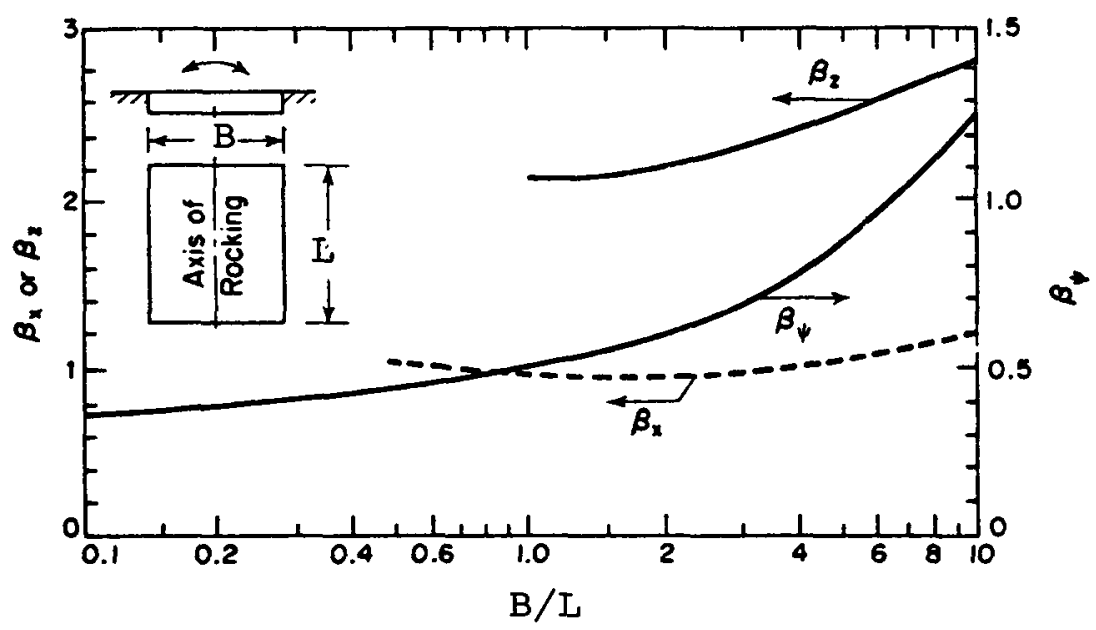

Constants $\beta_{x}, \beta_{\psi}$ and $\beta_{z}$ for

Rectangular Bases 


\section{TABLE 3-2 (Continued)}

\section{(c) Equivalent Radius For Rectangular Base}

For a rectangluar base having a dimension of BxL ( $B=$ width of base in the plane of horizontal vibration), the equivalent radius $R$ is taken to be the smallest of the parameters $R_{x}, R_{\psi}$ and $R_{z}$ defined below:

$$
\begin{aligned}
& R_{x}=\frac{(1+v)(7-8 v) \beta_{x} \sqrt{\mathrm{BL}}}{16(1-v)} \\
& R_{\psi}=\sqrt[3]{3 \beta_{\psi} \mathrm{B}^{2} \mathrm{~L} / 8} \\
& \mathrm{R}_{z}=\beta_{z} \sqrt{\mathrm{BL}} / 4
\end{aligned}
$$

The parameters $\beta_{x},{ }^{\beta^{\prime}}$, and $\beta_{z}$ are given by Table $3-2(b)$. 
BC-TOP $-4-\mathrm{A}$

Rev. 3

TABLE $3-3$

PROPERTIES OF THE STRUCTURAL MODELS OF

THE CONTAINMENT BUILDING AND INTERNALS

(*Concrete Modulus $\mathrm{E}=6.9 \times 10^{5} \mathrm{ksf}, \mathrm{G}=2.7 \times 10^{5} \mathrm{ksf}$ )

Joint Properties

\begin{tabular}{|c|c|c|c|c|c|c|c|c|c|}
\hline $\begin{array}{l}\text { Mass } \\
\text { No. } \\
\end{array}$ & $\begin{array}{c}m_{i} \\
(\mathrm{kips}) \\
\end{array}$ & $\begin{array}{r}I_{i} \times 10^{-6} \\
\left(k i p-f t^{2}\right) \\
\end{array}$ & & $\begin{array}{l}\text { LOC } \\
\text { bet } \\
\text { Joil }\end{array}$ & $\begin{array}{l}\text { atic } \\
\text { ween } \\
\text { nt } \mathrm{N}\end{array}$ & $\begin{array}{l}\frac{M e}{2 n} \\
\text { nn } \\
\text { No. }\end{array}$ & $\begin{array}{l}\text { Area } \\
\left(f t^{2}\right) \\
\end{array}$ & $\begin{array}{c}\text { Shear Area } \\
\left(f t^{2}\right)\end{array}$ & $\begin{array}{c}\text { Moment of } \\
\text { Inertia } x ~ \\
\left(f t^{4}\right)\end{array}$ \\
\hline base & 20000 & 21.1 & & & & & & & \\
\hline 1 & 4600 & 9.4 & 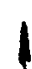 & base & to & 1 & 1400 & 700 & 2.8 \\
\hline 2 & 4200 & 8.5 & & 1 & to & 2 & & & \\
\hline 3 & & & & 2 & to & 3 & & & \\
\hline 4 & & & & 3 & to & 4 & & & \\
\hline 5 & & & C & 4 & to & 5 & & & \\
\hline 5 & $\gamma$ & & $\begin{array}{l}\mathrm{O} \\
\mathrm{N} \\
\mathrm{m}\end{array}$ & 5 & to & 6 & & & \\
\hline 7 & 4610 & 9.4 & A & 6 & to & 7 & & & \\
\hline 8 & 3020 & 5.9 & ד & 7 & to & 8 & 990 & 500 & 1.9 \\
\hline 9 & 2470 & 3.7 & - & 8 & to & 9 & & 1 & 1.5 \\
\hline 10 & 2120 & 1.7 & $N$ & 9 & to & 10 & & & 0.8 \\
\hline 11 & 190 & 0.1 & & 10 & to & 11 & \rfloor & 1 & 0.2 \\
\hline 12 & 2800 & 2.4 & & base & to & 12 & 2000 & 1320 & 1.1 \\
\hline 13 & 2510 & 1.9 & $\begin{array}{l}\mathrm{I} \\
\mathrm{N}\end{array}$ & 12 & to & 13 & 2560 & 1560 & 1.2 \\
\hline 14 & 6290 & 5.0 & $\begin{array}{l}\mathbf{T} \\
\mathrm{E}\end{array}$ & 13 & to & 14 & 2210 & 1460 & 1.2 \\
\hline 15 & 3760 & 6.6 & $\begin{array}{l}R \\
N\end{array}$ & 14 & to & 15 & 1960 & 730 & 1.3 \\
\hline 16 & 8540 & 12.6 & $\begin{array}{l}\text { A } \\
\mathrm{L}\end{array}$ & 15 & to & 16 & 1740 & 600 & 0.9 \\
\hline 17 & 1220 & 0.8 & $S$ & 16 & to & 17 & 780 & 360 & 0.2 \\
\hline 18 & 820 & 0.1 & & 17 & to & 18 & 190 & 70 & 0. \\
\hline
\end{tabular}


BC-TOP-4-A

Rev. 3

TABLE 3-4

FREQUENCIES AND MODAL DAMPING VALUES OF THE

P.W.R. CONTAINMENT AND INTERNAL MODELS

\begin{tabular}{|c|c|c|c|c|}
\hline \multirow{3}{*}{ mode no. } & \multicolumn{2}{|c|}{ Frequency (cps) } & \multicolumn{2}{|c|}{ Modal Damping (o Critical) } \\
\hline & (a) & (b) & (a) & (b) \\
\hline & fixed base & interaction & fixed base & interaction \\
\hline 1 & $5.28 *$ & 3.39 & 2.0 & 5.1 \\
\hline 2 & $13.05^{\#}$ & 8.94 & & 23.0 \\
\hline 3 & $16.29 *$ & 12.31 & & 2.0 \\
\hline 4 & $18.34^{\#}$ & 16.19 & & 6.4 \\
\hline 5 & $29.26 *$ & 17.18 & & 1.5 \\
\hline 6 & $41.80 *$ & 24.87 & & 3.5 \\
\hline 7 & $47.06^{\#}$ & 30.90 & & 2.0 \\
\hline 8 & --- & 42.15 & -- & 0.5 \\
\hline
\end{tabular}

\section{Remarks :}

* Frequencies of the fixed base containment structure

\# Frequencies of the fixed base internal system 
BC-TOP $-4-A$

Rev. 3

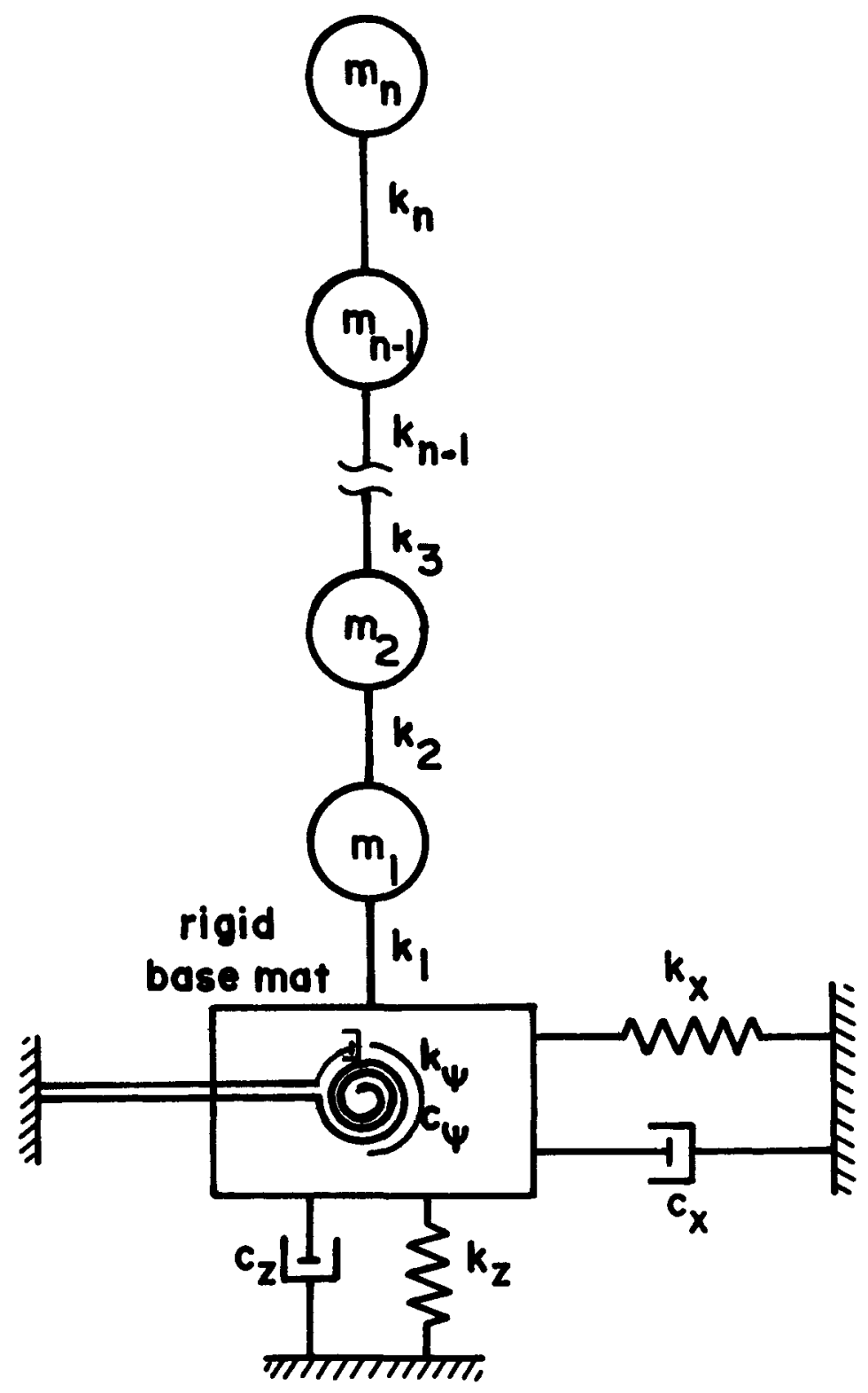

Fig. 3-1. A Lumped Mass Model of StructureFoundation system 


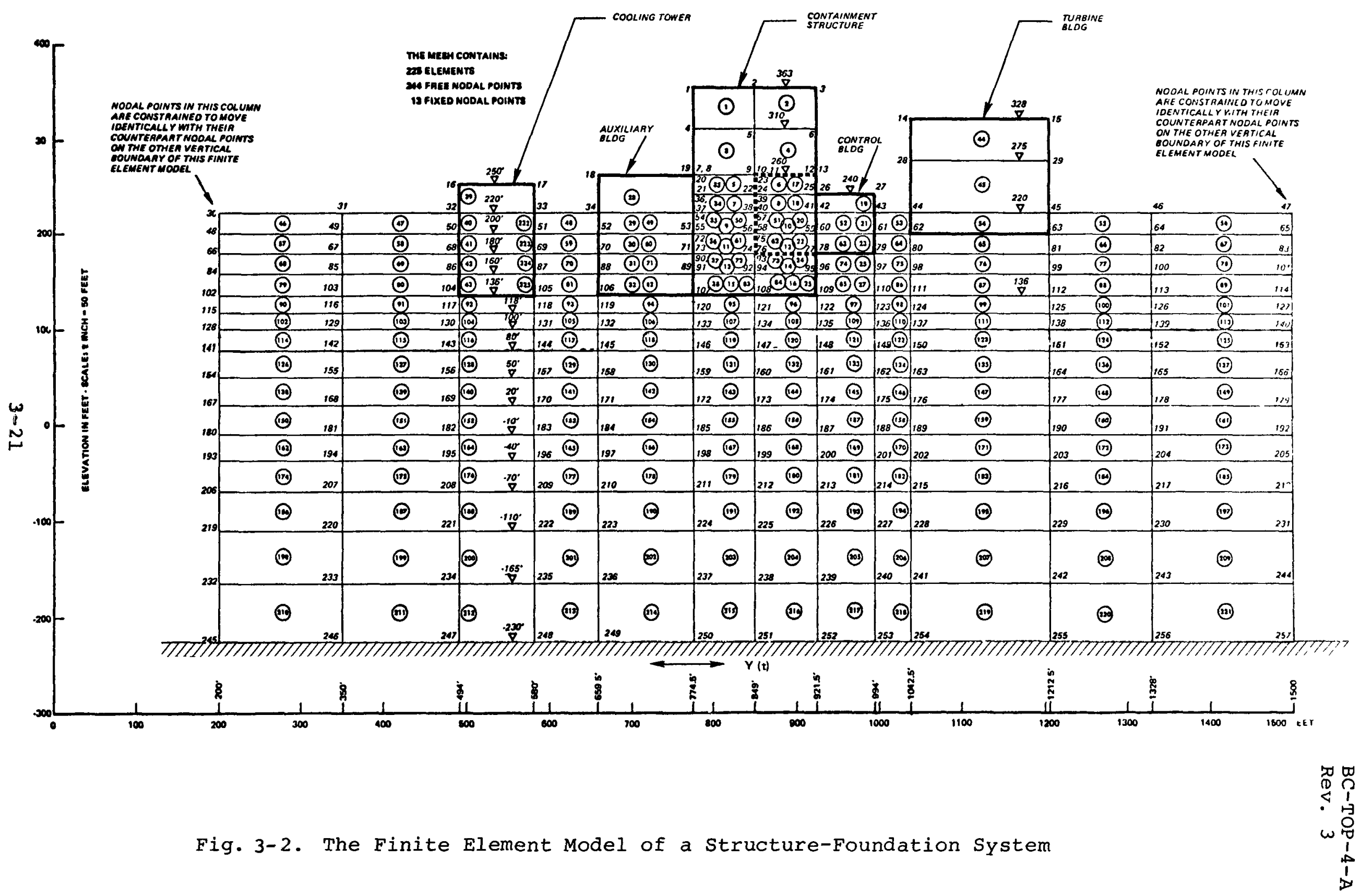


$\mathrm{BC}-\mathrm{TOP}-4-\mathrm{A}$

Rev. 3

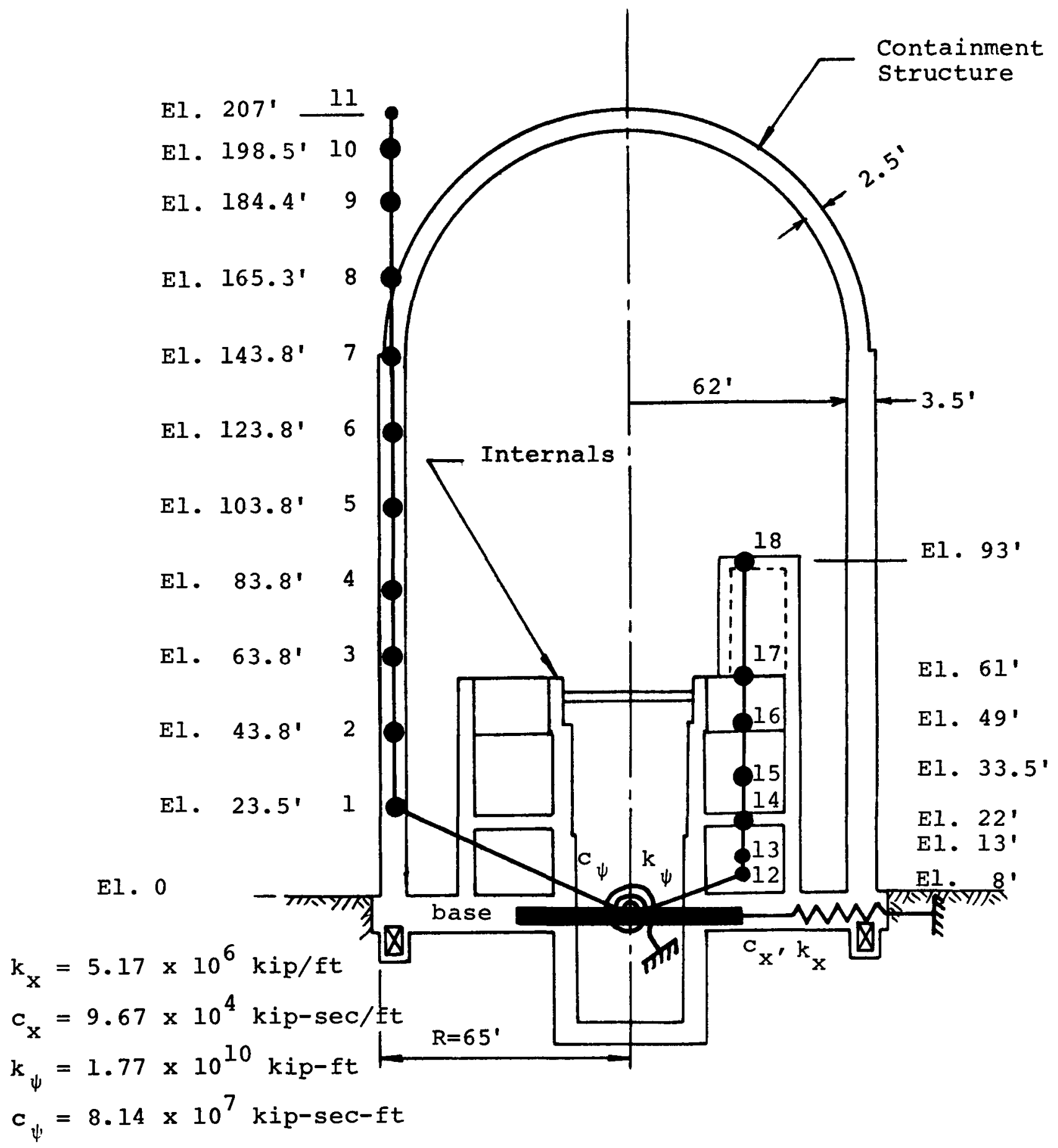

Fig. 3-3. Lumped Mass Model of the P.W.R. Containment Structure and Internal System 
BC-TOP $-4-A$

Rev. 3

1st Mode 2nd Mode 3rd Mode 4th Mode 5 th Mode 6 th Mode (a) Fixed Base

5.28 cps 13.05 cps 16.29 cps 18.34 cps 29.26 cps

Fixed Base
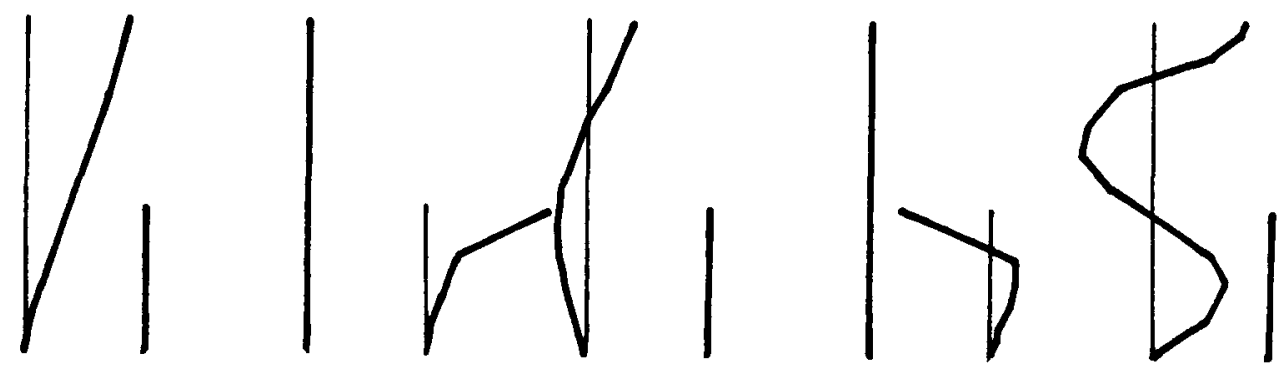

(b) Flexible Foundation
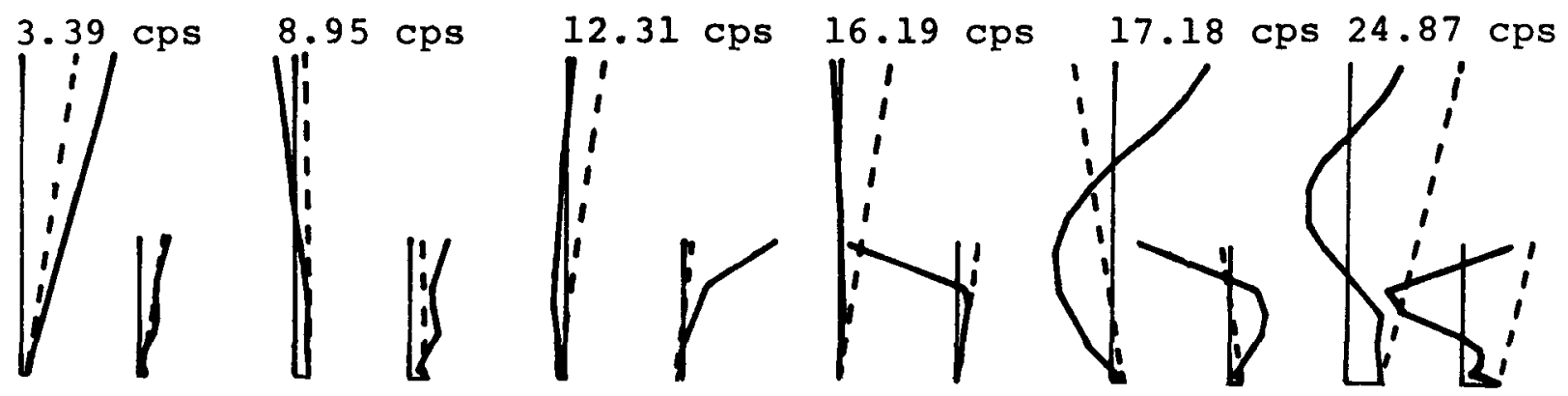

Note: Dashed lines indicate base rocking.

Fig. 3-4 Frequencies and Mode Shapes of the P.W.R. Containment and Internals Models 


\subsection{STRUCTURAL RESPONSE}

\section{1 SUMMARY}

This section summarizes the techniques for computing the response of structures subject to the specified ground acceleration. Separate lateral and vertical analyses are performed. The results are then combined to predict the total response of the structure. Also, based on the calculated structural responses, the factor of stability against overturning and the foundation soil pressure are predicted.

With the structural model described by the mass, stiffness and damping matrices, the structural response is predicted by solving the following equation of motion, Eq. $(3-1):$

$$
[M][\ddot{x}\}+[C]\{\dot{x}\}+[K]\{x\}=-[M]\{\ddot{u}\}
$$

Floor response spectra are then generated from the acceleration time history response for the seismic qualification of Category I equipment or piping systems (discussed in section 5.0).

The predicted displacement response is used to check against the allowable clearance between structures or equipment. The minimum clearance between any two structures, components or equipment is maintained at twice the absolute sum of the predicted displacements of the two items under consideration.

\subsection{RESPONSE ANALYSIS}

Depending on the properties of the mass, damping, and stiffness matrices, two methods of analyses, are 
generally used to solve Eq. (3-1). The first is the method of modal superposition which is used when the mathematical model can be represented by normal modes. The second is the method of direct integration, which is used when Eq. (3-1) cannot be decoupled. These methods are applicable to cases where all the parameters of the structure and foundation are frequency independent. In case frequency dependent parameters are present, such as the foundation impedance functions for a layered site, different techniques are used to solve Eq. $(3-1)$.

\subsubsection{Method of Modal Superposition}

To represent the structural model by normal modes is equivalent to applying the following transformation to Eq. $(3-1)$ :

$$
\{x\}=[\Phi]\{q\}
$$

where the normal mode matrix [ $\Phi]$ satisfies the following orthogonal transformation:

$$
\begin{aligned}
& {[\Phi]^{T}[M][\Phi]=\left[\backslash \bar{m}_{j} \backslash\right]} \\
& {[\Phi]^{T}[C][\Phi]=\left[\backslash 2 \bar{m}_{j} \beta_{j} \omega_{j} \backslash\right]} \\
& {[\Phi]^{T}[K][\Phi] \quad\left[\backslash \bar{m}_{j} \omega_{j}^{2} \backslash\right]}
\end{aligned}
$$

In Eq. $(4-2), \bar{m}_{j}$ is the generalized mass, $\beta_{j}$ is the modal damping, and $\omega_{j}$ is the natural frequency in radians per second. Eq. $(3-1)$ is then represented by the following modal equations:

$$
\ddot{q}_{j}+2 \beta_{j} \omega_{j} \dot{q}_{j}+\omega_{j}^{2} q_{j}=-\Gamma_{j} \ddot{u} \quad j=1,2 \ldots \quad(4-3)
$$


in which $\Gamma_{j}$ is the modal participating factor defined by

$$
\Gamma_{j}=\sum_{i=1}^{N} \Phi_{i j} m_{i} / \bar{m}_{j}
$$

and $\mathrm{N}$ is the total number of dynamic degrees of freedom.

For engineering purposes, all those modes with frequencies lower than 33 cps are used in the analysis; however, the lowest three modes are always used.

Because the design earthquake is specified by both the design spectra and a time history motion, two methods are used to solve Eq. (4-3).

a) Response Spectrum Technique - With the input given in terms of the design spectra, the modal displacement response is directly obtained from the design spectra as

$$
q_{j, \max }=\Gamma_{j} S a_{j} / \omega_{j}^{2} \quad j=1,2 \ldots
$$

where $\mathrm{Sa}_{j}$ is the value of the acceleration spectral response at frequency $\omega_{j}$ (or $f_{j}, f_{j}=\omega_{j} / 2 \pi$ ) and for damping $\beta_{j}$. From Eq. $(4-1)$, the displacement response per mode at any mass point is:

$$
x_{i j, \max }=\Phi_{i j} q_{j, \max }
$$

Other structural responses per mode, such as shears and moments, can be computed from $x_{i j, \max }$ by using the stiffness properties of the structural members. The modal responses are then combined according to the following criteria: 
Two consecutive modes are defined as closely spaced if their frequencies differ from each other by less than 10 percent. For modes that are not closely spaced, the criterion of "the square root of the sum of the squares" is used. When modes are closely spaced, they are first divided into groups in such a way that, in each group, the deviation in frequency between the first and the last mode does not exceed 10 percent of the lower frequency. The criterion of "the sum of absolute values" is then applied to each group, and the results from all the groups are then combined according to the criterion of "the square root of the sum of the squares".

Because of the nature of the design spectra and because most structures have a fundamental frequency within the frequency range of maximum spectral response, which is 2 to $7 \mathrm{cps}$, the effect on the response of these structures due to the possible variation in structural or foundation material properties would be negligible.

b) Time History Analysis - Given the ground motion time history as input, the modal equations, Eq. (4-3), are first solved for each mode, and then the modal responses are superimposed according to Eq. (4-1) to obtain the total response.

\subsubsection{Method of Direct Integration}

Equation $(3-1)$ is directly integrated by accetable numerical schemes when this equation cannot be decoupled. For this case, the input is the time history motion.

4.3 Total Structural Response From Separate Lateral And Vertical Analyses

The total structural response is predicted by combining the applicable maximum codirectional responses, say, $\mathbf{R}_{\mathbf{x}^{\prime}} \mid 3$ 
$R_{y}$ and $R_{z}$, calculated from the two lateral and the vertical analyses. The combination is done according to the criterion of "the square root of the sum of the squares" as follows:

$$
R_{\text {total }}=\sqrt{R_{x}^{2}+R_{y}^{2}+R_{z}^{2}}
$$

\subsection{Structural Overturning And Soil Pressure}

\subsubsection{Structural Overturning}

When the combined effect of earthquake ground motion and structural response is strong enough, the structure will undergo a rocking motion pivoting about either edge of the base. When the amplitude of rocking motion becomes so large that the center of structural mass reaches a position right above either edge of the base, the structure becomes unstable and may tip over (see structural position (b) as indicated by dotted lines in Fig. 4-1). The mechanism of such rocking motion is that of an inverted pendulum, and its natural period is very long compared with that of the linear, elastic structural response. Hence, so far as overturning evaluation is concerned, the structure can be treated as a rigid body.

The maximum kinetic energy is conservatively estimated to be:

$E_{S}=\frac{1}{2} \sum m_{i}\left[\left(v_{H}\right)_{i}^{2}+\left(v_{v}\right)_{i}^{2}\right]$

in which $\left(v_{H}\right)_{i}$ and $\left(v_{V}\right)_{i}$ are the maximum values of the total laeral velocity and total vertical velocity, respectively, of mass $m_{i} \cdot\left(v_{H}\right)_{i}$ and $\left(v_{v}\right)_{i}$ may be computed as follows: 


$$
\begin{aligned}
& \left(v_{H}\right)_{i}^{2}=\left(v_{x}\right)_{i}^{2}+\left(v_{H}\right)_{g}^{2} \\
& \left(v_{V}\right)_{i}^{2}=\left(v_{z}\right)_{i}^{2}+\left(v_{V}\right)_{g}^{2}
\end{aligned}
$$

in which $\left(v_{H}\right)_{g}$ and $\left(v_{V}\right)_{g}$ are the peak horizontal and vertical ground velocity, respectively, and $\left(v_{x}\right)_{1}$ and $\left(v_{z}\right)_{i}$ are the maximum values of the relative lateral and vertical velocity of mass $m_{i}$.

Letting $m_{0}$ be the total mass of the structure and base mat, the energy required to overturn the structure is equal to:

$$
E_{0}=m_{0} g \Delta h
$$

where $\Delta \mathrm{h}$ is the height for which the center of mass of the structure must be lifted to reach the overturning position, i.e., position (b) in Fig. 4-1. Because the structure may not be a symmetrical one, the value of $\Delta \mathrm{h}$ is computed with respect to the edge that is nearer to the center of mass. The structure is defined stable against overturning when the ratio $\mathrm{E}_{\mathrm{o}} / \mathrm{E}_{\mathrm{s}}$ exceeds 1.5 . To include in $E_{0}$ any significant effect of embedment or underground water, see Eq. (4-18).

\section{a) Effect of Embedment and Ground Water - The above} calculations assume the structure rests on the ground surface and hence are very conservative if the structure is embedded to a considerable depth. The embedment gives rise to additional resistance against overturning due to the side soil pressure which is considered as follows.

Let $d$ be the depth of embedment and $d$ ' be the submerged. depth in case the ground water table is above the elevation of the base. The structure is still assumed to rotate about the toe edge $\mathrm{R}$ (or $\mathrm{L}$ ) for the overturning evaluation. To simplify the analysis for practical purposes, only the passive soil pressure developed on the toe-side is considered, and the wall frictions 
and the rather complicated actions of the soil on the other side of the structure are neglected. The passive pressure diagram conventionally constructed would be modified to be consistent with the assumption that the structure rotates about the edge R. Granular and free-draining soil conditions are also assumed. Figures 4-2(a) to (c) show the resultant idealized pressure diagram for different elevations of the ground water table when it is above the base (i.e., $d^{\prime} \geq 0$ ). In these figures, the control parameter $\mathrm{p}_{\mathrm{dry}}$ is given by :

$$
p_{d r y}=k_{p} r_{\text {soil } 1} d
$$

and the parameter $p_{s u b}$ (for $d^{\prime} \geq 0$ ) is given by:

$$
p_{\text {sub }}=p_{d r y}-d^{\prime} \gamma_{\text {water }}
$$

where $k_{p}, Y_{\text {soil }}$ and $\gamma_{\text {water }}$ are the coefficients for passive soil pressure, the unit weight of soil and the unit weight of water, respectively.

For the structure to reach the overturning position shown in Fig. 4-1, the additional work required to be done against the side soil is, according to Fig. 4-2(a):

$$
W_{p}=\int_{0}^{d} p(z) b z \tan \theta d z=b \tan \theta \int_{0}^{d} p(z) z d z
$$

in which $\mathrm{p}(\mathrm{z})$ is the idealized passive soil pressure at the elevation $z$ above the base, $\theta$ is the angle of rotation at the overturning position, and $b$ is the effective length of the structure normal to the plane of rotation. The effective length $b$ is the structural dimension normal to the plane of rotation for rectangular structures, and 0.8 of the diameter for cylindrical structures (4-1). For the case that the ground 
water table is below the base, Eq. (4-13) gives:

$$
\left.\mathrm{w}_{\mathrm{p}}\right|_{\mathrm{d}^{\prime} \leq 0}=\frac{1}{8} \mathrm{p}_{\mathrm{dry}} \mathrm{bd^{2 } \operatorname { t a n } \theta}
$$

and for the extreme case that the water table is at the ground surface:

$$
\left.\mathrm{w}_{\mathrm{p}}\right|_{\mathrm{d}^{\prime}=\mathrm{d}}=\frac{1}{8} \mathrm{p}_{\mathrm{sub}} \mathrm{bd}^{2} \tan \theta
$$

The additional work $W_{p}$ required for overturning to take place is added to the work $E_{0}$ given by Eq. (4-10) for the evaluation.

b) Effect of Buoyancy - When the ground water table is above the base $\left(d^{\prime}>0\right)$, the buoyant force has the effect of increasing the overturning potential of the structure. Such an effect would be appreciable when the submerged depth, $d^{\prime}$, is appreciable. It is accounted for in the analysis by subtracting from $E_{0}$ the work done by buoyant force.

The buoyant force acts at the centroid of the volume of the water displaced by the submerged portion of the structure, and its magnitude varies from position to position during the overturning process. At any position before overturning takes place, let the centroid of the displaced volume of water be located at a height of $z$ above the elevation of the edge $R$ and let the buoyant force be $B(z)$. Denoted by $W_{b}$, the work done by the buoyant force is equal to:

$$
\mathrm{W}_{\mathrm{b}}=\int_{z_{\mathrm{a}}}^{z_{\mathrm{b}}} \mathrm{B}(\mathrm{z}) \mathrm{dz}
$$


in which, according to Fig. 4-3, $z_{a}$ and $z_{b}$ are the height of the centroid of buoyant force above the edge $R$ for the equilibrium position (a) and the tipping over position (b) respectively. Note that $z_{a}$ is equal to $d / 2$. For practical purposes, Eq. $(4-16)$ is approximated by:

$$
W_{b} \simeq\left(z_{b}+z_{a}\right)\left[B\left(z_{b}\right)-B\left(z_{a}\right)\right] / 2+B\left(z_{a}\right)\left(z_{b}-z_{a}\right)(4-17) \mid 3
$$

Therefore, when the effects of both embedment and buoyancy are taken into account for the overturning evaluation, Eq. (4-10) is modified as follows:

$$
E_{o}=m_{o} g \Delta h+w_{p}-w_{b}
$$

\subsubsection{Soil Pressure}

The maximum soil pressure under the base mat is predicted for the condition that soil has no tension capability. Also the distribution of the soil pressure is assumed linear so that only the pressure values at both edges of the base need to be computed.

Let $M_{x}, M_{y}$ and $V$ be, respectively, the maximum base moments from the two separate lateral analyses, and the maximum vertical inertial force from the vertical analysis. Because these seismic loads do not always occur simultaneously, an equivalent system of simultaneous seismic loads is defined, by the concept of the square root of the sum of squares, to simulate the most probable combined effects of $M_{x}, M_{y}$ and $V$ on the soil pressure.

The equivalent simultaneous seismic loads are then used together with the structural and base weight to predict the maximum soil pressure values. If tension is predicted from the initial computation, the soil pressure 
distribution is adjusted by an iterative process; the final soil pressure diagram is related to the initial diagram by two conditions:

- the total vertical force remains unchanged, and

- the moment about any reference axis remains unchanged.

In the event that the base mat is below the ground water table by a depth of $d$ ', the buoyancy effect is accounted for by subtracting the quantity d' $\gamma_{\text {water }}$ from the structural and base weight before calculating the soil pressure.

\subsection{Example - Response of The Pressurized Water Reactor}

The seismic response of the example PWR containment and internal models (see Fig. 3-7) was calculated. The design spectra shown in Fig. 2-ll were used for the spectral response analysis assuming a peak ground acceleration of $0.1 \mathrm{~g}$. For the time history response analysis, the synthetic time history shown in Fig. 2-12 was used as the ground input for a peak acceleration of $0 . \mathrm{gg}$. Both the fixed base and interaction models were examined.

\subsubsection{Fixed Base Model}

The fixed base structural frequencies and modal damping values have been given in Table 3-4. A spectral response analysis was made according to the method presented in Section 4.2. Figures 4-4(a) to 4-6(a) show the envelopes of the computed maximum floor acceleration, shear, and moment of the containment structure (the solid curves). Figures 4-4(a) to 4-6(a) also show the corresponding structural responses from the 
time history analysis, using the method of modal superposition (the dashed curves).

Fiqures 4-4 to 4-7 indicate that the time history analysis overestimated the structural response because the response spectra of the synthetic time history always conservatively envelop the smooth design spectra (see Figs. 2-13 and 2-14).

\subsubsection{Flexible Foundation Model}

With the foundation soil characterized by a shear modulus of $1.4 \times 10^{4} \mathrm{ksf}$, a Poisson's ratio of $1 / 3$ and a unit weight of $130 \mathrm{lb} / \mathrm{ft}^{3}$, the interaction model is analyzed according to the method in Appendix $D$. The frequencies and composite modal damping values of this interaction model were listed in Table 3-4.

A spectral response analysis was first performed to predict the acceleration, shear, and moment envelopes for the containment structure (see Figs. 4-4(b) to 4-6(b)). Compared with the fixed base case, the interaction has the effect of reducing the base shear and moment in this example.

A time history analysis was also performed, for which both the method of modal superposition (for Eq. (D-18)) and the method of direct integration (for Eq. (D-13)) were used. The responses are shown in Figs. 4-4(b) to 4-6 (b), which indicate that these two methods of time history analysis produce essentially the same results in this case.

\subsubsection{Floor Response Spectrum}

Based on the time history generated at mass point 11 of the containment structure (the flexible foundation case), the floor response spectra were computed. The 
1 percent damping spectrum is shown by the dashed curve in Fig. 5-1 of section 5.2.

\subsubsection{Effect of Variation In Soil Properties}

The shear modulus of the foundation soil appears to be a sensitive parameter in this case. Assuming a variation of \pm 35 percent in the shear modulus, the resultant variations in frequencies and composite modal damping are summarized in Table 4-1. The variations in fundamental frequency, $\Delta f_{1}$, are -14 and +9 percent respectively.

Figure 4-7 shows the envelopes of shear and moment for the containment structure, which were computed by the spectral response analysis. It indicates a variation of about -12 and +8 percent in both base shear and base moment. The corresponding variations in shear and moment from the time history analysis are even smaller. The variation in structure response is considered insignificant in this example for a variation in soil shear modulus of as large as \pm 35 percent. Nevertheless, this conclusion is not to be generalized to other cases having a fundamental structural frequency outside of the range of 2 to $7 \mathrm{cps}$ or a probable variation in soil modulus beyond \pm 35 percent. 


\section{SECTION 4.0 REFERENCES}

(4-1) Czerniak, E., "Design Criteria for Embedment of Piers", Consulting Engineers, March, 1958. 
TABLE 4-1

VARIATION IN FREQUENCY AND MODAL DAMPING VALUE DUE TO A VARIATION IN SHEAR MODULUS OF $\pm 35 \%$ FOR THE FOUNDATION MEDIUM

(a) -358G Variation

Mode No. $f_{j}($ cps $) \quad \Delta f_{j} \beta_{j}($ ocritical)

$\longrightarrow$

1

2

3

4

5

6

7

8
$2.91-14 \%$

$7.61-15 \%$

11.46

$-78$

$-38$

$-18$

17.07

$-28$

24.46

30.76

42.14
6.1

28.0

1.0

0.3

1.2

2.4

1.4

0.3 (b) +35\%G Variation

$f_{j}$ (cps) $\Delta f_{j} \quad \beta_{j}(8 c r i t i c a l)$

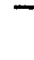

(1)

3.71

98

4.4

$9.7910 \%$

18.2

13.0768

7.9

$16.64 \quad 3 \%$

0.4

$17.48 \quad 28$

0.5

$25.28 \quad 28$

4.1

31.07

3.0

42.16

0.5 
BC-TOP $-4-A$

Rev. 3

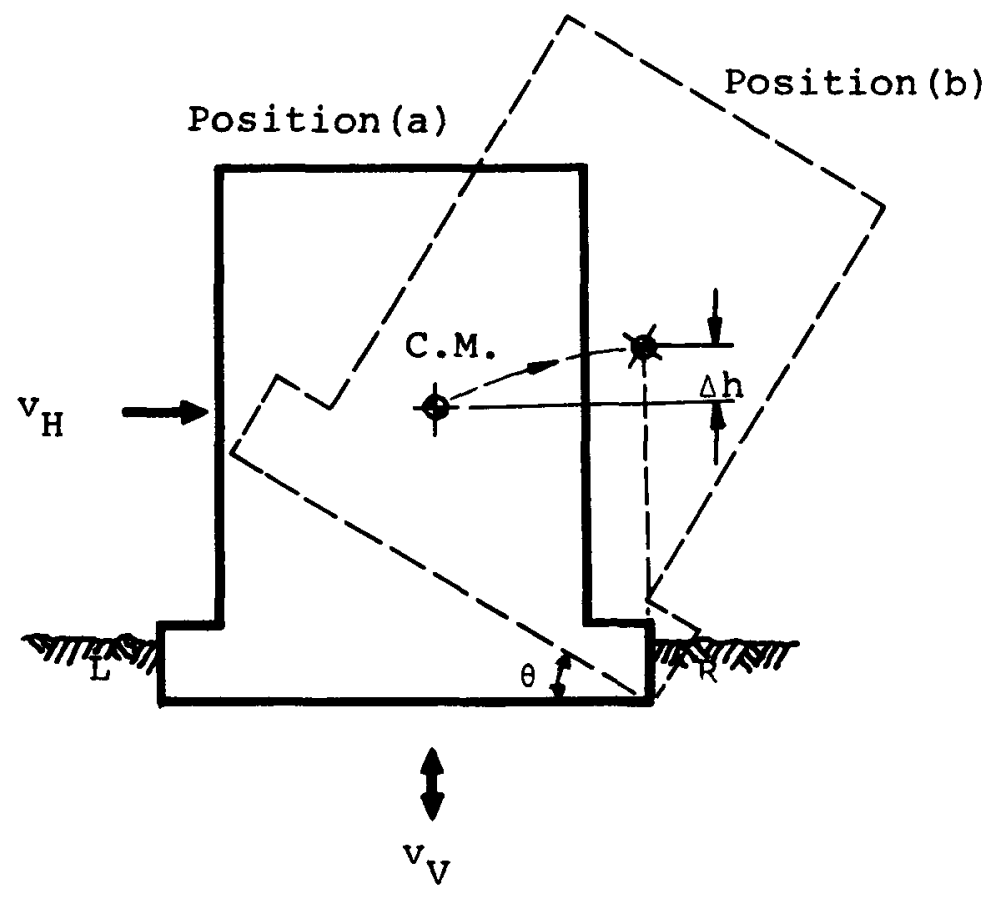

Fig. 4-1 Position of the structure when Overturning about one Edge 
BC-TOP $-4-\mathrm{A}$

Rev. 3

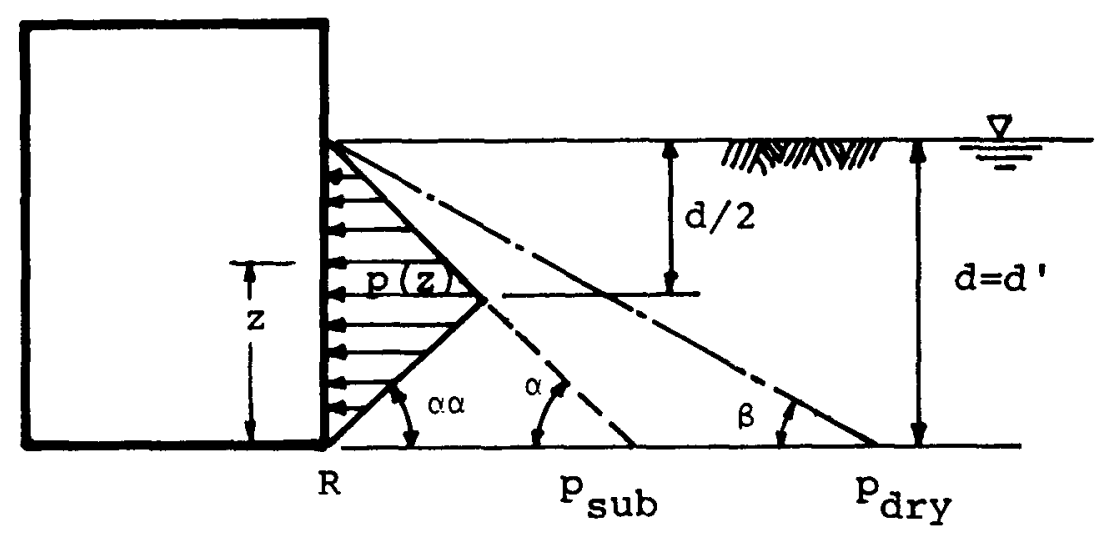

(a) $d^{\prime}=d$

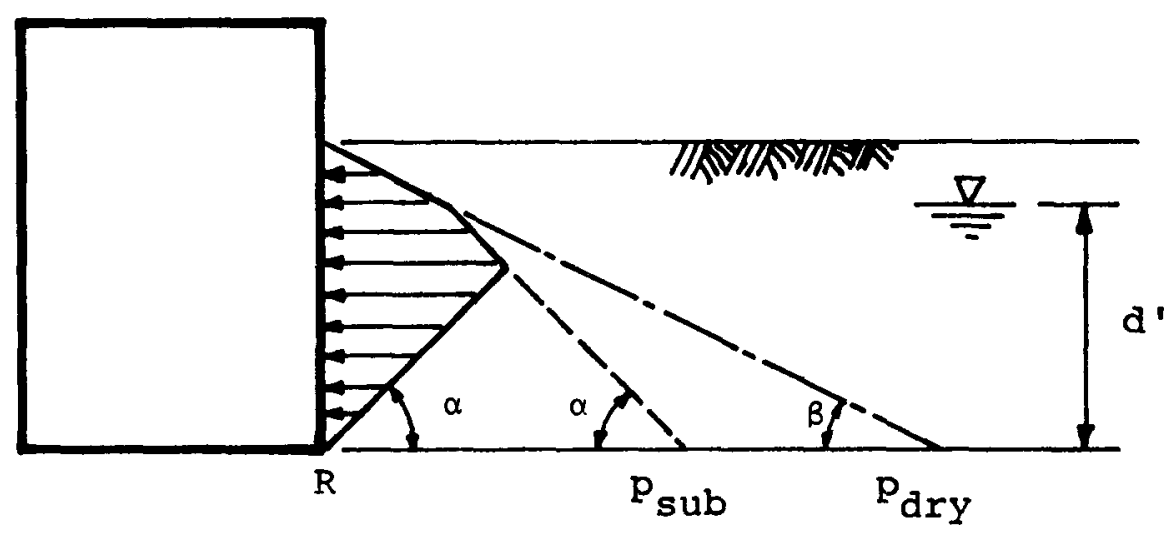

(b) d $/ 2<d^{\prime}<d$

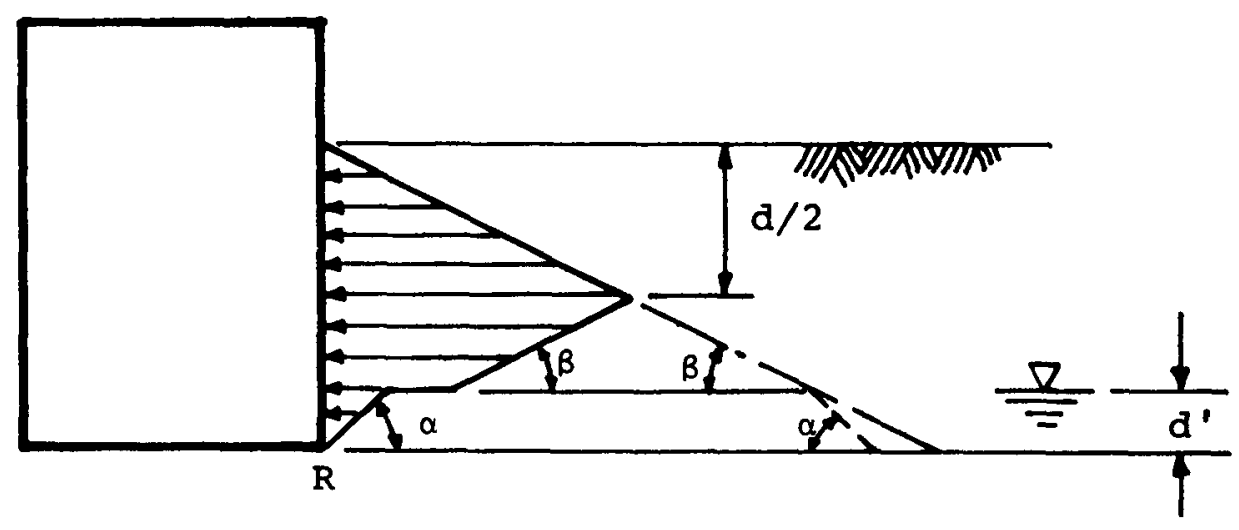

(c) $0<d^{\prime}<d / 2$

Fig. 4-2 Idealized Passive Soil Pressure for Overturning about Edge $R$ 


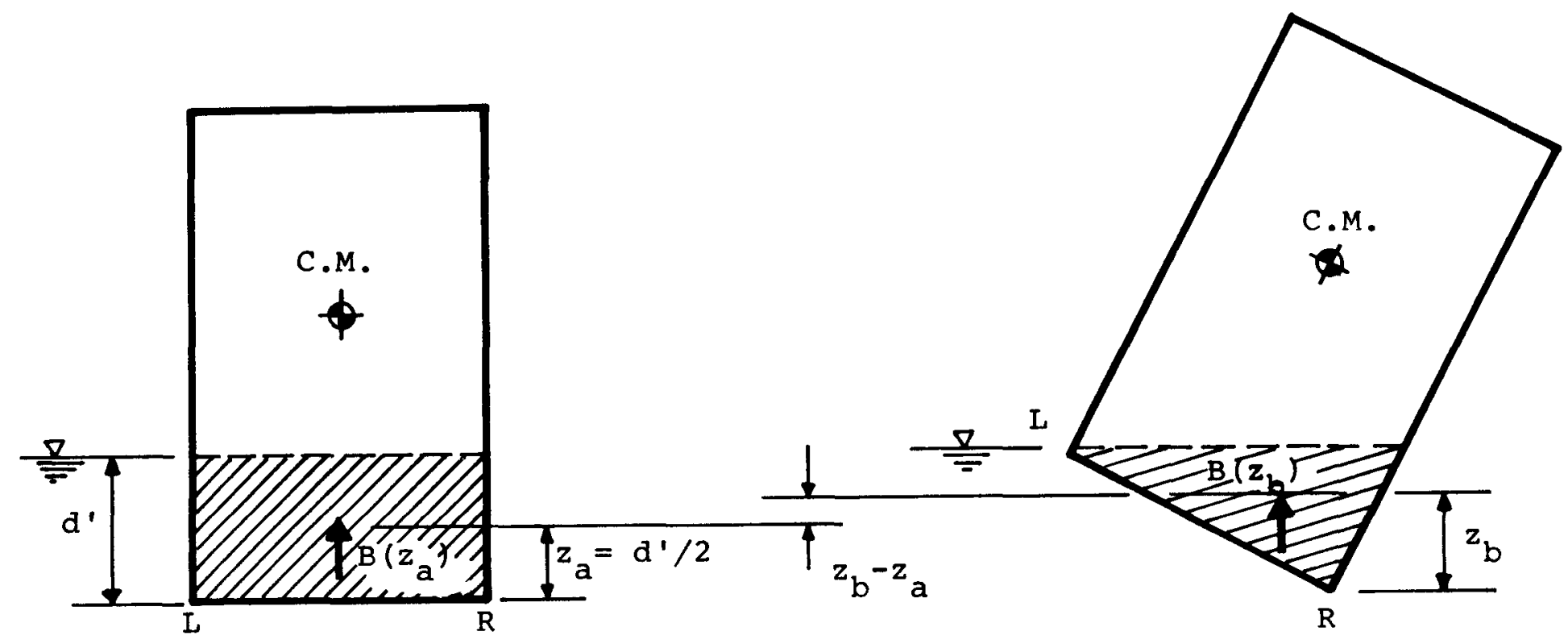

(a) Equilibrium Position

(b) Tipping-over Position 


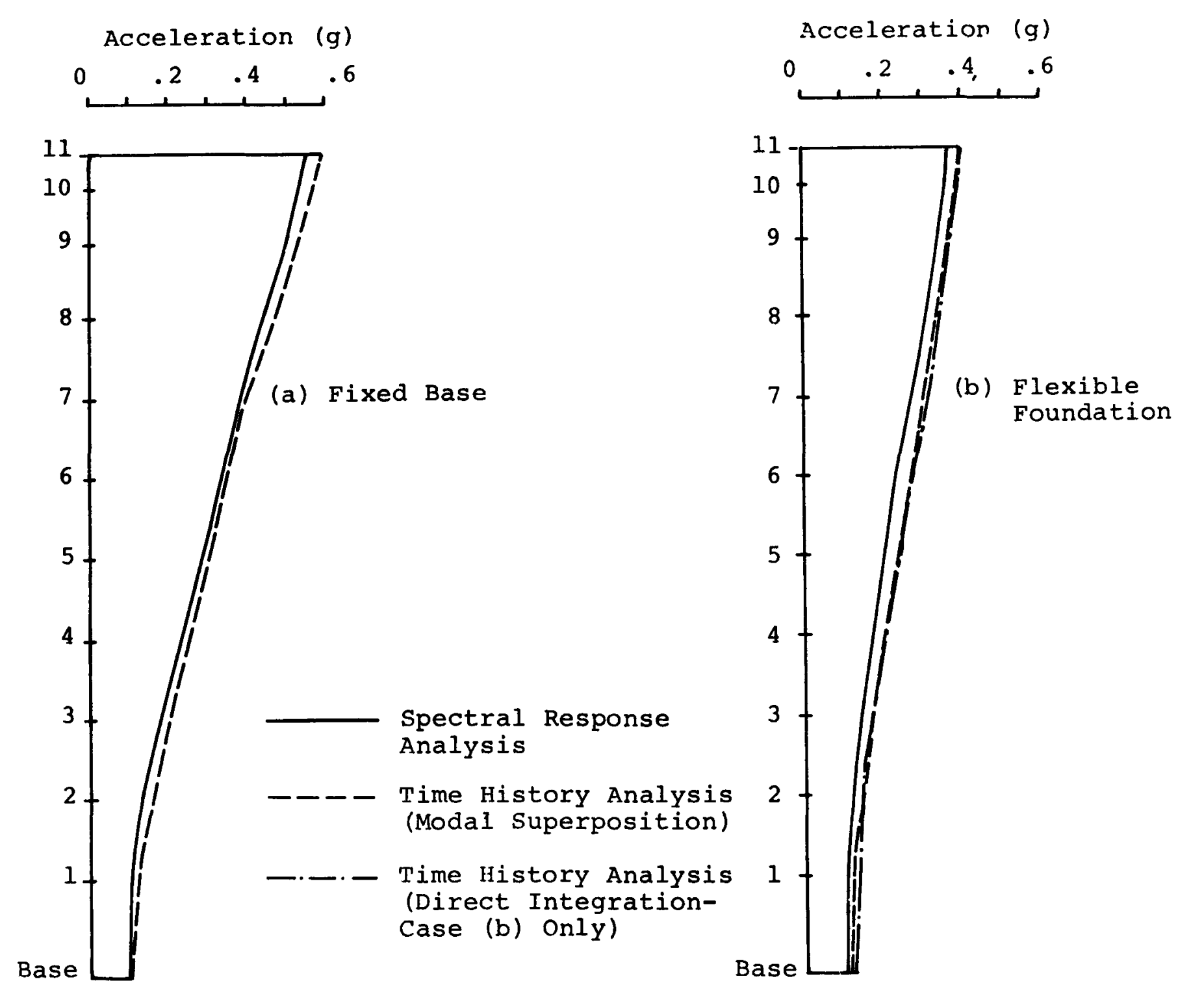

Fig. 4-4 Envelopes of Floor Accelerations of the Containment Structure 


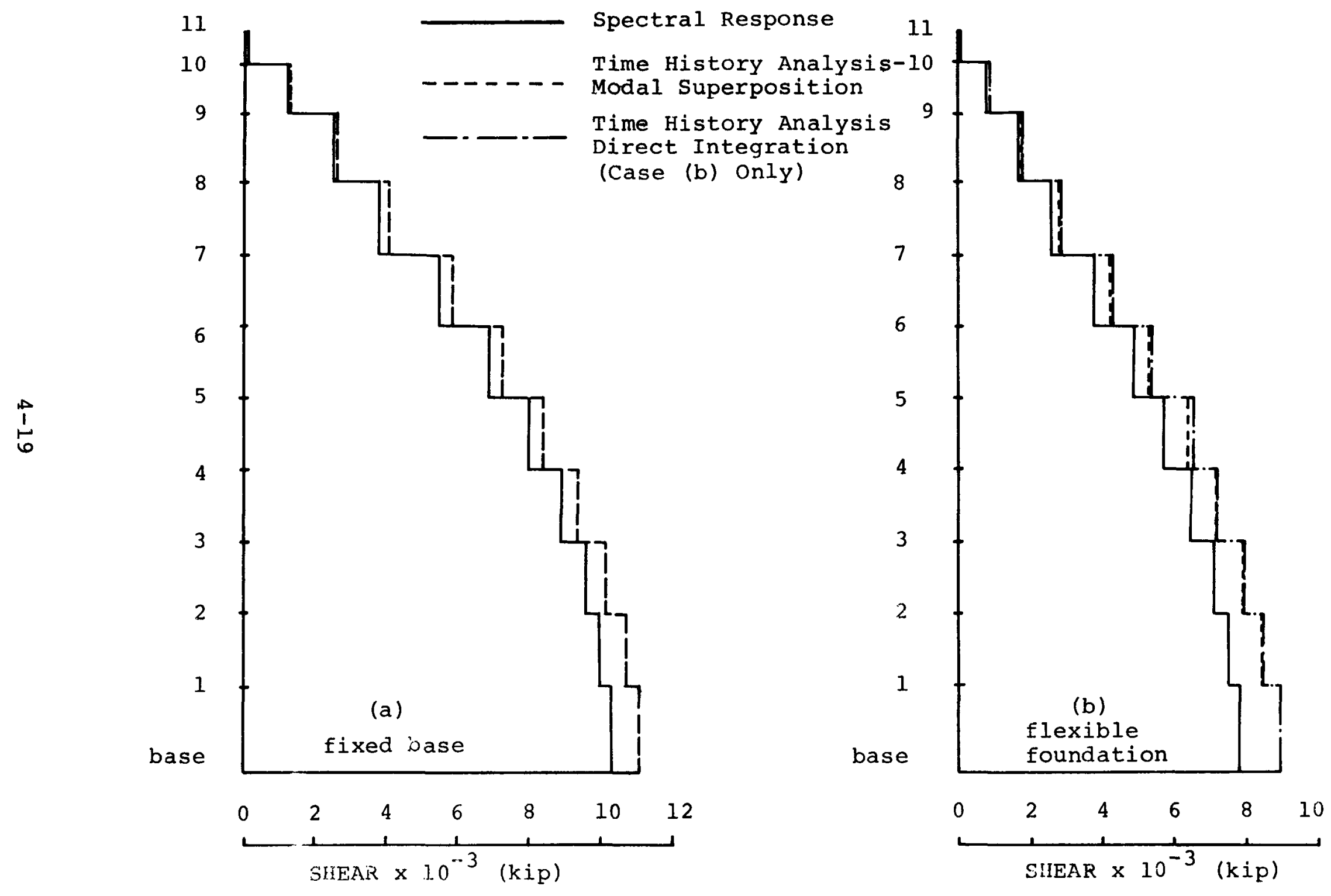

Fig. 4-5 Envelopes of Shear Force of the containment structure 


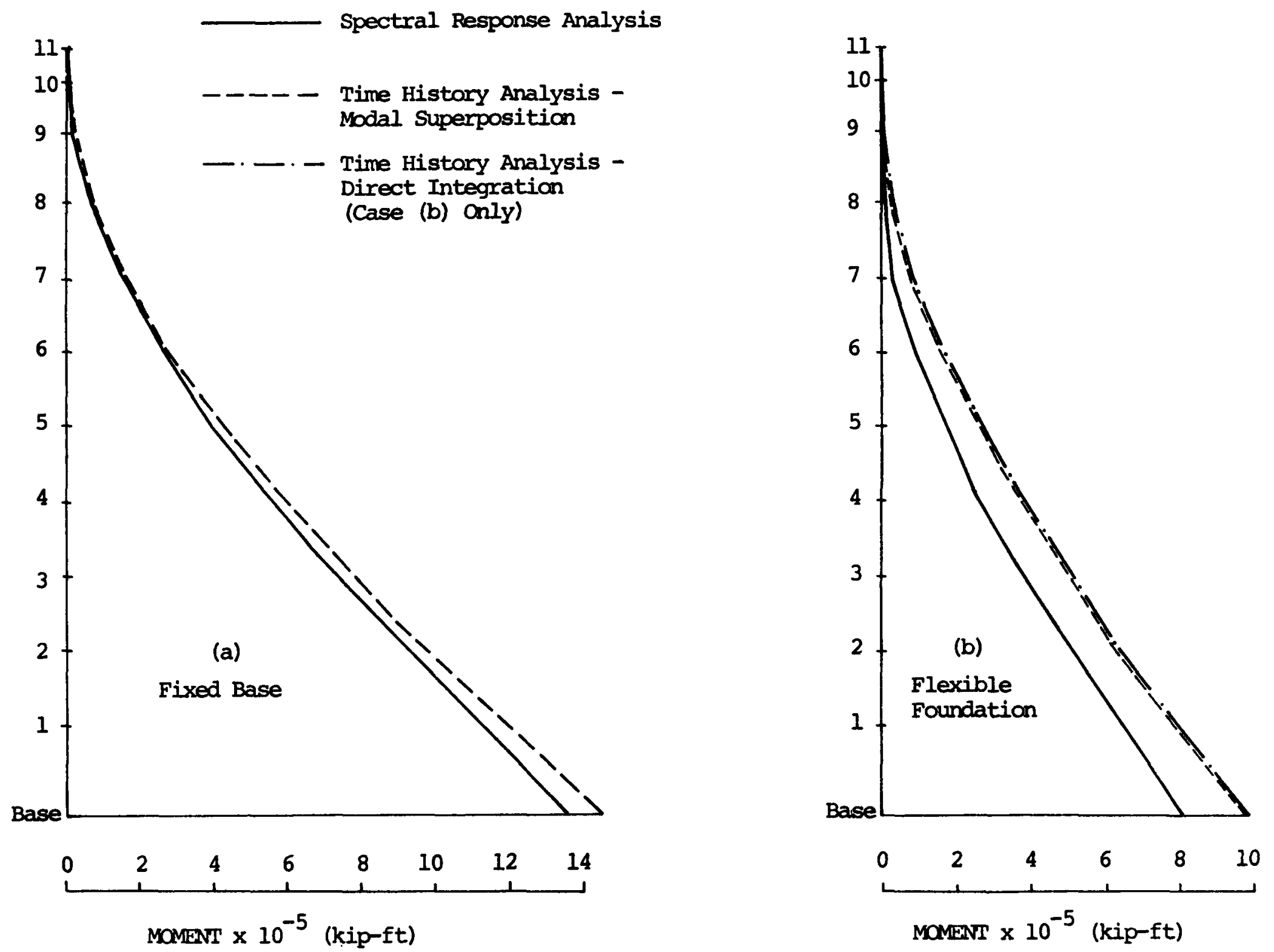

Fig. 4-6 Envelopes of Moment of the Containment Structure 

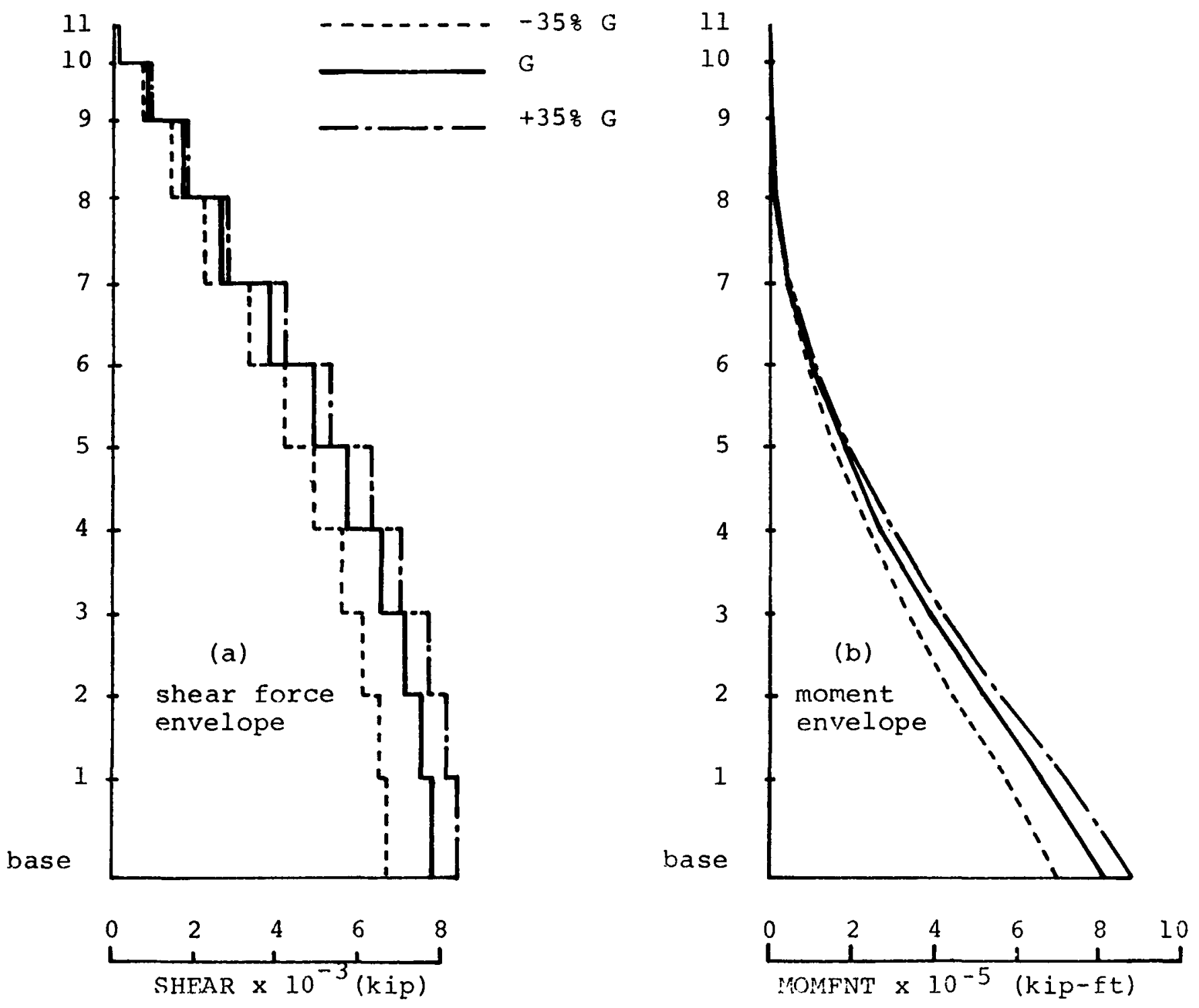

Fig. 4-7 Effect on Shear and Moment Due to a $\pm 35 \%$ Variation in the shear Modulus of soil ( $G=1 . \overline{4} \times 10^{4} \mathrm{ksf}$ ) for the Example. 


\subsection{ANALYSIS OF PLANT COMPONENTS}

\section{1 summary}

The seismic qualification of systems, components and equipment is accomplished by dynamic analysis or testing, or a combination of both. The choice is based on the practicality of the method for the type, size, shape, function and complexity of the component. The basis of choice and the procedure of seismic qualification are discussed in a separate document in the form of a specification. The specification includes the applicable horizontal and vertical floor response spectra resulting from the time history analysis of the structures. These response spectra are to be used for the seismic qualification. Floor response time histories, together with the instructions concerning their use, are furnished only upon request.

If components are to be qualified by dyanmic analysis, Section 5.3 provides the general procedures.

\subsection{Generation of Floor Response Spectrum}

Both the horizontal and vertical floor response spectra are computed from the time history motions at the various floors or other locations of concern. These motions are obtained from the time history analysis of the structures. The floor response spectra are computed at the 49 frequencies as tabulated in Table 5-1, in addition to the structural frequencies. For practical design purposes, and to account for the effect of structural frequency variation both due to the possible variations in the 
material properties of the structure and soil, and due to the uncertainties in the techniques of seismic analysis, the initially computed floor response spectra are smoothed, and peaks obviously associated with the structural frequencies are widened. The amount of peak widening, e.g., $\pm \Delta f_{j}$ associated with the structural frequency $\mathbf{f}_{j}$, is determined according to the method described below.

Let $f_{j}$ be the structural frequency, which is determined by using the most probable material and section properties in formulating structure model. The variation in the structural frequency is determined by evaluating the individual frequency due to the most probable variation in each parameter that is of significant effect, such as soil modulus, material density, etc. The total frequency variation, $\pm \Delta f_{j}$, is then determined by taking the square root of the sum of squares of a minimum variation of $0.05 f_{j}$ and the individual frequency variation $\left(\Delta f_{j}\right)_{n}$ ' that is:

$$
\Delta f_{j}=\sqrt{\left(0.05 f_{j}\right)^{2}+\Sigma\left(\Delta f_{j}\right)_{n}{ }^{2}}
$$

A value of $0.10 f_{j}$ is used if the actually computed value of $\Delta f_{j}$ is less than $0.10 f_{j}$.

Figure 5-1 shows a sample of the smoothed floor spectrum curve, which was derived from the actual spectrum computed from the time history at mass point 11 of the example containment building shown in Figure 3-7. This time history was obtained from the time history analysis described in section 4.5. The amount of spectral peak widening, $\Delta f_{j}$, was assumed to be \pm 15 percent for this example. 
When a two- or three-dimension structure analysis is performed, the structural motion at a given location and given direction would have contributions from both the vertical and the two horizontal analyses. In this case, at the given location and given direction, the structural acceleration motions from the individual analyses are first algebraically combined; the response spectrum of the combined motion is then computed.

\subsection{Dynamic Analysis}

To qualify components by analysis, the procedure is similar to that for the structures presented in sections 3.0 and 4.0. A mathematical modal is first formulated in the same manner as that used in structural analysis. The applicable damping values are given in Table 3-1. A higher damping value may be used if sufficient evidence justifies so.

It sometimes happens that the two principal axes of an equipment or system, say $x-x$ and $y-y$, are oriented at an angle $\theta$ from the two principal structural axes, say $\mathrm{N}-\mathrm{S}$ and $\mathrm{E}-\mathrm{W}$, in which the seismic analysis of the structure is done. See Figure 5-2. In this case, the floor

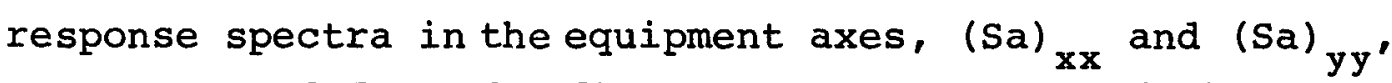
are generated from the floor response spectra (Sa) $N S$ and (Sa) ${ }_{E W}$ initially computed for the N-S and E-W structural axes, as follows:

$$
\begin{aligned}
& (\mathrm{Sa})_{\mathrm{xx}}=\sqrt{\left[(\mathrm{Sa})_{\mathrm{NS}} \sin \theta\right]^{2}+\left[(\mathrm{Sa})_{\mathrm{EW}} \cos \theta\right]^{2}} \\
& (\mathrm{Sa})_{\mathrm{yy}}=\sqrt{\left[(\mathrm{Sa})_{\mathrm{NS}} \cos \theta\right]^{2}+\left[(\mathrm{Sa})_{\mathrm{EW}} \sin \theta\right]^{2}}
\end{aligned}
$$

When items are supported at two or more elevations, the response spectra of these elevations are superimposed on each other and the resulting spectrum is the upper bound envelop of all the individual spectrum curves considered. These spectra are used to calculate the 
inertial response of multiple supported items. An additional analysis is also performed to evaluate the response of these items to boundary displacements by conventional static flexibility analysis procedures. The maximum relative support displacements can be predicted by referring to the structural response calculations or, as a conservative approximation, by using the floor response spectra. For the latter option, the maximum displacement of each support is predicted by $S d=S a g / \omega_{1}^{2}$, where $S a$ is the spectral acceleration in g's at the high frequency end of the spectrum curve, $g$ is gravity constant and $\omega_{1}$ is the fundamental structural frequency in radians per second. The support displacements are imposed on the supported item in the most critical fashion. Finally, the inertial and displacement responses are added absolutely.

\subsubsection{Spectral Response Analysis}

The spectral analysis uses the response spectrum technique presented in section 4.0. The analysis requires the floor response spectrum as the seismic input. In the particular case where there is more than one equipment frequency located within the frequency range of a widened spectrum peak that is obviously associated with a structural frequency, the floor spectrum curve is to be applied in accordance with the criterion described below. This is based on the fact that, in reality, the actual structural resonant frequency can possibly assume only one single value at one time, anywhere within the frequency range defined by $f_{j} \pm \Delta f_{j}$, but not a range of values. Consequently, only one, and not all, of these equipment modes can be in resonant response at one time, with a magnitude indicated by the peak spectral value $(5-1)$. 
The criterion is illustrated by the following example. Let there be three equipment frequencies, $\left(f_{e}\right)_{1},\left(f_{e}\right)_{2}^{\prime}$ and $\left(f_{e}\right)_{3}$, that are within the frequency range of a spectral peak on the floor spectrum curve shown in Figure 5-3(a). Following the reasoning previously given, this spectrum curve is not to be directly used to obtain the modal accelerations, e.g., $A_{1}, A_{2}$, and $A_{3}$, but to be used according to one of the three possible ways indicated by Figures 5-3(b) to (d). The one that produces the largest total response will be used for design.

\subsubsection{Time History Analysis}

The floor time history motion is obtained from analysis of the structure. Let this time history be digitized for a time interval, $\Delta t$. To account for the effect of possible frequency variation of the structure, the same time history data are to be used with at least three different time intervals: $\Delta t$ and $\left(1 \pm \Delta f_{1} / f_{1}\right) \Delta t$, for the analysis of equipment, where $f_{1}$ is the fundamental structural frequency. This variation of the time interval has a similar effect to widening the spectral peak when generating the smoothed floor response spectrum (5-1). If one of the equipment frequencies, $\mathrm{f}_{\mathrm{e}}$, is known to be within the range $f_{j} \pm \Delta f_{j}$, the time history is also to be used with a time interval of $\left[1-\left(f_{e}-f_{j}\right) /\right.$ $\left.f_{j}\right] \Delta t$. 
BC-TOP-4-A

Rev. 3

\section{SECTION 5.0 REFERENCE}

(5-1) Hadjian, A. H., "Earthquake Forces on Equipment in Nuclear Power Plants," Journal of Power Division, ASCE Proceeding Paper No. 8240, July 1971. 
TABLE 5-1

\section{THE 49 FREQUENCIES FOR}

FLOOR RESPONSE SPECTRA CALCULATION (CPS)

$0.2,0.3,0.4,0.5,0.6,0.7,0.8,0.9,1.0$

$1.1,1.2,1.3,1.4,1.5,1.6,1.8,2.0,2.2$

$2.4,2.6,2.8,3.0,3.3,3.6,4.0,4.4,4.7$

$5.0,5.5,6.0,6.5,7.0,7.5,8.0,8.5,9.0$

$10,11,12,13,14,15,16.5,18,20$,

$22,25,28,33$.

Notes :

1. Frequency increments are generally within 108 for the range of frequencies from 1.0 to 22 cps.

2. Spectral values will be also calculated at the structure frequencies. 
BC-TOP-4-A

Rev. 3

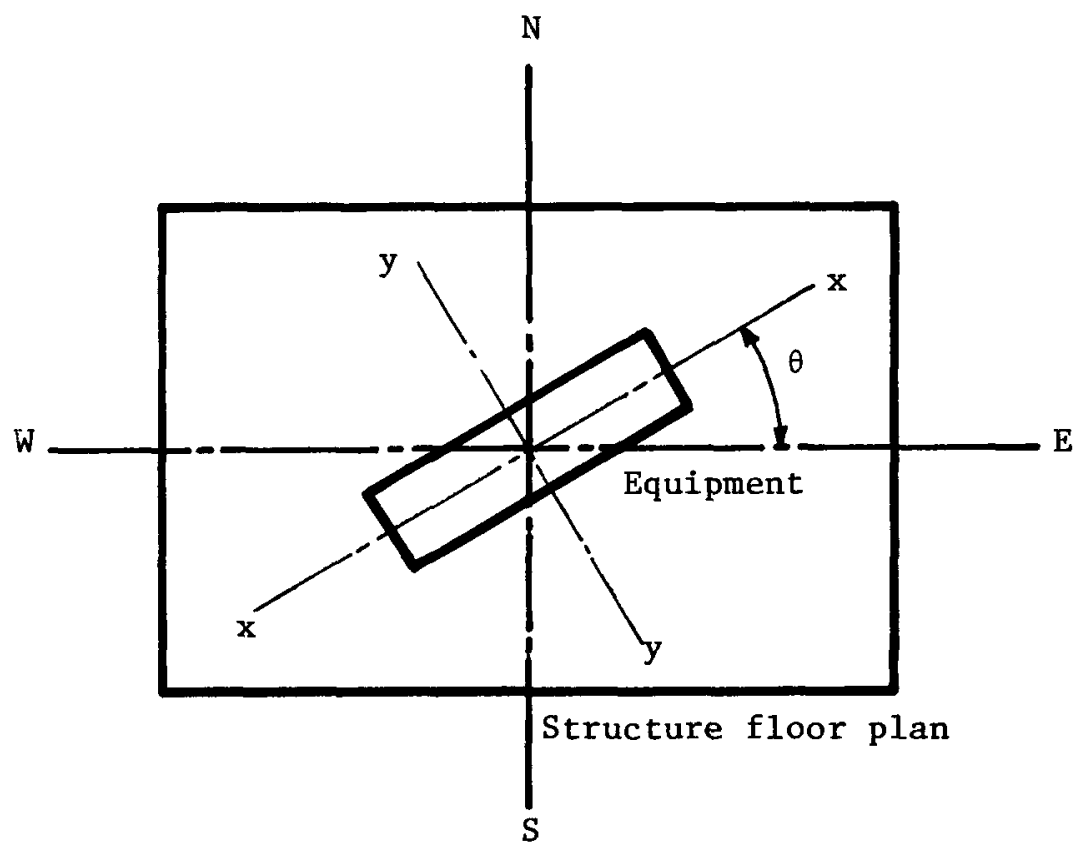

Figure 5-2 Equipment Principal Axes ( $x-x$ and $y-y)$ Oriented at an Angle $\theta$ from the Building Axes 
$\mathrm{BC}-\mathrm{TOP}-4-\mathrm{A}$

Rev. 3
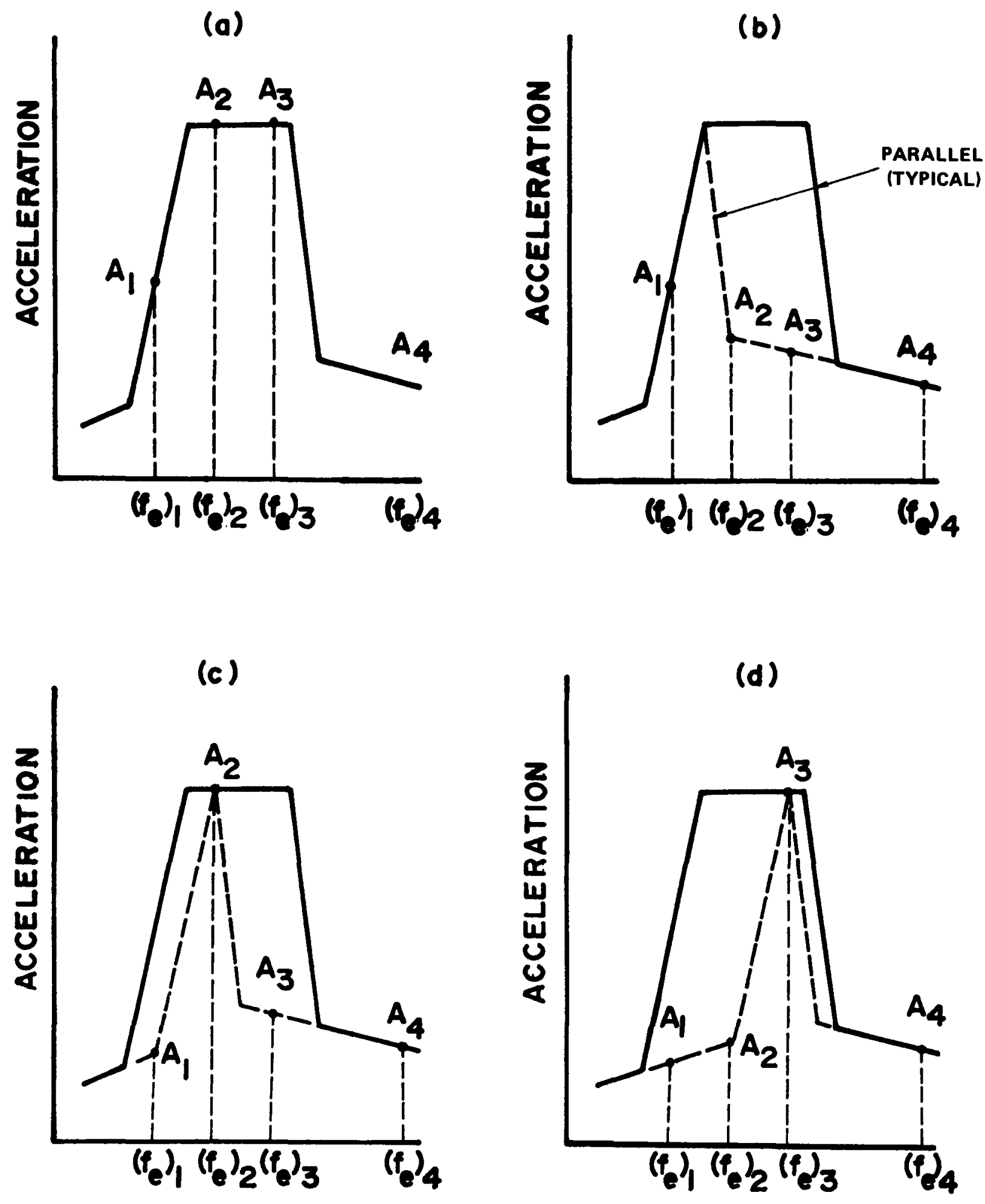

Fig. 5-3 Diagrams Illustrating the Use of Floor Spectrum Curve When More Than One Equipment Frequency is Within the Widened Spectral Peak 


\subsection{ANALYSIS OF LONG, BURIED STRUCTURES}

\subsection{SUMMARY}

This section outlines the methods generally used for seismic analysis of such buried tubular structures as conduits, tunnels, subways, and well casings. The effects of earthquakes on buried structures may be broadly grouped into two classes, namely faulting and shaking. Faulting includes the direct, primary shearing displacement of bedrock which may carry through the overburden to the ground surface. Such direct shearing of the rock or soil is generally limited to relatively narrow zones of seismically active faults which may be identified by geological and seismological surveys. From a structural viewpoint, landsliding, ground fissuring, and consolidation of backfill soil have similar effects on buried structures. In general it is not feasible to design structures to restrain such major soil displacements. However, design measures are taken to identify and avoid areas prone to such displacements.

In this section, it is assumed that the soil does not lose its integrity during an earthquake, and effects are therefore limited to the general case of shaking. Under ground shaking, a buried structure responds to various seismic waves propagating through the surrounding soil as well as to the dynamic differential movements of the buildings to which the tubular structure is connected. A rigorous analysis of the problem should consider the time-dependent stresses in the structure due to all the causes simultaneously, as well as differences in wave propagating velocities between the soil and the structure. Such an analysis 
is beyond the state of the art at present. For design purposes, the various effects are considered separately and then combined properly. The resulting stresses are further combined with other applicable design stresses.

\subsection{STRESSES DUE TO FREE FIELD SEISMIC WAVE PROPAGATION}

The portions of a long, buried structure far from the ends and free of any external support other than the surrounding soil, are assumed to move with the ground under the propagation seismic compressional waves ( $P$ waves) and shear waves (S waves) (Refs. 6-1 and 6-2). This is particularly true if the structure is sufficiently flexible relative to the surrounding soil (Ref. 6-3, p. 318). Under this assumption, the stresses in the structure are computed as the product of the soil strains and the modulus of elasticity of the structural material E. These stresses are discussed separately below. In general, the maximum stresses due to the compressional wave and the shear wave do not occur simultaneously.

\subsubsection{Axial Stress Due to Compressional Wave}

For a compressional wave propagating with wave velocity $c_{p}$ along the longitudinal axis (x-axis) of the buried structure, the particle displacement of the soil can be represented by:

$$
x=x(x, t)=x\left(x-c_{p} t\right)
$$

The axial strain of the soil is

$$
\epsilon_{\text {ap }}=\partial x / \partial x
$$


which is related to the particle velocity of the soil, $\dot{\mathrm{X}}$, as follows:

$$
\epsilon_{\mathrm{ap}}=\dot{\mathrm{x}} / \mathrm{c}_{\mathrm{p}}
$$

The maximum possible axial stress in the structure is predicted as

$$
\sigma_{\text {ap }}= \pm E v_{p} / C_{p}
$$

where $v_{p}=|\dot{x}|_{\max }$ is the maximum ground velocity due to the compressional wave.

Because the maximum ground velocity, $v_{S}$, obtained from integrating an earthquake record is mainly associated with the propagation of shear waves, $v_{p}$ may be taken to be a fraction of $\mathrm{v}_{\mathrm{s}}$.

\subsubsection{Axial Stress Due to Shear Wave}

A shear wave of wave length $L$, propagating at an angle $\psi$ from the $x$-axis, subjects different parts of the structure to out-of-phase displacements. This lesults in an apparent compressional wave propagating along the $x$-axis. The apparent wave velucity is $(6-2)$ :

$$
c_{p}^{\prime}=c_{s} / \cos \psi
$$

where $c_{s}$ is the shear wave velocity in the soil. The maximum possible axial stress in the structure due to the obliquely propagating shear wave can then be obtained from Eq. $(6-4)$ upon replacing $v_{p}$ by $v_{s} \sin \psi$ and $c_{p}$ by $c_{p^{\prime}}^{\prime}$ namely, 


$$
\sigma_{a \psi}= \pm\left(E v_{s} / c_{s}\right) \sin \psi \cos \psi
$$

where $v_{s}$ is the maximum integrated ground velocity obtained from the earthquake record.

When $\psi=45^{\circ}$, the above stress has the following maximum value:

$$
\sigma_{\text {as }}= \pm E v_{s} / 2 c_{s}
$$

\subsubsection{Bending Stress Due to Shear Wave}

The obliquely propagating shear wave described in 6.2.2 also induces an apparent shear wave of wave length $\mathrm{L} / \cos \psi$ in the $y$-direction, which is perpendicular to the $x$-axis $(6-2)$. The transverse displacement of the soil particle can be written as :

$$
Y=Y(x, t)=Y\left(x-c_{S} t / \cos \psi\right)
$$

This gives rise to the curvature of the structure as follows:

$$
\kappa=\partial^{2} Y / \partial x^{2}
$$

which can be related to the ground acceleration $\ddot{Y}$ by:

$$
\kappa=\left(\ddot{Y} / c_{s}^{2}\right) \cos ^{2} \psi
$$

Hence the maximum bending stress in the structure due to the oblique shear wave is 


$$
\sigma_{b \psi}= \pm\left(E R a_{s} / c_{s}^{2}\right) \cos ^{3} \psi
$$

where $R$ is the distance from the cross-sectional neutral axis of the structure to the extreme fiber, and

$$
a_{s}=|\ddot{Y}| \max ^{/ \cos \psi}
$$

where $|\ddot{Y}|_{\max }$ is the maximum ground acceleration from an earthquake record. When $\psi=00$ this stress has a maximum value as follows:

$$
\sigma_{\mathrm{bs}}= \pm \mathrm{ERa_{ \textrm {s } }} / \mathrm{c}_{\mathrm{s}}^{2}
$$

\subsubsection{Maximum Combined Axial Stress Due to a Single Shear Wave}

The axial stress and bending stress as predicted by Eqs. $(6-6)$ and $(6-11)$ are directly combined to predict the maximum combined axial stress due to the propagation of a shear wave with incident angle $\psi$. This combined stress is maximized for an incident angle between $0^{\circ}$ and $45^{\circ}$. This value will always be smaller than the sum of the two maximum stress values given by Eqs. $(6-7)$ and $(6-13)$, because the latter are obtained from two different incident angles and hence they do not occur simultaneously. A special case of this approach has been presented in Ref. (6-2) for subway applications under seismic ground shaking. The results in Ref. (6-2) have also been extended to buried pipes in Ref. $(6-4)$. 
6.3 STRESSES DUE TO SOIL-BUILDING DIFFERENTIAL MOVEMENTS

Near the entry points into any building, additional stresses in the buried structure are induced by differential movements between the building and the soil. The differential movements, $\Delta x$ and $\Delta y$, (which are respectively parallel and perpendicular to the $x$-axis) are predicted by the seismic analysis of each building with soil-building interaction taken into account. These movements induce additional stresses in the buried structure, which are again dynamic in nature. But the state of the art only allows a static analysis of the stresses by considering the maximum values of $\Delta x$ and $\Delta y$.

For buried structures connecting two buildings, the differential movements at entry points of the two buildings are assumed completely out of phase in order to obtain a conservative evaluation.

\subsubsection{Axial Stress Due to a Differential Movement $\Delta x$}

In order to compute the axial stress, the buried structure is assumed to be held by the friction force per unit length, $F$, between the soil and the structure

$$
F=C \gamma H f
$$

where

$$
\begin{aligned}
C= & \text { the circumference of the structural cross } \\
& \text { section }
\end{aligned}
$$


BC-TOP $-4-A$

Rev. 3

$$
\begin{aligned}
Y= & \text { weight of soil per unit volume } \\
H= & \text { depth of the structure } \\
\mathrm{E}= & \text { coefficient of friction between soil and } \\
& \text { surface of the structure }
\end{aligned}
$$

If $P$ is the axial force at the entry point necessary to cause a total end displacement $\Delta x$, then

$$
\Delta x=\int_{0}^{P / F} \frac{P-F x}{E A} d x=\frac{P^{2}}{2 E A \bar{F}}
$$

where $A$ is a cross-sectional area of the structure. Hence the maximum axial stress due to the differential movement $\Delta \mathrm{x}$ is equal to

$$
\sigma_{\mathrm{ad}}=\frac{\mathrm{P}}{\mathrm{A}}=(2 \mathrm{EF} \Delta \mathrm{x} / \mathrm{A})^{1 / 2}
$$

at the point of entry into the building.

\subsubsection{Bending and Shearing Stresses Due to a Differential Movement $\Delta y$}

For these stresses, the buried structure is assumed to be a semi-infinite beam supported on an elastic foundation, with a fixed or hinged end at the entry point to a building.

(a) Fixed End - According to the theory of beams on elastic foundations (see Ref. (6-5), p. 24) a displacement $\Delta_{y}$ (perpendicular to the structure axis) at the fixed end induces the following moment distribution 


$$
M(x)=\frac{k}{2 \lambda^{2}} \Delta y e^{-\lambda x}(\sin \lambda x-\cos \lambda x)
$$

and shear distribution

$$
Q(x)=\frac{k}{\lambda} \Delta y e^{-\lambda x} \cos \lambda x
$$

along the structure. In these equations,

$$
\begin{aligned}
\lambda= & \left(\frac{\mathrm{k}}{4 \mathrm{EI}}\right)^{1 / 4} \\
I= & \text { moment of inertia of the structural cross- } \\
& \text { section about its neutral axis } \\
\mathrm{k}= & \text { spring constant of soil perpendicular to } \\
& \text { the structure axis (lb/ft } \left.{ }^{2}\right)
\end{aligned}
$$

According to Ref. $(6-5)$

$$
\mathrm{k}=\mathrm{Bk}_{\mathbf{s}}
$$

where

$$
\begin{aligned}
B= & \text { width of the buried structure (feet) } \\
k_{s}= & \text { coefficient of subgrade reaction of soil } \\
& \text { for a beam along the } x \text {-axis and of a width } \\
& B \text { feet }\left(1 \mathrm{~b} / \mathrm{ft} \mathrm{t}^{3}\right)
\end{aligned}
$$

In the absence of field data for $\mathrm{k}_{\mathbf{s}}$, the recommended formulas and values of $\mathrm{k}_{\mathbf{s}}$ in vertical and horizontal directions can be found in Ref. $(6-6)$. 
The maximum values of $M(x)$ and $Q(x)$ in Eqs. (6-17) and (6-18) occur at $x=0$, i.e., the point of building penetration. Hence the maximum bending stress is

$$
\sigma_{b d}= \pm \frac{M(O) R}{I}= \pm \frac{k R}{2 \lambda^{2} I} \Delta Y
$$

and the maximum shearing stress is

$$
\tau_{\text {sd }}=\frac{\alpha Q(O)}{A}=\frac{\alpha k}{\lambda A} \Delta y
$$

where $\alpha$ is the shape factor for the structural crosssection and is equal to 2 for a thin circular tube.

(b) Hinged End - According to Ref. (6-5) a displacement $\Delta y$ at the hinged end induces a moment distribution,

$$
M(x)=\frac{k}{2 \lambda^{2}} \Delta y e^{-\lambda x} \sin \lambda x
$$

and a shear distribution,

$$
Q(x)=\frac{k}{2 \lambda} \Delta y e^{-\lambda x}(\cos \lambda x-\sin \lambda x)
$$

along the structure.

The maximum values of $M(x)$ and $Q(x)$ occur at $x=\pi / 4 \lambda$ and $x=0$ respectively. Hence the maximum bending stress due to $\Delta y$ is

$$
\sigma_{\mathrm{bd}}= \pm \frac{M(\pi / 4 \lambda) R}{\mathrm{I}}= \pm 0.1612 \frac{\mathrm{kR}}{\lambda^{2} \mathrm{I}} \Delta \mathrm{y}
$$


and the maximum shearing stress due to $\Delta y$ is

$$
T_{s d}=\frac{\alpha Q(0)}{A}=\frac{\alpha k}{2 \lambda A} \Delta y
$$

\subsubsection{Bent Buried Structures}

Consider a buried structure having a bent as shown in Figure 6-1(a). The displacement $\Delta_{A}$ and the a associated force $P_{A}$ at Point $A$, as induced by an end displacement $\Delta x$, is given by:

$$
\begin{aligned}
& \Delta_{A}=\Delta x-\frac{1}{E A}\left(P d-F d^{2} / 2\right) \\
& P_{A}=P-F d
\end{aligned}
$$

in which $d$ is the length of the member between Point $A$ and the building. The other end of the buried structure is assumed infinitely long, and the lower end, Point $B$, of the bent is assumed a fixed end. Making use of the theory of a finitelength beam supported on elastic foundation, the displacement $\Delta_{A}$ and the bending moment at Point $B, M_{B}$ due to the force $\mathrm{P}_{A}$ (see Fig. 6-1(b)) are given by:

$$
\Delta_{A}=C_{1} P_{A} \lambda / k
$$

and

$$
M_{B}=-C_{2} P_{A} / \lambda
$$

where $k$ and $\lambda$ are defined in Eq. (6-19) and 


$$
\begin{aligned}
& c_{1}=\frac{\sinh (2 \lambda h)-\sin (2 \lambda h)}{\cosh ^{2}(\lambda h)+\cos ^{2}(\lambda h)} \\
& c_{2}=\frac{\sinh (\lambda h) \cos (\lambda h)+\cosh (\lambda h) \sin (\lambda h)}{\cosh ^{2}(\lambda h)+\cos ^{2}(\lambda h)}
\end{aligned}
$$

In Eq. (6-20), $h$ is the length of the bent as defined in Fig. 6-1(a).

Using the compatibility relationship at Point $A$, the end force $\mathrm{P}$ induced by the building movement $\Delta \mathrm{x}$ is given below:

$$
P=\frac{2 A E\left(k \Delta x+F d \lambda C_{1}\right)+k F d^{2}}{2\left(C_{1} \lambda A E+k d\right)}
$$

The maximum axial stress takes place at where the buried structure enters the building, and is equal to:

$$
\left(\sigma_{\text {ad }}\right)_{\max }=\mathrm{P} / \mathrm{A}
$$

The maximum bending stress takes place at the bent portion and is equal to:

$$
\left(\sigma_{b d}\right)_{\max }= \pm \frac{R\left(2 A E k \Delta x-k F d^{2}\right)}{2 \lambda\left(C_{1} \lambda A E+k d\right) I} C_{2}
$$


(6-1) Sakurai, A. and Takahashi, T., "Dynamic Stresses of Underground Pipeline During Earthquakes", Proceedings of the Fourth World Conference on Earthquake Engineering, Santiago, Chile, Vol. II, 1969.

(6-2) Kuesel, R. T., "Earthquake Design Criteria for Subways", Journal of Structural Division, ASCE Proceeding, Vol. 95, No. ST6, June 1969, pp. 1213-1231.

(6-3) Newmark, N. M. and Rosenblueth, E., Fundamentals of Earthquake Engineering, Prentice-Hall, Inc., N.J., 1971.

(6-4) Hadjian, A. H., Discussion on the Paper "Earthquake Design Criteria for Subways" by R. T. Kuesel, Journal of Structural Division, ASCE, Vol. 96, No. S'Tl, January 1970, pp. 159-160.

(6-5) Hetenyi, M. , Beams on Elastic Foundation, The University of Michigan Press, 1946.

(6-6) Terzaghi, K., "Evaluation of Coefficients of Subgrade Reaction", Geotechnique, Vol. 5, 1955, pp. 297-326. 
BC-TOP $-4-A$

Rev. 3

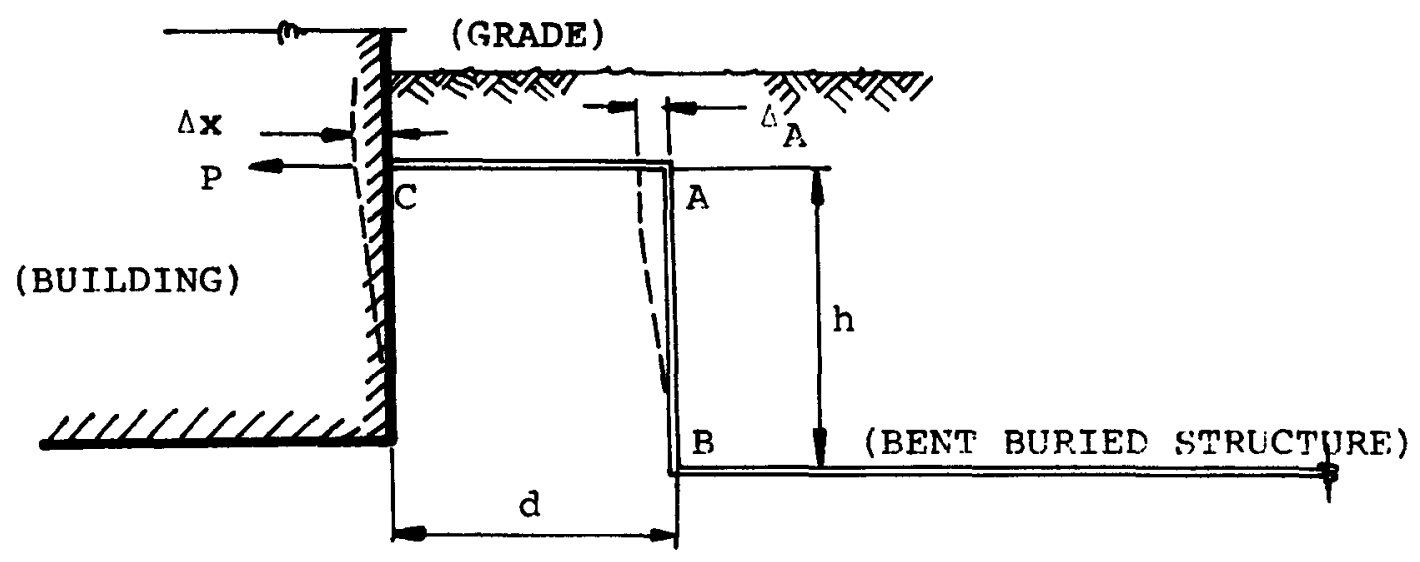

(a) Configuration of the Bent Buried structure
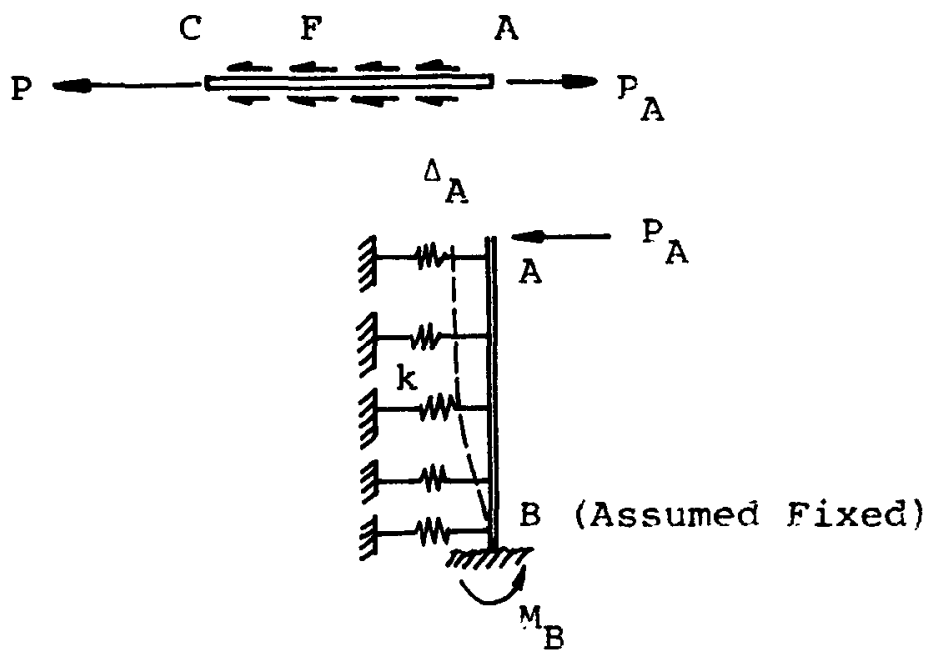

(b) Free Body Diagrams

Fig. 6-1 A Bent Buried structure subjected to an Fnd Displacement $\Delta x$ 


\section{APPENDIX A}

\section{CROSS-REFERENCE LISTING TO AEC FORMAT}

This Appendix cross-references applicable sections of the AEC standard format for SAR's and sections of this topical report.

\section{AEC FORMAT}

$$
\begin{aligned}
2.5 .1 \ldots & (1) \text { to }(10) \\
& (11) \\
2.5 .2 \ldots & (1) \text { to }(11) \\
& (12),(13)
\end{aligned}
$$

$2 \cdot 5 \cdot 3$

2. 5.4

2.5 .5

3. 2.1

$3.7 .1 \ldots(1),(2)$

(3)

(4), (5)

(6)

$3.7 .2 \ldots(1)$

(4), (5)

(6)

(7)

(8)

\section{SEISMIC TOPICAL}

2.2

2.3

2. 4

2.5

2.4

2.3

2.3

1. 0

2.5

2.2 and 3.2

SAR's

3.4 and Appendix D

1.0 to 6.0

SAR's

3.2

3.3

Not Applicable

SAR' $\mathbf{s}$

5.2

BP-TOP-l for Piping,

if applicable

3.2 and Appendix $C$

4.5 or SAR's

SAR' $S$

4.4

3.2 and 3.3 
BC-TOP $-4-A$

Rev. 3

AEC FORMAT

$3.7 .3 \ldots(1)$

(2)

(3)

(4)

(5)

(6)

(7)

(8)

(9)

(10)

(11)

(12)

(13)

(14), (15)

\section{SEISMIC TOPICAL}

BP-TOP-1

SAR's, if applicable

Not Applicable

Not Applicable

Not Applicable

BP-TOP-1

$4.3,5.3$ and BP-TOP-1

BP-TOP-1 for Piping,

if applicable

BP-TOP-1

5.2

BP-TOP-1

6.0, SAR's and BP-TOP -1

BP-TOP-1

SAR'S

Not Applicable

SAR's 
APPENDIX B

MINIMUM NUMBER OF LUMPED MASSES VERSUS

NUMBER OF MODES USED

The following study serves to justify the criterion in subsection 3.2 regarding, for each subsystem, the minimum number of lumped masses versus the number of modes to be considered in the dynamic analysis.

The sample structure considered is a containment which was assumed to be a cantilever beam with uniform properties throughout (Figure B-1). It was modeled by a lumped mass model, the lumped mass being calculated and located in two slightly different ways. Figure B-2 shows these two different lumping methods, referred to as Model (I) and Model (II), respectively.

For each model, the total number of lumped masses, $\mathbf{N}$, was varied. The effect of $\mathrm{N}$ on the accuracy of the computed frequencies, $\omega_{j}$ ' for the $j-t h$ mode was then assessed by comparing $\omega_{j}$ with the theoretical solutions $\left(\omega_{j}\right)_{T}$, for both the horizontal and vertical vibrations. The theoretical solutions were obtained from the equation of motion for a uniform cantilever beam.

Figures B-3 to B-6 show the frequency ratio, $\omega_{j} /\left(\omega_{j}\right){ }_{T}$, plotted against the total number of lumped masses, $N$, for the horizontal vibration of Model (I), vertical vibration of Model (I), horizontal vibration of Model (II), and vertical vibration of Model (II), respectively. It can be seen that the maximum error in frequency, $\omega_{j}$, associated with using the lumped mass models is always within 10 percent so long as $N$ is at least twice the mode number $j$. This is within engineering acceptable accuracy. In application to the analysis of actual structural systems, the accuracy in frequency for the entixe system would be even higher when this same criterion is applied to every subsystem. 


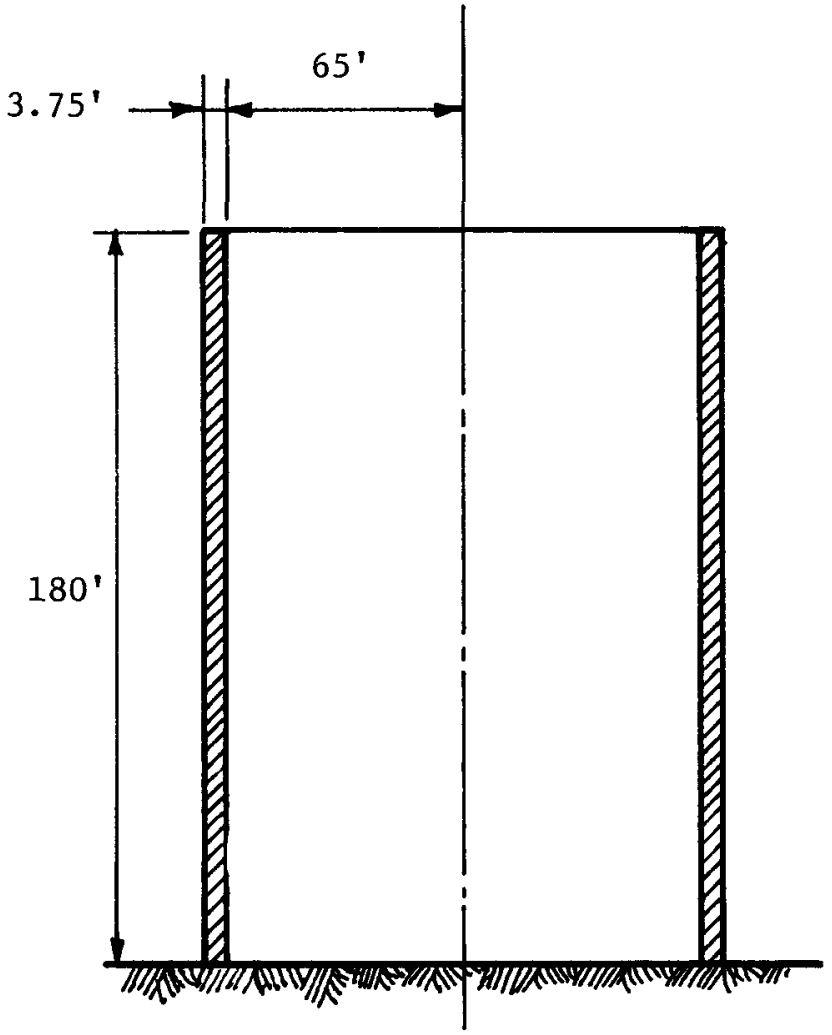

Figure B-1 The Example Cylindrical Containment Structure

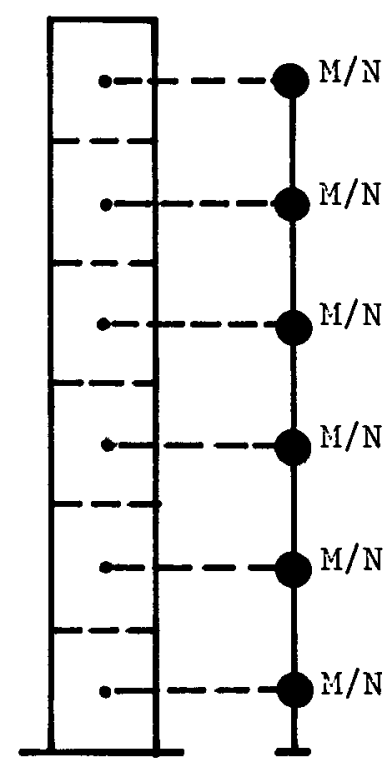

(a) Model I

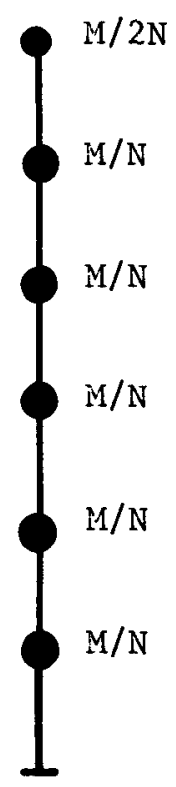

(b) Model II
Figure B-2 The Two Common Methods of Constructing an N-Mass Lumped Mode1: (a) Constant Mass, and (b) Constant Member Length 


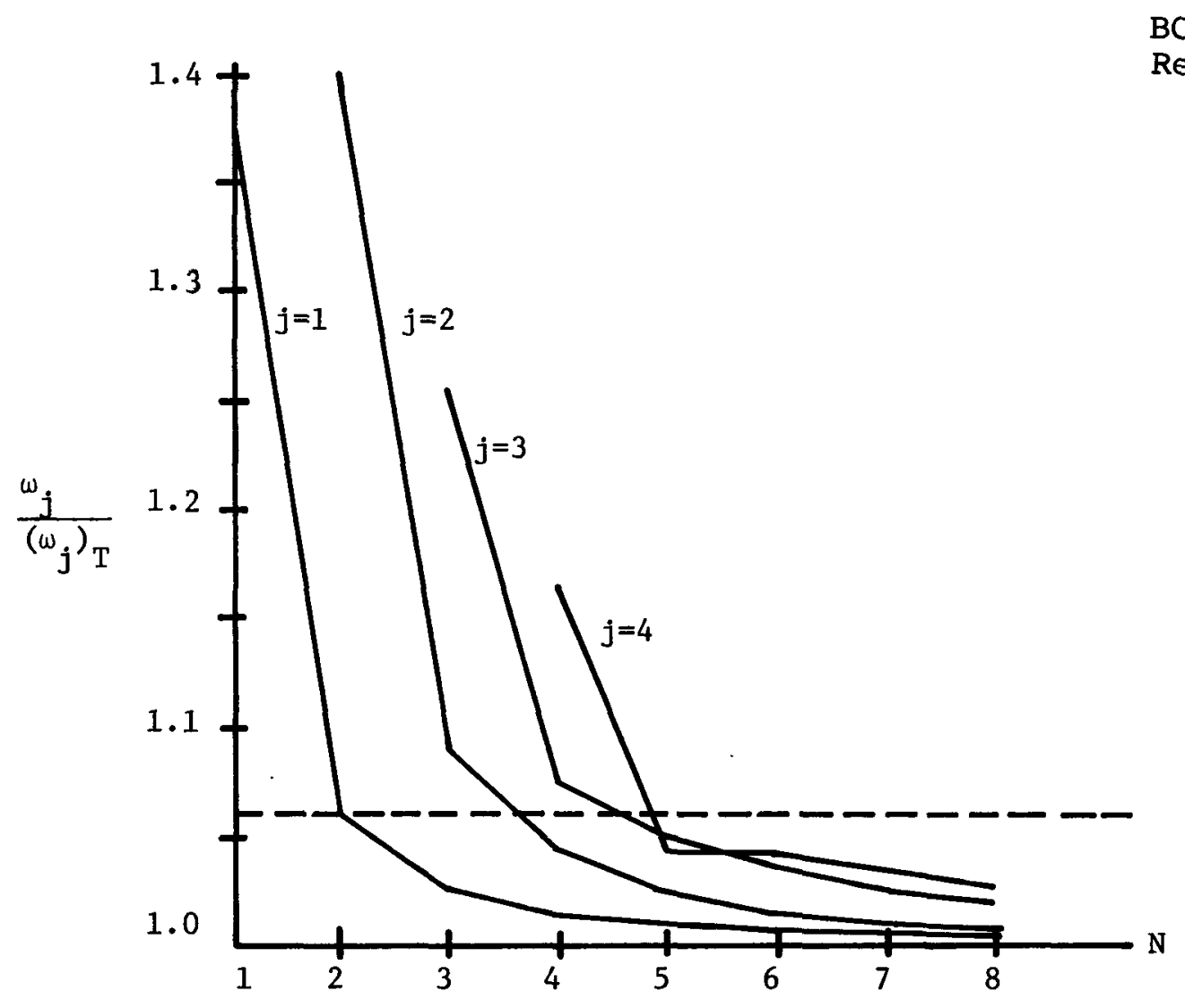

Figure B-3 Frequency Ratio $\omega_{j} /\left(\omega_{j}\right)_{T}$ vs. N for Horizontal Vibration of Iodel (I)

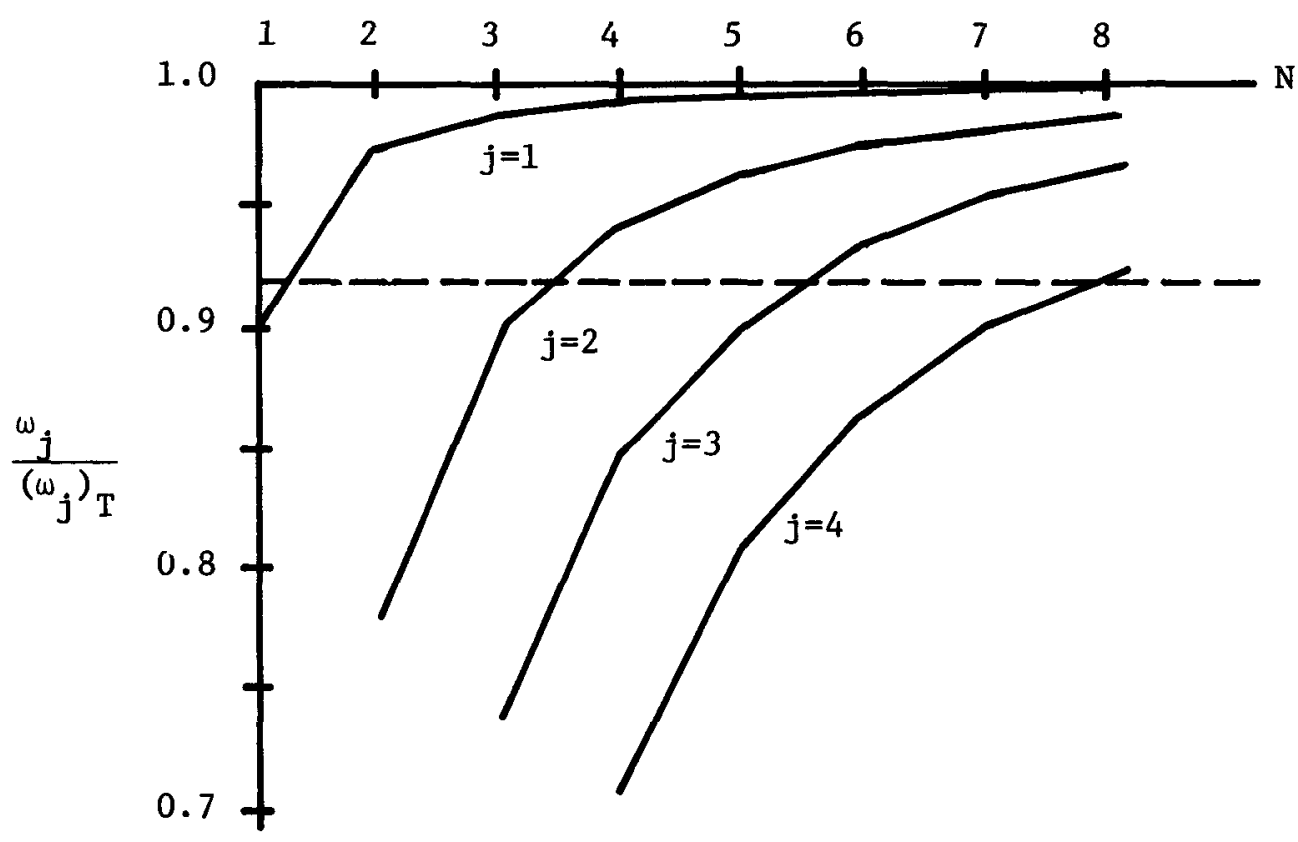

Figure B-4 Frequency Ratio $\omega_{j} /\left(\omega_{j}\right)_{T}$ vs. N for Vertical Vibration of Model (I)

$$
\mathrm{B}-3
$$


BC-TOP $-4-A$

Rev. 3

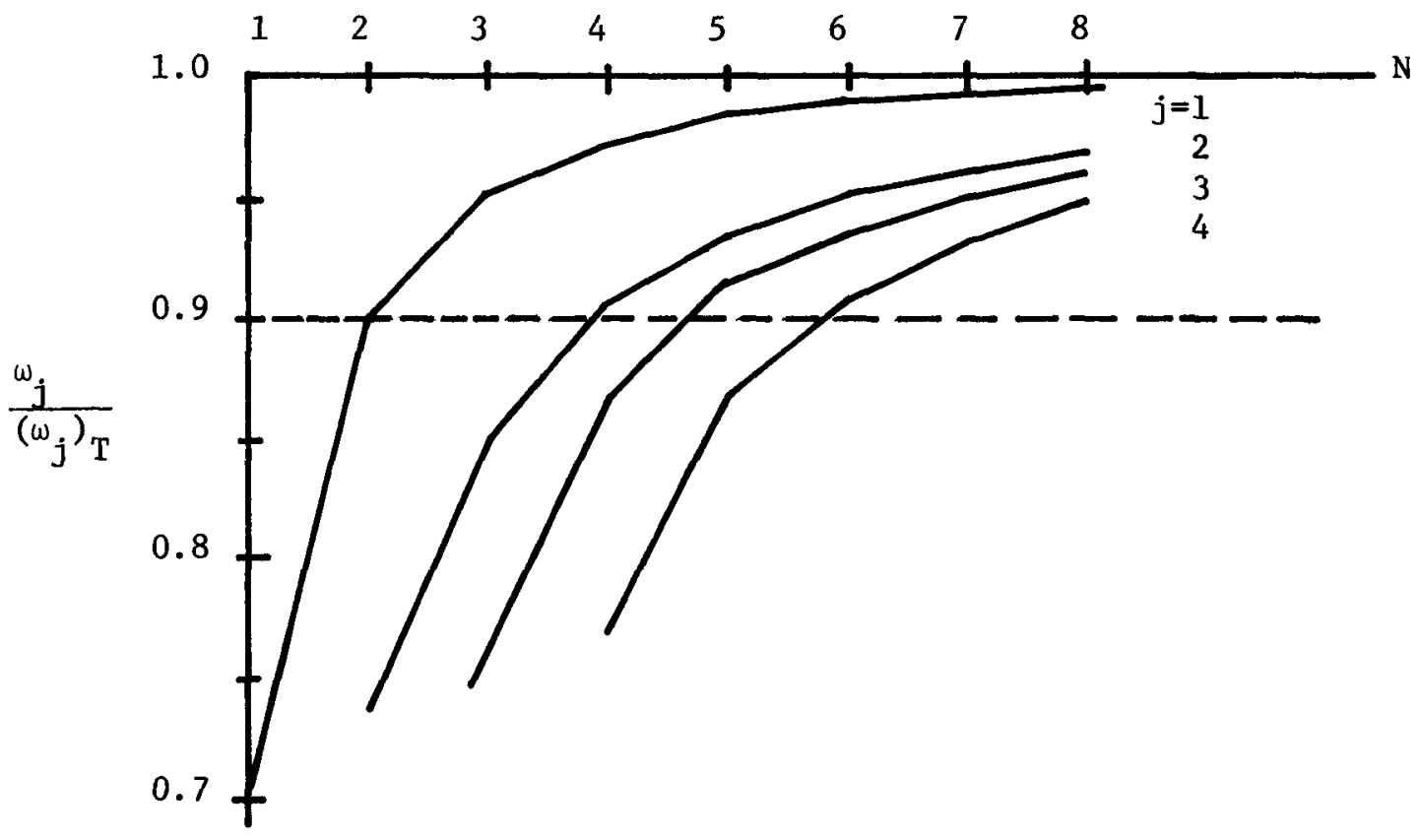

Figure B-5 Frequency Ratio $\omega_{j} /\left(\omega_{j}\right)_{T}$ vs. N for Horizontal Vibration of Model (II)

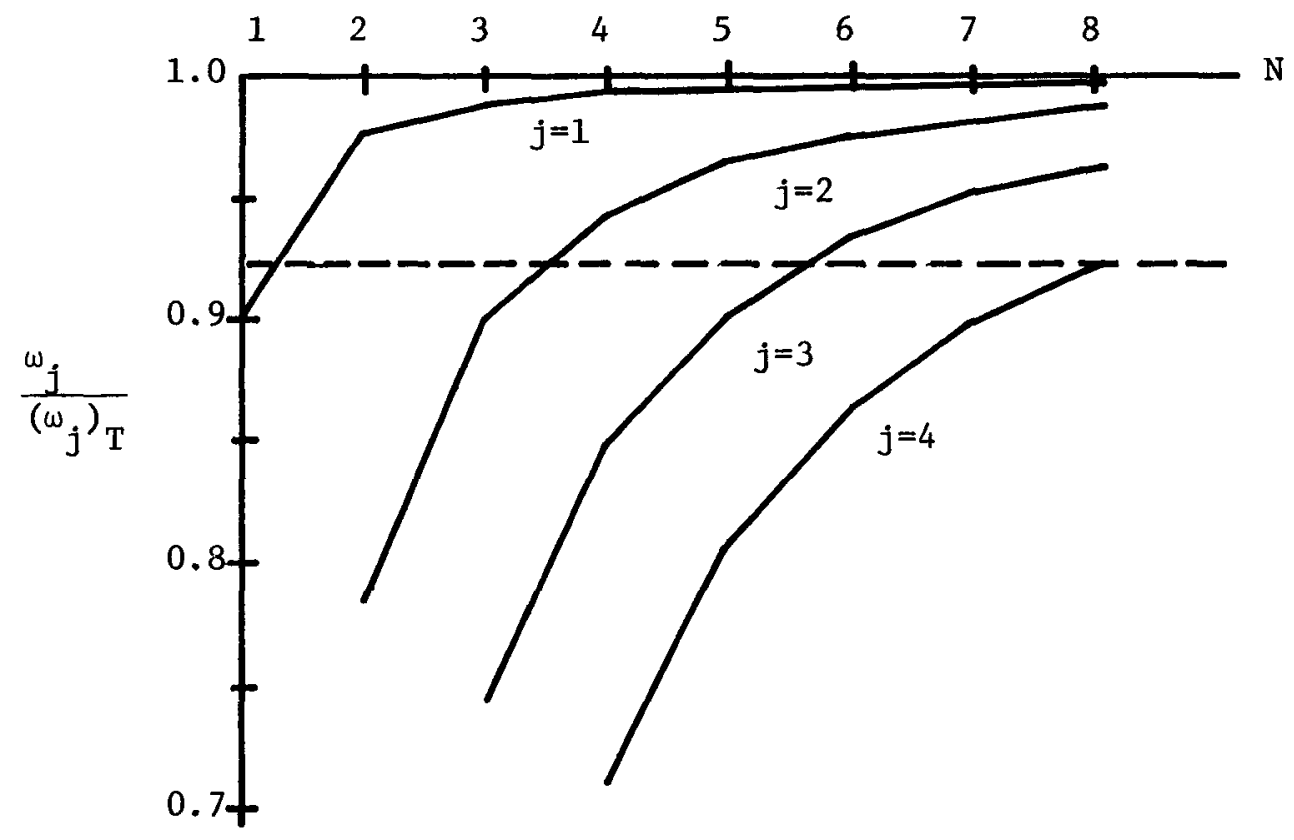

Figure B-6 Frequency Ratio $\omega_{j} /\left(\omega_{j}\right)_{T}$ vs. $N$ for Vertical Vibration of Mode1 (II) 
BC-TOP-4-A

Rev. 3

\section{APPENDIX C}

LATERAL TORSIONAL MOTION DUE TO

\section{LATERAL EXCITAIION}

If a structure is irregularly, shaped or the mass distribution is nonuniform, the center of mass and the center of resistance usually do not coincide. This will lead to coupled translational and torsional motions for a structure excited under i purely translational ground motion. The extent of coupliny depends on the magnitudes of the eccentricities and the rela. tion between the uncoupled translational frequencies and uncoupled torsional frequencies.

For the lateral analysis of structures with translation-torsion coupling taken into account, there are, in general, three dynamic degrees of freedom per mass (two translations and onc: torsion), or totally $3 \mathrm{~N}$ dynanic degrees of freedom for a structure with $\mathrm{N}$ lumped masses. However, because only one horjzontal input ground motion is considered in each analysis, the effects of the eccentricity components parallel to the dijection of the ground motion are assumed negligible. That is, only the eccentricity components that are perpendicular to the direction of the ground motion are considered in the following discussions. The above assumption reduces the total number of dynamic degrees of freedom flom $3 \mathrm{~N}$ to $2 \mathrm{~N}$. This appendix examines the effect of eccentricity on the coupled frequencies of a simple one-mass model, and derives the equations of motjun for a general structure with coupling between the lateral translation and torsion.

The simple model shown in Figure $C-1$ has one translational, $x$, one torsional, $\theta$, degree of freedom, a translational stiffness, $k_{x}$, a torsional stiffness, $k_{y}$, and an eccentricity $e$. 
BC-TOP $-4-A$

Rev. 3

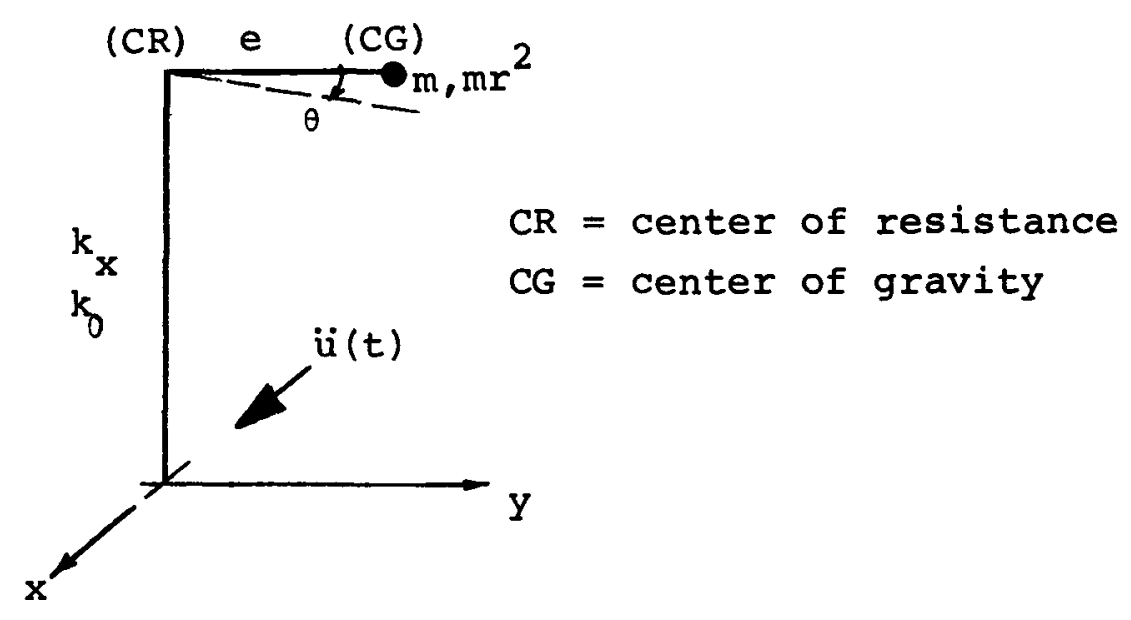

Fig. C-1 A Two-Degree-of-Freedom, Torsion-Translation Model

Let the mass and mass moment of inertia about the center of mass be designated by $m$ and $\mathrm{mr}^{2}$ respectively. The equations of motion of the undamped system about the center of resistance (CR) are:

$$
\left[\begin{array}{cc}
1 & e \\
e & r^{2}+e^{2}
\end{array}\right]\left\{\begin{array}{c}
\ddot{x} \\
\ddot{\theta}
\end{array}\right\}+\left[\begin{array}{cc}
\omega_{x}^{2} & 0 \\
0 & r^{2} \omega_{\theta}^{2}
\end{array}\right]\left\{\begin{array}{l}
x \\
\theta
\end{array}\right\}=-\ddot{u}(t)\left\{\begin{array}{l}
1 \\
e
\end{array}\right\}
$$

where

$$
\begin{aligned}
\omega_{\mathrm{x}} & =\sqrt{\mathrm{k}_{\mathrm{x}} / \mathrm{m}}=\text { uncoupled translational frequency } \\
\omega_{\theta} & =\sqrt{\mathrm{k}_{\theta} / \mathrm{mr}^{2}}=\text { uncoupled torsional frequency } \\
\ddot{\mathrm{u}}(t) & =\text { lateral input ground motion, } \\
\mathrm{x} & =\text { displacement of } C R \text { relative to the base. }
\end{aligned}
$$


The natural frequencies of this system, $\omega_{1}$ and $\omega_{2}$, are given by :

$$
\frac{\omega_{1,2}^{2}}{\omega_{x}^{2}}=\frac{1}{2}\left[1+\frac{e^{2}}{r^{2}}+\frac{\omega_{\Theta}^{2}}{\omega_{x}^{2}} \mp \sqrt{\left(1-\frac{\omega_{\Theta}^{2}}{\omega_{x}^{2}}\right)^{2}+\frac{e^{2}}{r^{2}}\left[\frac{e^{2}}{r^{2}}+2\left(1+\frac{\omega_{\Theta}^{2}}{\omega_{x}^{2}}\right)\right]}\right]
$$

The frequency ratio, $\omega_{1,2} / \omega_{x}$, is shown in Figure $c-2$ for various values of $\omega_{\theta} / \omega_{x}$ and $e / r$. It indicates that, the effect of coupling is negligible on the frequencies if $e / r$ is small and if the torsional frequency is high with respect to the translational frequency. On the other hand, the coupling between translation and torsion is most significant when the uncoupled translational and torsional frequencies are close to each other. Under this condition, the two coupled frequencies are close to each other. When the two frequencies are close to each other, beating type responses occur and, therefore, in the use of the response spectrum technique the sum of the absolute values is used. This is an example of such a situation.

In the following, the equations of motion are derived for a lateral analysis of a multimass structure with $2 \mathrm{~N}$ degrees of freedom. Normally, the mass matrix is a tridiagonal matrix. The diagonal terms represent the mass and mass moment of inertia of the structure at each location of the lumped masses. The off-diagonal terms represent the coupling effect due to the eccentricity of the masses.

The stiffness matrix of the coupled model is a full matrix in general. It consists of two essential parts: the lateral stiffness, $\mathrm{k}_{x^{\prime}}$ of the members and the rotational stiffness, $\mathrm{k}_{\theta}$, of the structure. The assembling of this matrix follows the general procedure outlined for the lateral analysis. It is 
noted, however, that the torsional stiffness of the structure is evaluated on the basis of the lateral stiffnesses of the structural elements and their distance to the center of resistance for a particular story. The torsional rigidity of the individual element is relatively small and thus neglected in determining the overall torsional rigidity of the structure. Figure $\mathrm{C}-3$ shows the model for a multistory building, in which $G_{i}$ is the distance measured from the center of resistance to the reference axis $z$ (positive to the right).

To formulate the equations of motion of the coupled system, an equivalent spring-mass model is constructed as shown in Figure $\mathrm{C}-4$. Let $\mathrm{k}_{i j}$ be the lateral stiffness coefficients, $R_{i j}$ be the torsional stiffness coefficients, $x_{i}$ be the translation of the centers of resistance relative to the input motion $u(t)$, and

$$
J_{i}^{*}=J_{i}+m_{i}\left(e_{i}-G_{i}\right)^{2}
$$

where $J_{i}$ is the local mass moment of inertia. With damping excluded, the equations of motion with respect to the centers of resistance are as follows:

(a) Equilibrium of lateral forces:

$$
\begin{aligned}
m_{i}\left[\ddot{x}_{i}+\left(e_{i}-G_{i}\right) \ddot{\theta}_{i}\right]+x_{i} \sum_{j=1}^{N} k_{j i}-\sum_{j \neq i}^{N} k_{i j} x_{j}+\left(\sum_{j=1}^{i} k_{j i} G_{i}+\sum_{j=i+j}^{N} k_{j} G_{j}\right) \theta_{i} \\
\quad-\sum_{j=1}^{i-1} k_{i j} G_{i} \theta_{j}-\sum_{j=i+1}^{N} k_{i j} G_{j} \theta_{j}=-m_{i} \ddot{u}(t)
\end{aligned}
$$

(b) Equilibrium of torsional moments: 
BC-TOP $-4-A$

Rev. 3

$$
\begin{aligned}
& J_{i}^{*} \ddot{C}_{i}+m_{i}\left(e_{i}-G_{i}\right) \ddot{x}_{i}+\left(\sum_{j=1}^{N} R_{j i}+\sum_{j=1}^{i} k_{j i} G_{i}^{2}+\sum_{j=i+1}^{N} k_{j i} G_{j}^{2}\right) \theta_{i}-\sum_{j \neq i}^{N} R_{i j}{ }^{\Theta} j \\
& -\sum_{j=1}^{i-1} k_{i j} G_{i}^{2} \Theta_{j}-\sum_{j=i+1}^{N} k_{i j} G_{j}^{2} \theta_{j}+\left(\sum_{j=1}^{i} k_{j i} G_{i}+\sum_{j=i+1}^{N} k_{j i} G_{j}\right) x_{i}-\sum_{j=1}^{i-1} k_{i j} G_{i} x_{j} \\
& -\sum_{j=i+1}^{N} k_{i j} G_{j} x_{j}=-m_{i} \ddot{u}\left(e_{i}-G_{i}\right)
\end{aligned}
$$

Eqs. $(\mathrm{C}-4)$ and $(\mathrm{C}-5)$ can be combined in the following matrix form:

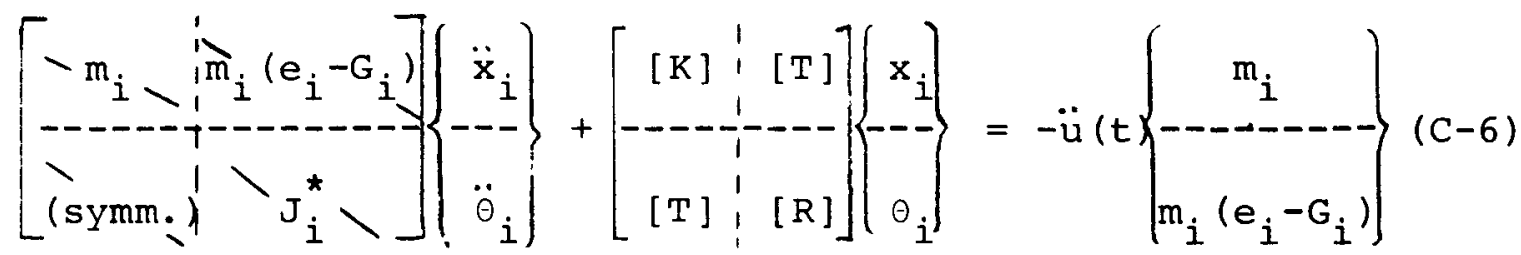

in which $[K]$ is the lateral stiffness matrix when torsion is not included in the analysis, i.e.,

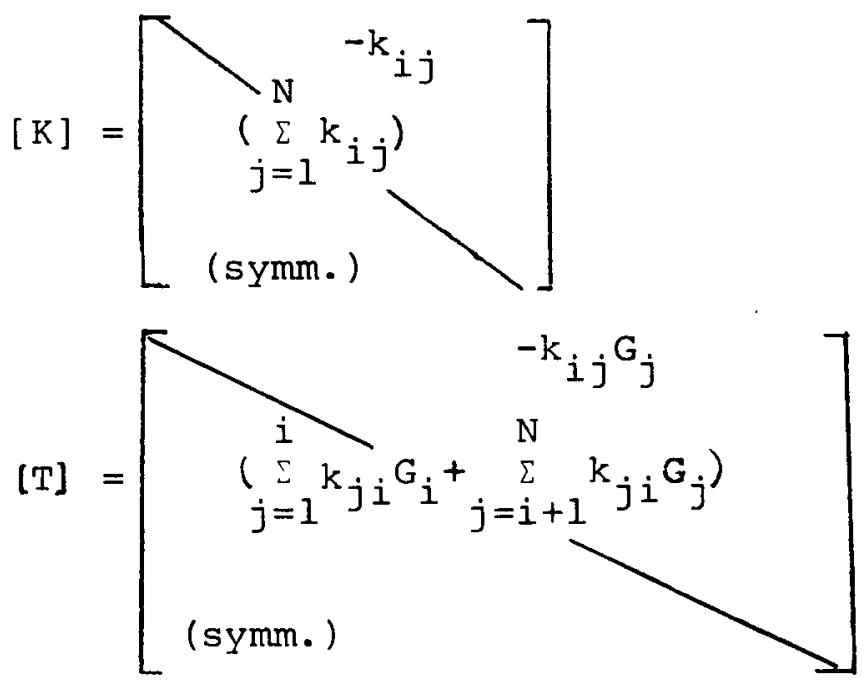




$$
[R]=\left[\begin{array}{l}
\left.\sum_{j=1}^{N} R_{i j}+\sum_{j=1}^{i} k_{i j} G_{i}^{2}+\sum_{j=i+1}^{N} k_{i j} G_{j}^{2}\right) \\
(\text { symm. })
\end{array}\right]
$$

Note that [T] is mainly associated with the lateral stiffnesses of the members and the distances between the centers of resistance and the z-axis. For a typical reactor building or containment structure, the centers of resistance at different elevations usually do not differ much throughout the height of the structure. In this case, the effects of $G_{j}$ can be neglected in the analysis which makes the matrix [T] vanish.

For the same reason, the terms associated with $G_{j}$ in [R] may be dropped out. The reduced [R] matrix will consist of only the torsional stiffnesses of the structure, and it has a form similar to that of the [K] matrix.

The method of analysis, with damping included, is similar to the method described for the uncoupled lateral analysis (Sections 3.0 and 4.0 ).

The total response at any point of the structure is given by:

$$
u_{i}=x_{i}+d_{i} \theta_{i}
$$

where $d_{i}$ is the normal distance between that point and the $\mathrm{x}$-axis. 
Hence, the time history response on the same floor varies from point to point for a coupled analysis, depending on the distance to the center of resistance. The motion of the remotest point on either side of the center of resistance on each floor is taken to be the representative motion of that floor.

With the floor motion computed and the floor response spectrum curves generated, the dynamic analysis of equipment may proceed as described in section 5.0 . 
BC-TOP $-4-A$

Rev. 3

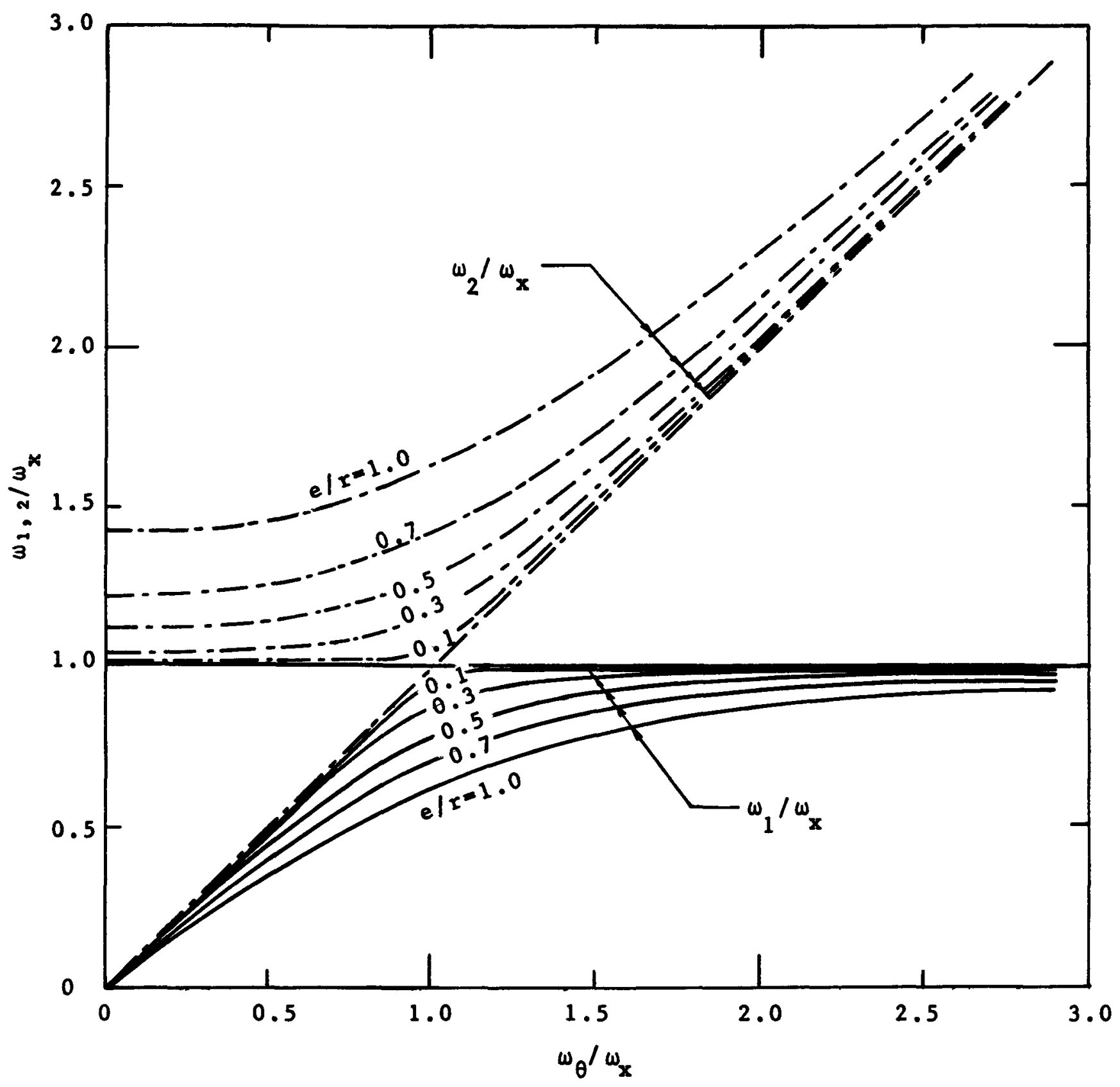

Fig. C-2 Ratio of Coupled Frequencies to Translational Frequency as a Function of $e / r$ and $\omega_{\theta} / \omega_{x}$ 
BC-TOP-4-A

Rev. 3

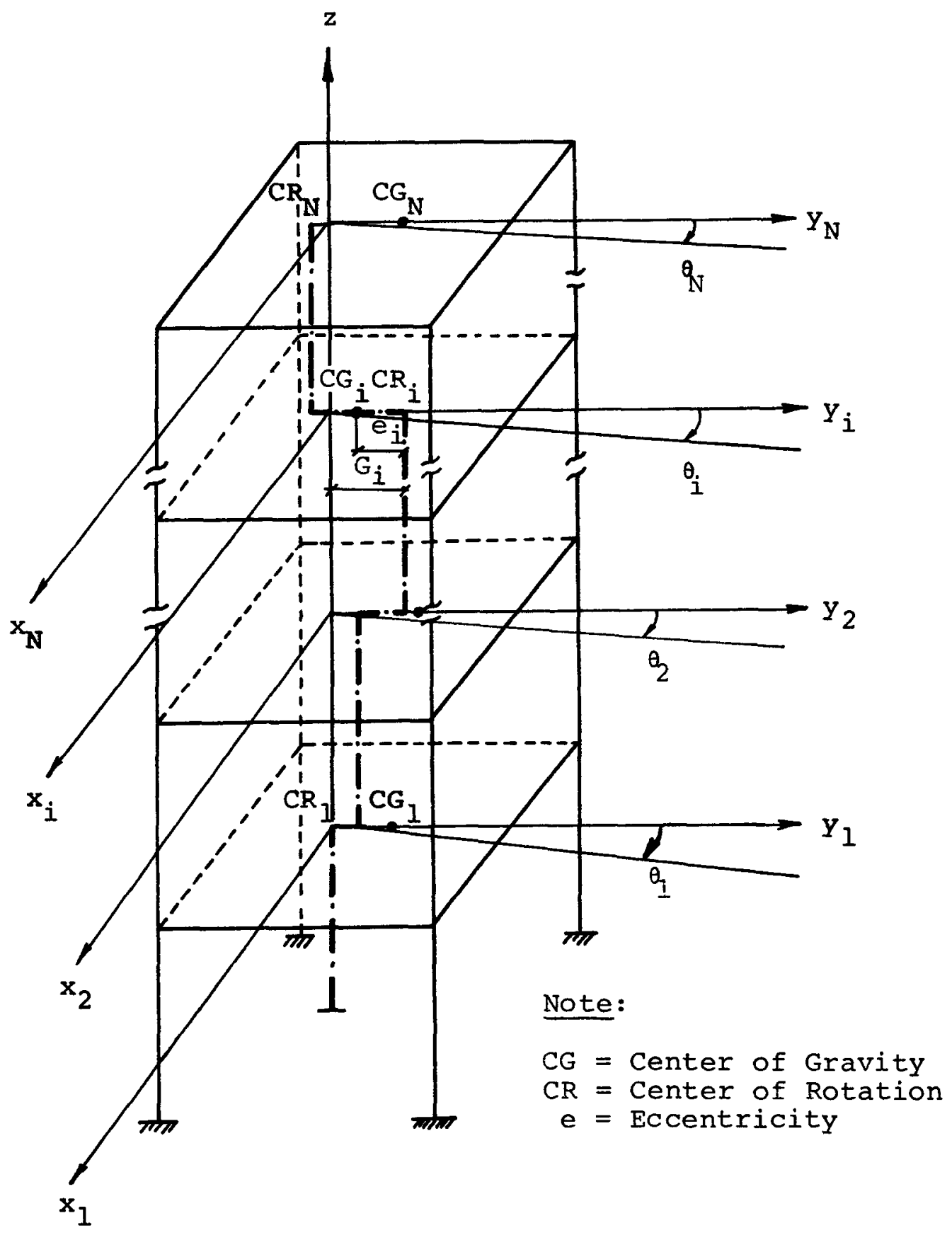

Fig. C-3 structural Model for Coupled Translation-Torsion Analysis 


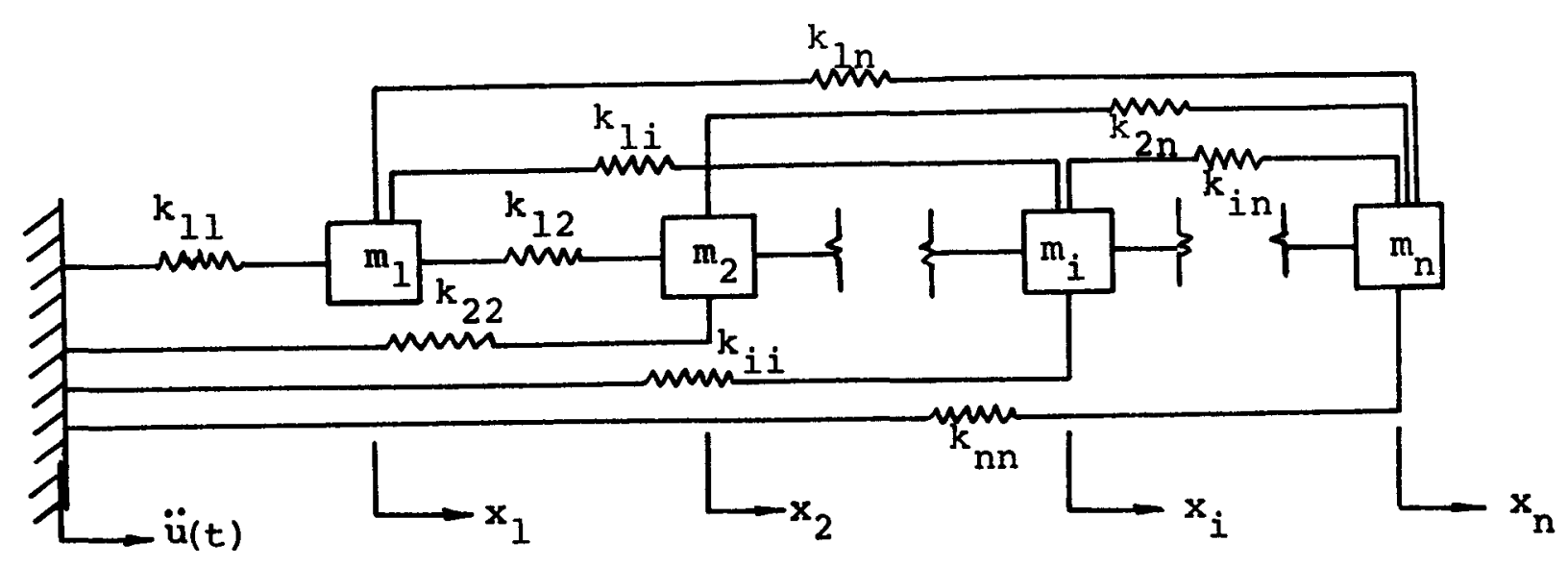

Fig. C-4 A Spring-Mass Analog for the Coupled Translation-Torsion Analysis 
BC-TOP-4-A

Rev. 3

\section{APPENDIX D}

\section{ANALYSIS OF STRUCTURE-} FOUNDATION SYSTEMS

This appendix presents the derivation of the equations of motion for a structure-foundation system subjected to horizontal seismic excitations, where the structure is represented by normal modes. This system becomes a coupled one and, except for very flexible foundations, may usually be approximated by normal modes The technique: for determining the composite structure-foundation modal damping is also presented. The interaction out of the plane of the ground input motion is assumed negligible.

Let $\mathrm{N}$ be the number of lateral translation degrees of freedom, and let $x_{i}, i=1, \ldots, N$, be the lateral translations of the structure relative to the base. The equations of motion for the structure, when it is on a rigid foundation, can be written as:

$$
[M]\{\ddot{x}\}+[C]\{\dot{x}\}+[K]\{x\}=-\ddot{u}(t)\{M\}
$$

in which

$$
\begin{aligned}
& {[M]=\text { mass matrix, }} \\
& {[K]=\text { stiffness matrix, }} \\
& {[C]=\text { damping matrix, }} \\
& \{M\}=\left\{\begin{array}{l}
m_{1} \\
:
\end{array}\right\}
\end{aligned}
$$


BC-TOP-4-A

Rev. 3

Because the structure is represented by normal modes, the normal mode matrix [ $\Phi]$ is such that the following holds:

$$
\begin{aligned}
& {[\Phi]^{T}[M][\Phi]=[1 \backslash]} \\
& {[\Phi]^{T}[K][\Phi]=\left[\omega_{j}^{2} \backslash\right],} \\
& \left.[\Phi]^{T}[C][\Phi]=\left[2 \beta_{j} \omega_{j}\right\rangle\right],
\end{aligned}
$$

In Eq. (D-3) $\quad B_{j}$ and $\omega_{j}$ are the fixed base structural modal damping and frequency respectively.

When the previous structure is interacted with a flexible foundation, the foundation is represented by the base mat, the foundation springs, $\mathrm{k}_{\mathbf{x}}$ and $\mathrm{k}_{\psi}$, and the radiation dampers, $\mathrm{c}_{\mathbf{x}}$ and $\mathrm{c}_{\psi}$. According to Fig. D-1, let $h_{i}$ be the floor elevation, $I_{b}$ and $I_{i}$ be the mass moments of inertia of the base mat and each floor about its individual centroid axis, $y_{b}$ and $y_{i}$ be the structural motion relative to the free field motion $\ddot{u}$, and $\psi$ be the rigid body rocking of the base and structure. Letting

$$
\{y\}=\left\{\begin{array}{l}
y_{1} \\
\cdot \\
\cdot \\
y_{N}
\end{array}\right) \quad\{h\}=\left(\begin{array}{l}
h_{1} \\
\cdot \\
\vdots \\
\dot{h}_{N}
\end{array}\right), \quad \text { and }\{1\}=\left\{\begin{array}{c}
1 \\
\cdot \\
: \\
1
\end{array}\right)
$$


it can be seen that

$$
\{x\}=\{y\}-y_{b}\{1\}-\psi\{h\}
$$

The equations of motion for the structure foundation system then become:

$$
\begin{aligned}
& {[M](\{\ddot{y}\}+\ddot{u}\{1\})+[C]\{\dot{x}\}+[K]\{x\}=\{0\}} \\
& m_{b}\left(\ddot{y}_{b}+\ddot{u}\right)+c_{x} \dot{y}_{b}+k_{x} y_{b}=\sum_{i=1}^{N} m_{i}\left(\ddot{y}_{i}+\ddot{u}\right) \\
& I_{s} \ddot{\psi}+c_{\psi} \dot{\psi}+k_{\psi} \psi=-\sum_{i=1}^{N} m_{i} h_{i}\left(\ddot{y}_{i}+\ddot{u}\right)
\end{aligned}
$$

where

$$
I_{s}=I_{b}+I_{1}+\ldots+I_{N}
$$

Making use of Eq. (D-4) and letting

$$
\{v\}=\left\{\begin{array}{c}
\{y\} \\
y_{b} \\
\psi
\end{array}\right\}
$$

Eq. $(D-6)$ can be rewritten as:

$$
\begin{aligned}
& {\left[\begin{array}{c:c:cc}
{[\mathrm{M}]} & \\
\hdashline & \mathrm{mb}_{\mathrm{b}} & \\
& \mathrm{I}_{\mathrm{s}}
\end{array}\right]\{\ddot{\mathrm{v}}\}+\left[\begin{array}{ccc}
{[\mathrm{C}]} & -[\mathrm{C}]\{1\} & -[\mathrm{C}]\{\mathrm{h}\} \\
\hdashline-\{1\}^{\mathrm{T}}[\mathrm{C}] & \mathrm{c}_{\mathrm{x}}+\{1\}^{\mathrm{T}}[\mathrm{C}]\{1\} & \{1\}^{\mathrm{T}}[\mathrm{C}]\{\mathrm{h}\} \\
-\{\mathrm{h}\}^{\mathrm{T}}[\mathrm{C}] & \{1\}^{\mathrm{T}}[\mathrm{C}]\{\mathrm{h}\} & \mathrm{c}_{\psi}+\{\mathrm{h}\}^{\mathrm{T}}[\mathrm{C}]\{\mathrm{h}\}
\end{array}\right]\{\dot{v}\}+} \\
& \left.+\left[\begin{array}{c:cc}
{[K]} & -[K]\{1\} & -[K]\{h\} \\
\hdashline-\{1\}^{\mathrm{T}}[K] & k_{x}+\{1\}^{\mathrm{T}}[K]\{1\} & \{1\}^{\mathrm{T}}[K]\{h\} \\
-\{h\}^{\mathrm{T}}[K] & \{1\}^{\mathrm{T}}[K]\{h\} & \mathrm{k}_{\psi}+\{h\}^{\mathrm{T}}[K]\{h\}
\end{array}\right]\{v\}=-\ddot{\mathrm{u}}(t)\left(\begin{array}{c}
\{M\} \\
\hdashline \mathrm{m}_{\mathrm{h}} \\
0
\end{array}\right\} \quad D-8\right)
\end{aligned}
$$


Let

$$
\begin{aligned}
& \{\Gamma\}=[\Phi]^{\mathrm{T}}[M]\{1\} \\
& \{\lambda\}=[\Phi]^{\mathrm{T}}[\mathrm{M}]\{\mathrm{h}\}
\end{aligned}
$$

where it can be shown that

$$
\begin{aligned}
& {[\Phi]\{\Gamma\}=\{1\}} \\
& {[\Phi]\{\lambda\}=\{h\}}
\end{aligned}
$$

Then, use the following transformation:

$$
\{\mathrm{v}\}=[\mathrm{A}]\{\mathrm{r}\}
$$

where

$$
[\mathrm{A}]=\left[\begin{array}{c:cc}
{[\Phi]} & & \\
\hdashline & 1 / \sqrt{\mathrm{m}_{\mathrm{b}}} & \\
& & 1 / \sqrt{I_{s}}
\end{array}\right]
$$

Premultiply Eq. (D-8) by $[A]^{\mathrm{T}}$ and apply Eq. (D-11). Eq. (D-8) becomes, upon substituting Eqs. (D-5), (D-9) and (D-10) and considering only the first $n$ structural modes ( $n \leqq N$ ):

$$
\{\ddot{\mathbf{r}}\}+[\overline{\mathrm{C}}]\{\dot{\mathbf{r}}\}+[\overline{\mathrm{K}}]\{\mathbf{r}\}=-\ddot{\mathrm{u}}(t)\{\mathrm{f}\}
$$

in which

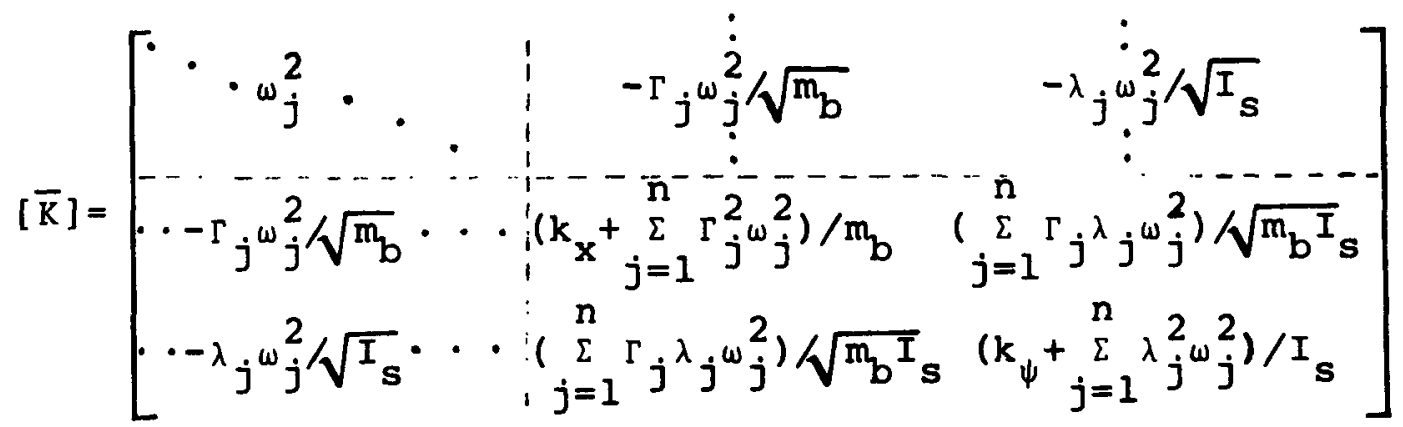


$[\bar{c}]=[\bar{k}]$ with $\omega_{j}^{2}$ replaced by $2 \beta_{j} \omega_{j}, k_{x}$ by $c_{x^{\prime}}$ and $k_{\psi}$ by $c_{\psi^{\prime}}$ $\{f\}=\left|\begin{array}{c}\vdots \\ r_{j} \\ \hdashline \vdots \\ \hdashline \sqrt{m} \\ 0\end{array}\right|$

The number $n$ in Eq. $(D-14)$ is such that $\omega_{n}$ is the first fixed base structural frequency that exceeds the frequency range of interest, which is $33 \mathrm{cps}$ in this case.

Due to the presence of the damping matrix [C], Eq. (D-13) represents a coupled set of equations and must be solved by direct integration. Nevertheless, this coupled structure-foundation system may be sufficiently represented by normal modes in many cases, except when the foundtion medium is very felxible. This implies that upon a transformation of coordinates of

$$
\{r\}=[Q]\{q\}
$$

such that

$$
\begin{aligned}
& {[\mathrm{Q}]^{\mathrm{T}}[\mathrm{Q}]=[\mathrm{I}]} \\
& {[\mathrm{Q}]^{\mathrm{T}}[\overline{\mathrm{K}}][\mathrm{Q}]=\left[-\bar{\omega}_{\mathrm{k}}^{2}-\right] \quad(\mathrm{k}=1,2, \ldots, \mathrm{n+2})}
\end{aligned}
$$

Eq. (D-13) can be approximated by the following set of uncoupled modal equations:

$$
\{\ddot{\mathrm{q}}\}+\left[-2 \bar{\beta}_{\mathrm{k}} \bar{\omega}_{k} \backslash\left[\{\dot{\mathrm{q}}\}+\left[-\bar{\omega}_{k}^{2} \backslash\{q\}=-\ddot{\mathrm{u}}(t)\{\overline{\mathrm{f}}\} \quad(D-18)\right.\right.\right.
$$

In Eq. (D-18) $\bar{w}_{k}$ is the undamped frequency of the structurefoundation system, $\bar{\beta}_{k}$ is the composite modal damping yet to be determined, and

$$
\{\bar{f}\}=[Q]^{T}\{f\}
$$


The composite modal damping is determined by matching the dynamic amplification functions for a predetermined location of both the coupled and uncoupled systems at the natural frequencies $(D-1)$. This predetermined location is usually the floor at the top or other high elevations where the structural response is most sensitive to the values of damping. Let this location be $p$, and let $H_{p}(\omega)$ and $\bar{H}_{p}(\omega)$ be the dynamic amplification functions of the coupled and uncoupled system, respectively, at location $p$. The criterion here states that

$$
\overline{\mathrm{H}}_{\mathrm{p}}\left(\bar{\omega}_{\mathrm{k}}\right)=\mathrm{H}_{\mathrm{p}}\left(\bar{\omega}_{\mathrm{k}}\right), \quad \mathrm{k}=1, \ldots . \quad(\mathrm{D}-20)
$$

This is a set of nonlinear algebraic equations of the unknowns $\bar{\beta}_{k}$, and may be solved by iteration. For the starting values suggested below, the modal damping can usually be obtained within two or three iterations with sufficient accuracy:

$$
\left(\bar{\beta}_{k}\right)_{\text {start }}=\frac{\left|\bar{\Phi}_{p k} \bar{f}_{k}\right|}{2\left|H_{p}\left(\bar{\omega}_{k}\right)\right|}
$$

where

$$
[\bar{\Phi}]=[A][Q]
$$


BC-TOP-4-A

Rev. 3

APPENDIX D REFERENCE

(D-1) Tsai, N.C., Soil-structure Interaction During

Earthquakes, Technical Report, Power and Industrial

Division, Bechtel Corporation, San Francisco,

California, May 1972. 
BC-TOP $-4-A$

Rev. 3

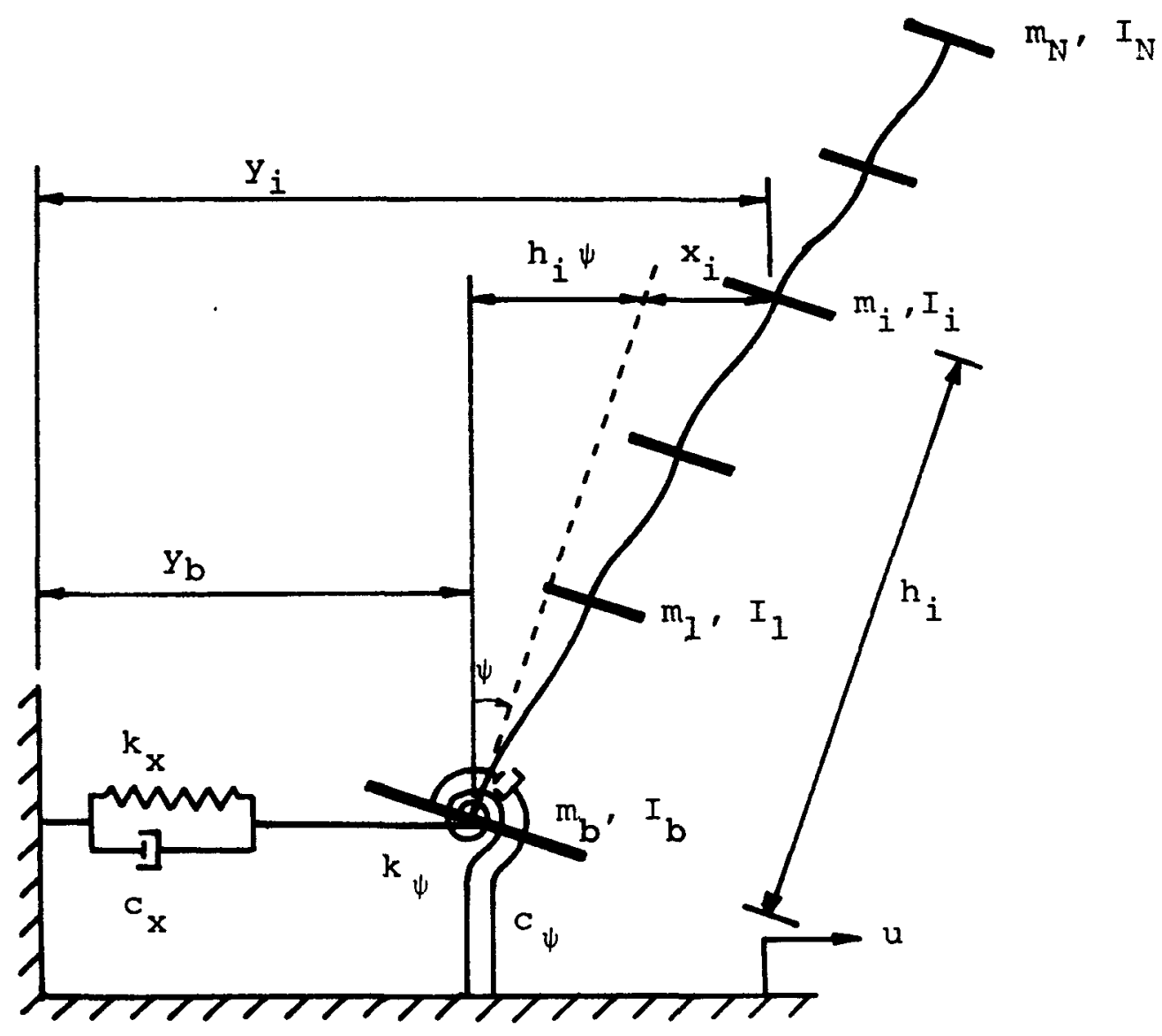

Fig. D-1 A Lumped Mass Model of the Structure-Foundation system

De 


\section{APPENDIX E}

\section{VALIDITY OF MODELING A CYLINDRICAL}

CONTAINMENT STRUCTURE BY CANTILEVER BEAM

To justify the validity of modeling a cylindrical containment structure by an equivalent cantilever beam in horizontal analysis, a study was made of a typical reinforced concrete containment structure which was more realistically modeled as an axisymmetric shell. The containment structure is composed of a 3.75-foot-thick circular cylinder having a mean diameter of 133.75 feet and standing 132.5 feet high, with a 3.25-footthick dome and thickened ring girder.

The modes, or Fourier harmonics, of an axisymmetric shell are usually categorized into two coupled sets - the circumferential modes (denoted by $N, N=0,1,2 \ldots$ ) and the longitudinal modes (denoted by $M, M=1,2,3, \ldots$ ). A plane view of the first five circumferential mode shapes $(\mathrm{N}=0$, ..,4) is shown in Fig. E-1.
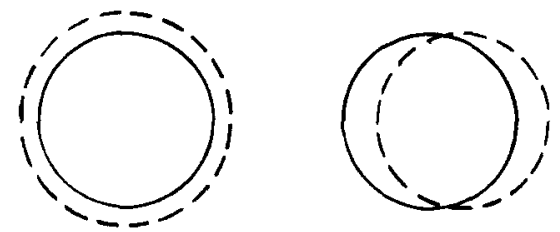

$\mathrm{N}=0$

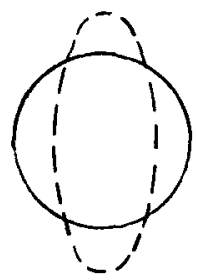

$\mathrm{N}=2$

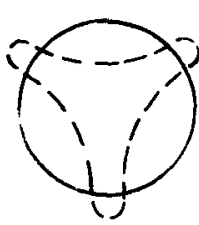

$\mathrm{N}=3$

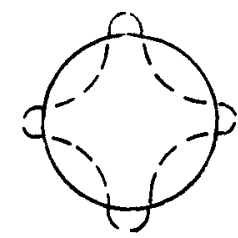

$\mathrm{N}=4$

Fig. E-1 Mode Shapes of the First Five Circumferential Modes

The first circumferential mode $(\mathrm{N}=0)$ is called the breathing mode, and the second $(\mathrm{N}=1)$ is called the beam mode in which any plane section of the shell moves as a rigid ring. The 
higher circumferential modes $(\mathrm{N} \geq 2)$ are called the ovaling modes. Listed in Table E-l are the first two natural frequencies ( $M=1$ and 2$)$ associated with each of the first five circumferential modes for the particular containment structure investigated $(E-1)$.

\section{TABLE E-1}

\section{Fourier Harmonic}

$\mathrm{N}$

0

1

2

3

4

\section{Natural Frequency (cps)}

$\begin{array}{rr}M=1 & M=2 \\ 10.98 & 14.29 \\ 5.27 & 9.98 \\ 9.63 & 19.50 \\ 7.60 & 16.54 \\ 9.96 & 15.42\end{array}$

If the containment structure is a perfectly axisymmetric shell, only the beam mode $(\mathrm{N}=1)$ will be excited when the structure is subjected to horizontal excitation at its base. However, an actual containment structure will deviate from being a perfectly axisymmetric shell. Under such circumstances, a nonlinear coupling exists between the beam mode and ovaling modes so that the ovaling modes will also be excited when the containment structure is subjected to horizontal ground excitations. The validity of assuming beam equivalence for an actual containment structure in a horizontal analysis thus depends upon the relative contribution to the maximum membrane force from the ovaling modes as compared to the contribution from the beam mode alone.

The previous containment model was subjected at its base to the simultaneous excitation of a horizontal motion and a vertical motion (taken to be two-thirds of the horizontal motion). Assuming a small perturbation from perfect axisymmetry and 
considering the nonlinear coupling among the first five circumferential modes, the maximum membrane force at the containment base was found for each of the five circumferential modes. The relative contributions to the total membrane force from each mode are shown in Table E-2. (See Ref. (E-2).)

\section{TABLE E-2}

\section{Percent Contribution to Total}

10.4

1

87.6

The membrane force associated with the first circumferential mode was due mainly to the vertical excitation, and the membrane force associated with the beam mode was due mainly to the horizontal excitation. Table E-2 indicates that the ovaling modes, even though excited, did not contribute significantly to the total membrane force at the base of the containment shell, which justifies the validity of modeling an actual cylindrical containment structure by an equivalent cantilever beam for seismic analysis in the horizontal direction. 
BC-TOP-4-A

Rev. 3

\section{APPENDIX E REFERENCES}

(E-1) Technical Report No. 270.231, Anamet Laboratories, Incorporated, Feb. 1970

(E-2) Technical Report No. 670.157, Anamet Laboratories, Incorporated, June 1970 
APPENDIX G

\section{COMPUTER CODES FOR SEISMIC ANALYSIS}

The following is a list of the computer codes used by Bechtel Corporation for seismic analysis.

\begin{tabular}{|c|c|c|c|}
\hline Code No. & Title & $\begin{array}{l}\text { Document } \\
\text { Traceability }\end{array}$ & Program Capabilitıes \\
\hline CE 309 & STRESS & $\operatorname{PIC}(1)$ & $\begin{array}{l}\text { Generates flexibilities or reduced stiffnesses } \\
\text { for structural models. }\end{array}$ \\
\hline CE 533 & $\begin{array}{l}\text { SLOPE } \\
\text { STABILITY } \\
\text { ANALYSIS }\end{array}$ & PIC & $\begin{array}{l}\text { Determines soil slope stability by the "method } \\
\text { of slices" }\end{array}$ \\
\hline CE 548 & SMIS & PIC & $\begin{array}{l}\text { A command oriented, general purpose matrix } \\
\text { operation program }\end{array}$ \\
\hline CE 576 & $\begin{array}{l}\text { SLOPE } \\
\text { STABILITY } \\
\text { ANALYSIS }\end{array}$ & PIC & $\begin{array}{l}\text { Determines soil slope stability by the } \\
\text { "accurate method of slices" }\end{array}$ \\
\hline
\end{tabular}


COMPUTER CODES FOR SEISMIC ANALYSIS (COn't)

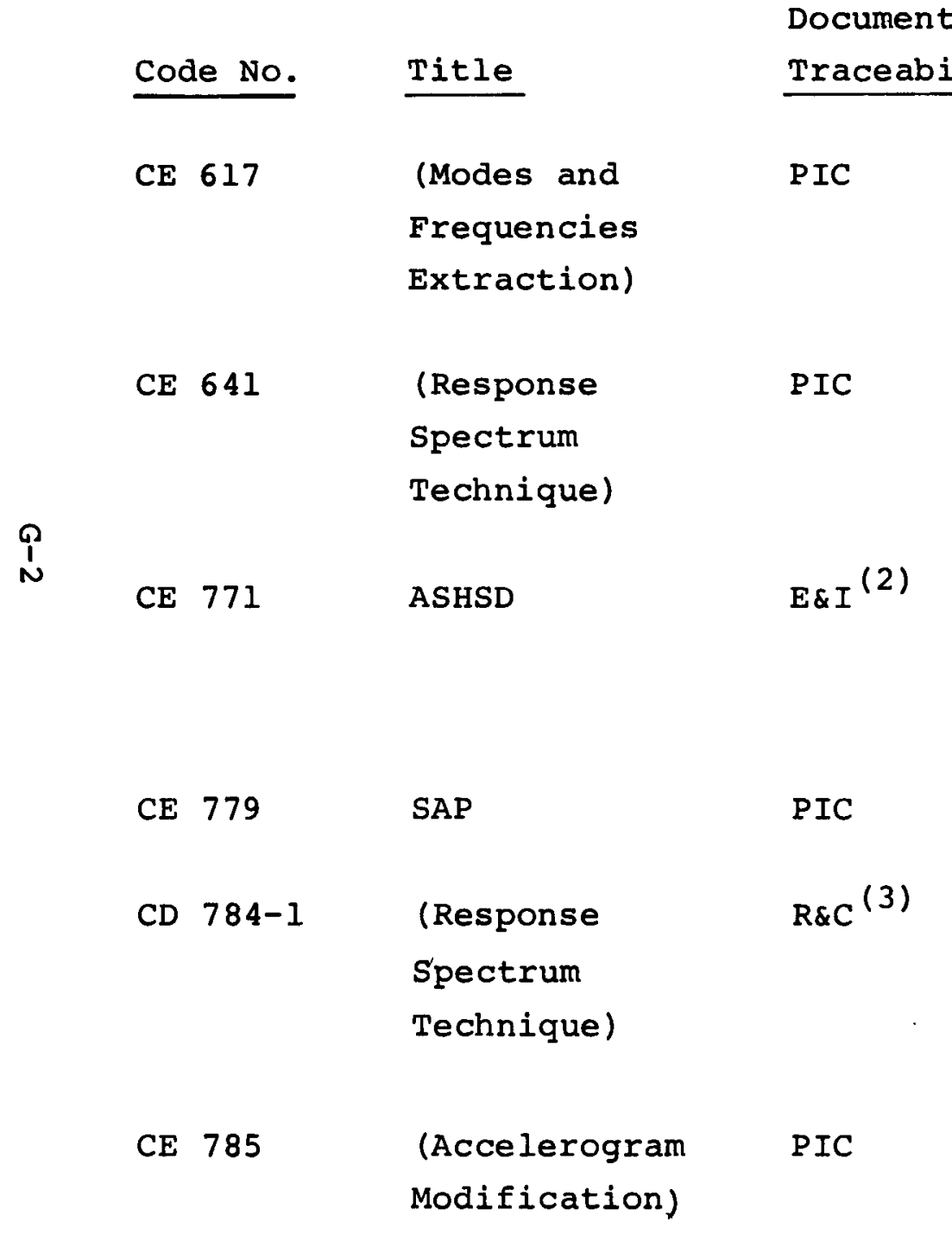




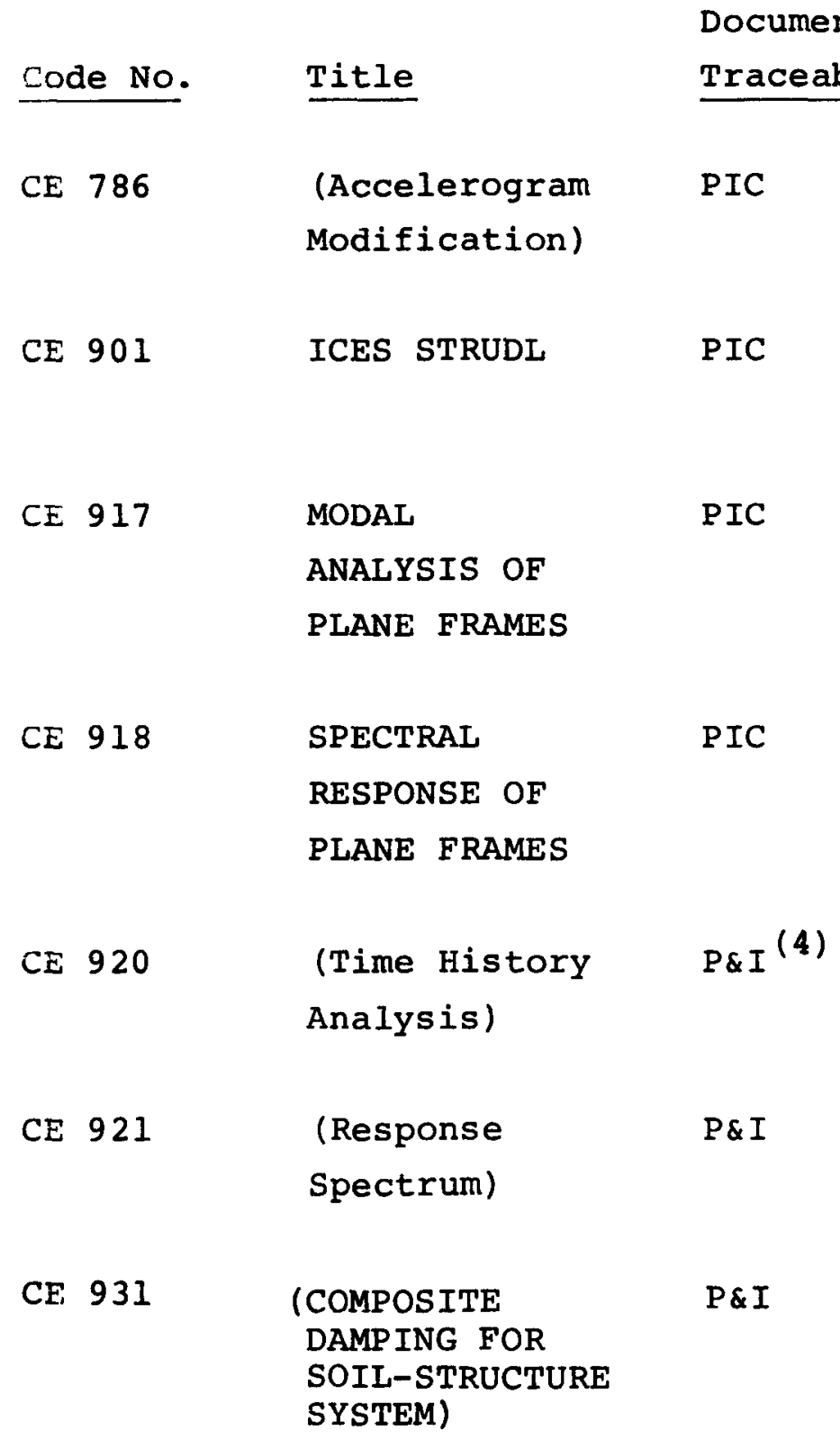

\section{$\underline{\text { Program Capabilities }}$}

Raises locally the response spectrum of a given accelerogram

Similar to $\mathrm{CE} 309$, but has some provisions for dynamic analysis

Determines modes and frequencies of general plane frame structures

Spectral response of general plane frame structures

Time history analysis by modal

superposition

Computes response spectra

Computes composite modal damping for lumped parameter soil-structure interaction. 


\section{COMPUTER CODES FOR SEISMIC ANALYSIS (Con't}

\begin{tabular}{|c|c|c|c|}
\hline \multirow[b]{2}{*}{ Code No. } & \multirow[b]{2}{*}{ Title } & \multicolumn{2}{|l|}{ Document } \\
\hline & & Traceability & Program Capabilities \\
\hline UE 965 & CALCOMP & PIC & CALCOMP plotting on zeta plotter \\
\hline & PLOTTING & & \\
\hline--- & ICES-DYNAL & $E \& I$ & $\begin{array}{l}\text { Determines modes and frequencies of gen- } \\
\text { eral structural models, and performs time } \\
\text { history or spectral response analysis by } \\
\text { modal superposition }\end{array}$ \\
\hline-- & MARC & $\mathrm{CDC}^{(5)}$ & Nonlinear finite element analysis \\
\hline-- & NASTRAN & E\&I & $\begin{array}{l}\text { Structural analysis by a finite element } \\
\text { approach }\end{array}$ \\
\hline--- & SADSAM & $E \& I$ & $\begin{array}{l}\text { Determines real and complex mode shapes } \\
\text { and frequencies, and time history analy- } \\
\text { sis of structures }\end{array}$ \\
\hline--- & SPECTRA & $E \& I$ & Computes and plots response spectra \\
\hline
\end{tabular}




\section{COMPUTER CODES FOR SEISMIC ANALYSIS (CON' $t$ )}

\begin{tabular}{|c|c|c|c|}
\hline Code No. & Title & $\begin{array}{l}\text { Document } \\
\text { Traceability }\end{array}$ & Program Capabilities \\
\hline--- & STARDYNE & $\mathrm{CDC}$ & $\begin{array}{l}\text { Static and dynamic analysis of general } \\
\text { structures }\end{array}$ \\
\hline-- & SUPER SMIS & $E \& I$ & $\begin{array}{l}\text { Static and dynamic analysis of general } \\
\text { structures (a refined version of SMIS) }\end{array}$ \\
\hline
\end{tabular}

I NOTES: (1) Pacific International Computing Corporation
(2) Electrical and Industrial Division, Bechtel Corporation
(3) Refinery and Chemical Division, Bechtel Corporation
(4) Power and Industrial Division, Bechtel Corporation
(5) Control Data Corporation


APPENDIX $\mathrm{H}$

A COMMENTARY

ON

SOIL-STRUCTURE INTERACTION

PREPARED BY:

N. C. Tsai

A. H. Hadjian 
BC-TOP $-4-A$

Rev. 3

\section{TABLE OF CONTENTS}

1. SUMMARY AND CONCLUSIONS

2. INTRODUCTION

3. DISCUSSIONS

3.1 Analytical Approach

3.1.1 Elastic Half-Space Approach

3.1.2 Plane Strain Finite Element Approach

3.1.3 Simplification of the Elastic Half-Space Model

3.2 Dynamic Tests

3.2.1 Tests on Structures

3.2.2 Tests on Footings

3.3 Earthquake Response Observations 
BC-TOP $-4-A$

Rev. 3

\section{SUMMARY AND CONCLUSIONS}

The soil-structure interaction problem is reviewed by evaluating the available theoretical aspects, test data and earthquake observations. A comparison of the assumptions and limitations associated with both the elastic half-space approach and the finite element approach indicates that, for shallowly embedded structures, the elastic half-space approach is preferred and, for deeply embedded structures, the finite element approach might be preferred at the present time owing to the lack of sufficient analytical studies for the first approach.

For the elastic half-space approach, the elastic half-space is usually represented by equivalent lumped parameters which, when correctly considered in the analysis, are acceptable for design purposes. A correct lumped parameter representation implies the use of the interaction damping coefficients as derived analytically from the elastic half-space theory. The lumped parameter interaction system can be analyzed by the method of direct integration or the method of modal superposition; for the latter, the equivalent modal damping values as determined by properly considering the interaction damping coefficients must be used.

To substantiate the fact that relatively high damping values do exist for certain frequencies during interaction, test data and observations during earthquakes are cited. It is concluded that the lumped parameter interaction model using the correctly specified interaction damping values is an acceptable model for predicting the response of at least the shallowly embedded structures. 


\section{INTRODUCTION}

Soil-footing and soil-structure interaction have been the subject of engineering studies since $1936(1,2)$. As the interest in nuclear power plants began to intensify during the last ten years, an extensive research and development effort was launched and is still being continued. The evidence amassed to date is so exhaustive that there should be no doubt at all that both the lumped parameter method and the finite element method are equally acceptable tools if applied appropriately.

Broadly speaking, soil-footing and soil-structure interaction can be predicted in three ways:

\section{(I) Analytical approach,}

(II) Dynamic tests,

(III) Earthquake response observations.

Each of these three ways is discussed in the following.

\section{DISCUSSIONS}

\subsection{Analytical Approach:}

Like most other engineering problems, the most important step in this approach is to realistically define the model. The subsequent mathematical manipulations, although necessary, do not alter the validity of the defined model. The two commonly used analytical approaches for the interaction analysis are the elastic half-space approach, in which the structural foundation is considered a rigid footing resting on an idealized elastic half-space $(3,4,5)$ and the finite element approach in which the soil and the structure are represented by finite elements. 
3.1.1 Elastic Half-Space Approach - Several criticisms are often advanced with regards to the elastic half-space model:

(i) the foundation is not rigid,

(ii) the soil profile is not an elastic half-space,

(iii) the structure is seldom ideally located on the surface of the ground,

(iv) the interaction parameters are derived by applying external excitations to the footing and hence are not applicable to earthquake interaction problems where the excitations come from within the ground; and

(v) the results should not be extended to large foundations.

Each of the above criticisms will be evaluated below.

(i) Regarding the rigid slab assumption, it is very important to distinguish a slab alone on the ground from the foundation slab of a structure. A slab alone, with a given thickness and plan dimensions, is relatively flexible for rocking motion when compared with the same slab supporting, say, a containment structure of about 200 feet tall. This is true because the stiffness of the structure is so large that the slab foundation is not free to deform as it would in the absence of the structure; the slab must follow the general motion of the superstructure. The adequacy of the rigid slab assumption is similar to that of the common practice in representing the walls and other resistant elements between the floors by the static stiffnesses of beam elements when establishing a lumped mass structural model, while in reality 
there is always local, higher mode deformation between the floors. Therefore, any local bending deformation of the slab foundation is of a secondary order of magnitude in comparison with the rigid body rotation. The stiffening effect of the slab foundation of a structure has been studied even for limber structures such as highrise buildings ( 6$)$.

(ii) Regarding the assumption of an elastic halfspace, it would be interesting to raise the same question to all materials used by the engineers. First of all, the conventional assumptions of "elastic, homogeneous and isotropic" have been proved to be an acceptable practice for all engineering analyses for a long time. With regards to soil, due to the overburden and confining pressure at depth the assumption of elastic, isotropic, homogeneous material is still a reasonable approximation. This becomes more valid in view of the magnitude of the static pressure underneath the foundation, which is usually about $5 \mathrm{ksf}$ and is equivalent to about 40 feet of soil overburden. Thus, even if the structure is at ground surface, the soil immediately underneath the structure base is under pressure high enough to justify the assumption of an elastic half-space.

Secondly, in using geophysical surveys to measure the parameters necessary for the interaction analysis, the effect of any inhomogeneity or layering of the soil is automatically accounted for in the measurements. Because the measured 
data represent the averaged over-all geophysical properties of the site, there is no reason why the site cannot be treated as an equivalent elastic half-space with the measured data as its properties.

Thirdly, the criticism against the assumption of uniform half-space is usually intended for more flexible soil because layering is anticipated to be more pronounced in this case. However, a fact has always been overlooked; that is, the material damping also increases with the soil flexibility. This increasing material damping helps diminish the wave reflection at the layer interfaces, thus making the more flexible subsoil still behave like a uniform half-space. It is this same reason that the conventional finite element approach has to rely on the material damping in the soil to reduce the effect of wave reflection at the boundaries so as to approximately simulate the wave radiation effect in the interaction analysis. In addition, the elastic half-space approach usually uses only the interaction damping as derived from the theory. With layering present the interaction damping will be slightly reduced (4), but the increased material damping could just offset the reduced amount of interaction damping. Therefore, from an overall point of view it is still reasonable to assume the interaction damping derived for a uniform half-space closely represents the combined effect of the actual interaction damping and material damping for flexible, possibly layered soils. 
(iii) Regarding the criticism that the structural foundations are seldom ideally on the ground surface, it is true that the embedment could play an important role if it is considerable. For relatively shallow embedment, however, tests indicate that the side soil plays a very minor role, if any (7). The reason is simple, as is demonstrated below. The effect of the side soil depends on the depth of embedment, its ratio to the height or width of the structure, and the flexibility of the structure. Referring to Figure 1 for the same structure but with different depth of embedment, as the embedment increases a larger passive soil pressure must be mobilized to allow for structural movement.

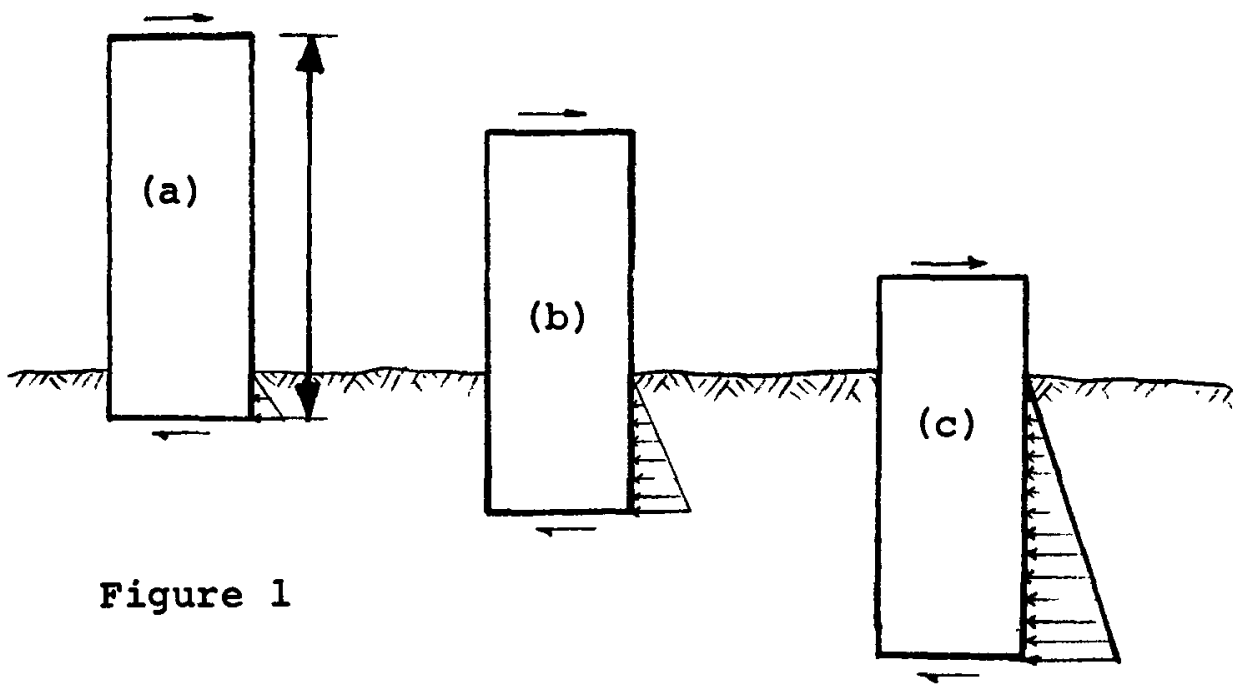

Obviously, it is much easier for structure (a) to push against the side soil and vibrate almost freely than for structure (c) because the side soil in Case (a) is more liable to being displaced permanently and hence losing contact with the structure. Looking from another point of view, for the same structural displacement at the top, structure (a) moves less at the ground surface level than does structure (c) in the 
absence of the side soil, thus making the side soil interaction in Case (a) a relatively minor problem. This implies that both the depth of embedment and its ratio to the total structural height determine the significance of the side soil effect. The latter becomes more obvious by examining the three structures of different total height but the same embedment (see Figure 2). Structure (a) can probably be analyzed by neglecting the embedment effect while structure (c) would probably require considering the embedment effect in the analysis.

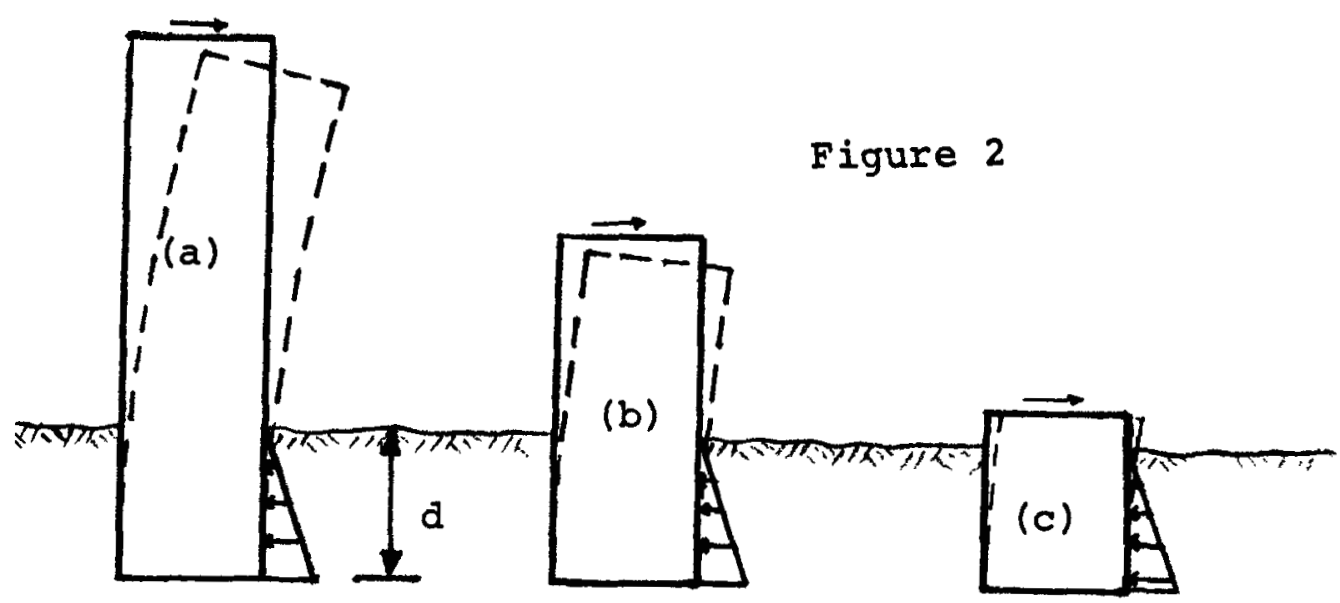

The significance of the embedment also depends on the ratio of the depth of embedment to the width of the structure. Figure 3 shows three rectangular structures having the same dimension normal to the plane of motion, the same total height and embedment but different width. The resistance to motion due to the side soil is the same for all cases, but the resistance underneath the base is evidently larger for structure

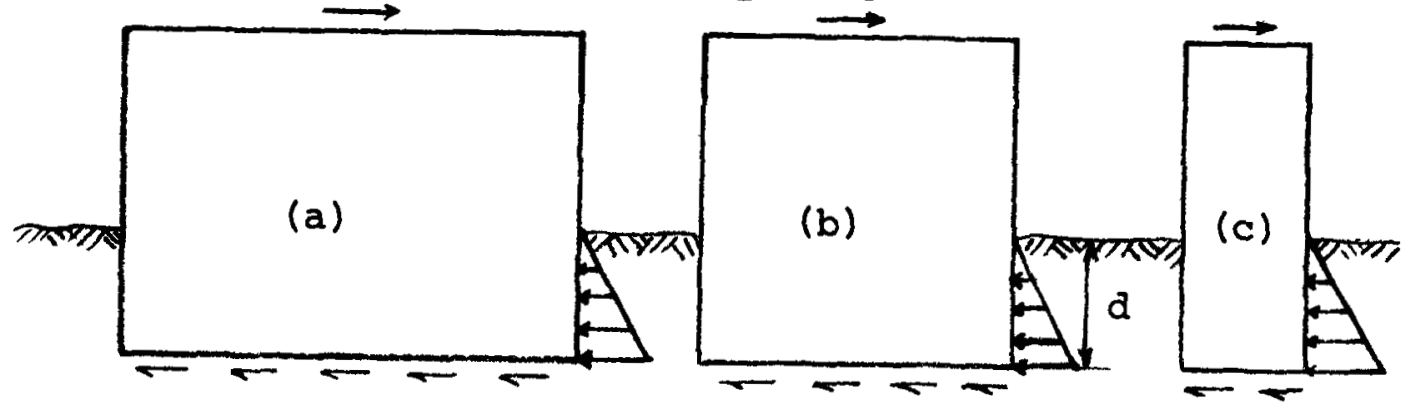

Figure 3 
BC-TOP $-4-\mathrm{A}$

Rev. 3

(a) than for Structure (c). Hence, the side soil effect becomes relatively less significant for Structure (a) to the extent that it can be neglected in the analysis.

Finally, the effect of embedment depends on the flexibility of the structure. Referring to Figure 4 , the deflection of a more flexible structure at the ground surface level is larger in the absence of the side soil. With the presence of the side soil, the

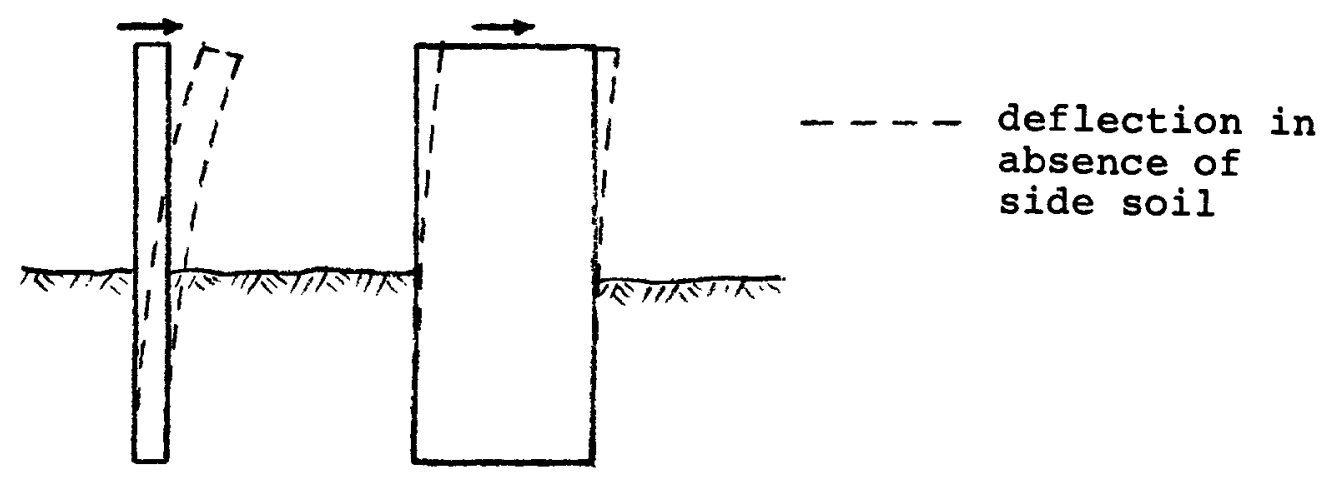

Figure 4

more flexible structure will enhance larger interaction effects since a larger passive pressure must be mobilized due to the larger displacement. This observation would be valid for nuclear power plant structures although it may not for extremely flexible structures.

In short, it can be concluded that, by evaluating the physical behavior of the side soil, a shallowly embedded containment structure is not significantly affected by the embedment. For relatively deep 
embedment, the effect of embedment should be accounted for, possibly with some of the soil close to the ground surface removed from the analysis because it offers little resistance and could in effect distort the structural response if it is included in the analysis.

(iv) Regarding the criticism against the applicability of the parameters derived from external excitations to the earthquake interaction problem, it can be shown that this criticism is unfounded.

During earthquakes, the interaction takes place not as a direct result of the earthquake motion itself, but because of the inertia force of the base slab and the forces transmitted to the base from the structure above. These forces are still external ones, and they cause the interaction. Thus the thought that applying external excitations to the footings would overestimate the interaction damping that should be used for earthquake interaction problems, has no basis. In terms of the equations of motion:

$$
[M]\{\ddot{x}\}+[C]\{\dot{x}\}+[K]\{x\}=\{f\}
$$

the interaction damping in the damping matrix [C] as determined by applying external excitations should not vary because of earthquake problems. The only difference between an external excitation and an earthquake excitation is reflected in the right-hand side of Equation (1) $(\{f\}=-\ddot{u}\{M\}$ for the earthquake case).

(v) Regarding the applicability to large foundations, the previous evaluations will provide the answer. Having established in subsection (i) that the foundation slab 
of containment type structures can be adequately considered rigid, in subsection (ii) that the assumption of an elastic half-space is a reasonable approximation, and in subsection ( $i i i)$ that the usual embedment for containment structures has only minor effects, if any, it is adequate to use the elastic half-space approach for a reasonable interaction analysis. As the theory does not make any assumption regarding the size of the foundation, it is most interesting to question the applicability of the theory to large foundations. Several factors must be borne in mind when one evaluates large footing test data against the theory:

- As argued in (i), a footing alone may not be rigid enough to justify a comparison with the theory.

- The experimental evidence could be mistranslated, as is often the case.

- The experiments are not necessarily valid. How the tests are done is a very important consideration.

- Other experiments indicate the opposite conclusions $(8,9,10)$. It must be noted that the foundations of those structures dynamically tested are by no means "small" ones.

3.1.2 Plane Strain Finite Element Approach - The State-ofthe-Art is such that under certain circumstances the finite element approach seems to be the more appropriate means of analysis. The case of deeply embedded structures is a typical example because analytical work for flexible, deeply embedded structures has not been generally available. However, the finite element approach also has some shortcomings, as listed below: 
a) The finite elements only approximate the elastic continuum.

b) The mesh size dictates the validity of the response of high frequencies unless very fine elements are used, but then there is a solution feasibility limit on the number of elements that can be used.

c) The overall size of the model is also restricted by economic and solution feasibility limits. This is because the finite boundary conditions are perfect reflectors of waves, thus distorting the response computations.

d) This approach requires the generation of a base rock motion from the design motion specified at the ground surface. Such generation is not yet satisfactorily resolved and hence the response depends largely on how the base rock motion is generated. The elastic half-space approach does not have this problem because it uses the design ground surface motion directly.

e) The plane strain representation of the actual three-dimensional nature of the structure and the soil is an apfroximation while the elastic half-space approach correctly accounts for the three-dimensional nature of the problem.

\subsubsection{Simplification of the Elastic Half-Space Model -}

Although the half space theory can be implemented without any simplification (5), for practical purposes it is worthwhile to simplify the solution by using equivalent parameters. It has been shown that the elastic half-space can be conveniently approximated by pairs of springs and dampers for each interaction degree of freedom. These parameters are frequency dependent. For translation, the frequency dependency 
is small over a wide range of frequencies and a constant approximation of the parameters is adequate (4). For rocking, the variation with frequency is larger but it is still adequate to select the parameters for rocking according to the computed rocking frequency.

Once the equivalent lumped parameters are determined they should be used without any modification because there is no justification at all for such adjustment. For instance, to arbitrarily set an upper limit value on the interaction damping can create amplified response at some frequencies that have never been detected over the long history of structural testing or observations during earthquakes. From a mathematical point of view, there are $\mathrm{N}+2$ degrees of freedoms for lateral interaction analysis of a structure having $\mathrm{N}$ degrees of freedom. However, the testing records on all types of structures consistently miss the two additional interaction frequencies because, during a test, a resonant frequency is identified only when a large amplitude response is observed. Furthermore, the few available data indicate that the earthquake motions recorded at both the basement and the free field of a structure are always similar to each other (2, $10,11,12)$. All these evidences indicate that the additional interaction frequencies must be somehow suppressed from a theoretical point of view.

In analytical calculations there should also be no resonant response introduced at the two additional interaction frequencies if the interaction damping coefficients are correctly considered $(5,10,13,14)$. When the method of direct integration is used to solve the equation of motion which contain a non-proportional damping matrix, no erroneous resonant 
response will be introduced. However, when the method of modal superposition is used, to limit all the modal damping values at the same order of magnitude as those used for fixed base structural analyses could introduce erroneous resonant response. This aspect is usually overlooked. Instead, it is generally thought that using the modal damping as properly computed from the correct interaction damping coefficients would pronouncedly "filter" the response if relatively high damping is predicted for the interaction modes.

In conclusion, the classically held opinion of low damping is based on the dynamic tests of structures while it has been shown above that the tests are not able to detect the suppressed interaction modes which theoretically exist. To obtain reasonable response, the appropriately determined modal damping values should be used. Both dynamic tests and earthquakes observations support this conclusion.

\subsection{Dynamic Tests}

Dynamic Tests have been performed by many researchers on both structures and footings in order to verify the adequacy of the analytical approaches. Some representative test results are summarized below.

3.2.1. Tests on Structures - A typical example is the one recorded in Reference (12). The structure model is a reinforced concrete one, having a single story and a basement. Its dimension is $3.5 \mathrm{~m} \times 3.5 \mathrm{~m}$ square in plan and $7.4 \mathrm{~m}$ in overall height. Testing was first done with the structure base sitting in an open excavation $3.5 \mathrm{~m}$ deep. The structure may be considered as sitting on the ground surface in this case. The two observed frequencies within 
$30 \mathrm{cps}$ are 6.9 and $29 \mathrm{cps}$. The associated damping value is 58 of critical for the first mode and exceeds $20 \%$ of critical for the second mode.

The same structure was tested again after the excavation was backfilled to the original ground surface. The observed resonant frequency became $7.5 \mathrm{cps}$ for the first mode and the resonant amplitude dropped remarkably when compared with that observed before the backfill. The associated damping became $12 \%$.

For analytical interpretations, the authors of (12) were able to obtain reasonably good agreement by simply considering the structure as a rigid body and using lateral and rocking springs and dampers to represent the foundation soil. Later, structural and ground motions were recorded during several small tremors. Again, the authors closely predicted the structural motion by using the same mathematical model developed for the dynamic tests.

The above results indicate that: a) the lumped parameter represenation is adequate for simulating interaction, b) as anticipated, the backfill increased the equivalent foundation resistance and, more importantly, the interaction damping value. The latter is obvious from a theoretical point of view because, with the backfill, the larger surface area of contact between the structure and the soil allowed more wave energy to transmit from the structure into the ground through the interaction.

As another example of structural testing, a recent case study of soil-structure interaction (10) clearly demonstrated the existence of highly damped interaction modes when the structure was considered with interaction springs and damping (with $\mathrm{N}+2$ modes) instead of a fixed base (with $\mathrm{N}$. modes). This is so because the 
BC-TOP-4-A

Rev. 3

results from both the flexible and the fixed base models would agree with each other as well as with the test results only if the additional interaction modes for the flexible base structure analysis are highly damped. The conclusion is, therefore, the suppression of the interaction modes is necessary to realistically simulate the interaction mechanism.

3.2.2 Tests on Footings - A typical example is the test done by Novak (15). Novak conducted both vertical and lateral vibration tests on a cubic steel body having a dimension of $\operatorname{lm} \times 1 \mathrm{~m} \times \mathrm{lm}$. The steel body was tested for different embedment conditions, namely, fully embedded, two-thirds embedded, one-third embedded and unembedded. Typical test results in terms of the frequency response curves are shown in Figure 5 which is a reproduction from Figure 14 of Reference (15). It is evident that the embedment increases both the effective stiffness of the soil and the interaction damping.

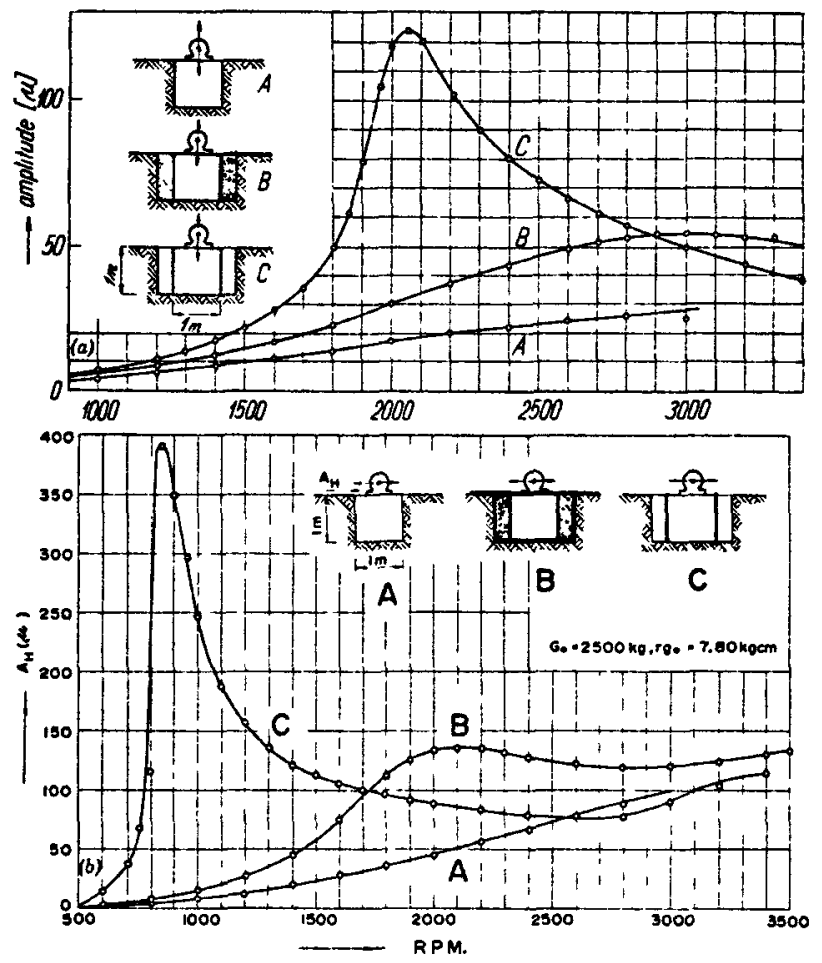

Figure 5

FIG. 14.-COMPARISON OF FOUNDATION RESPONSE TO: (a) VERTICAL; (b) HORIZONTAL EXCITATIONS WITH VARIOUS TYPES OF CONTACT BETWEEN SIDES AND SURROUNDING SOIL, AT SAAIE EXCITATION INTENSITIES. [A-undisturbed soll, Bcompacted ftll material, C-air gab (vertical excitation $r g_{0}=11.55 \mathrm{~kg}$ per cm, hortzontal excitation $r g_{0}=7.80 \mathrm{~kg}$ per $\mathrm{cm}$ )]

(From Reference (15)) 
According to Reference (15), the interaction damping from the vertical tests of the unembedded steel block varied from 98 to 188 of critical. For the fully embedded case, the damping was more than double that of the unembedded case. On the other hand, typical damping values from the lateral shaking tests were $4 \%$ of critical for the unembedded case to about $10 \%$ of critical for the fully embedded case (see Figure 5).

It would be interesting to compare the observed interaction damping with that predicted by the simplified elastic halfspace theory (see Table 3.2 of Bechtel Seismic Topical, BC-TOP-4, Revision 1) for the unembedded case:

a) For vertical vibration, Curve $\mathrm{C}$ in the upper diagram of Figure 5 gives a damping value of $12 \%$ of critical. According to the Bechtel Seismic Topical, it can be shown that the vertical interaction damping is, in terms of percentage of critical damping:

$$
\beta_{z}=0.85 \sqrt{\gamma R^{3} / G_{0}(1-v)}
$$

in which $\gamma, R, G_{0}$ and $\nu$ are, respectively, the unit weight of the soil, the equivalent circular base radius, the weight of the fourdation and Poisson's ratio. From Reference (15) and Figure 5:

$$
\begin{aligned}
& \gamma \simeq 0.13 \mathrm{kip} / \mathrm{ft}^{3} \\
& R \simeq 1.6 \mathrm{ft}(=0.5 \mathrm{~m}) \\
& G_{0}=5.5 \mathrm{kip}(=2.500 \mathrm{~kg}) \\
& \nu=0.4
\end{aligned}
$$

Hence,

$$
\beta_{z} \simeq 108
$$

which is in good agreement with the observed value of 128 . 
b) For lateral vibration, curve $C$ in the lower diagram of Figure 5 gives a damping of about 48 of critical. It must be pointed out here that the observed resonant frequency is most probably the rocking frequency rather than the translation frequency. This is because the shaking force was applied at $1.4 \mathrm{~m}$ high above the base of the steel body and it is apparent from this point of application that the rocking mode would predominate over the translational mode. This observation can be verified analytically by the elastic half-space theory. Hence, the observed damping value should be compared with that computed analytically for the rocking mode.

According to the Bechtel Seismic Topical, the rocking damping is, in terms of percentage of the critical damping

$$
B_{\psi}=\frac{0.3 R^{2}}{1+B_{\psi}} \sqrt{\frac{2 \gamma R}{3 I_{0}(1-v)}}
$$

The numerical value is $\left(B_{\Psi} \simeq 4, I_{0} \simeq 5 G_{0} R^{2} / 3\right.$ in this case):

$$
\beta_{\psi} \simeq 1.58
$$

which is more conservative than the observed value of $4 \%$. The above numerical calculations verify the adequacy of the interaction damping for the test cases presented in Figure 5. Novak made the similar conslusion in favor of the lumped parameter approach. It must be noted that the elastic half-space theory specified the interaction damping in terms of the damping coefficients rather than the percentage of critical damping. The damping coefficients are independent of the mass of the footing and depend only on the stiffness of the soil and the dimension of the footing. Consequently, the interaction damping coefficients are the same for two equal size footings on the same soil profile, but the per- 
centage of critical damping will be different if the masses of these two footings are not the same. When applied to Novak's test results, this means that all the observed interaction damping in terms of the percentage of critical damping would be increased by a factor of $\sqrt{2}$ if the masses of the footings tested are reduced by one-half while the base areas remain the same.

\subsection{Earthquake Response Observations}

Housner made one of the earliest studies on soil-structure interaction during actual earthquakes (2). He compared the velocity spectra of both the basement motion of the Hollywood storage Building and the motion at a nearby parking lot (112 feet away) recorded during the 1952 Arvin-Tehachapi earthquake. The spectra are very similar to each other, indicating that the interaction effect was not appreciable in general. The building is a concrete box type structure having a measured resonant frequency of 2 cps in the stiffer direction (the longer direction). It is on a pile foundation in soft alluvium. The basement velocity spectrum in the stiffer direction of the building is consistently lower than the corresponding parking lot spectrum, indicating an across-the-board damping effect. The fact that no distinguished peaks are observed on the velocity spectrum of the basement record can be analytically interpreted only if high damping is used for the interaction modes, as concluded in Section 3.1 .

The similarity between the spectra of the recorded basement motion and a nearby free field motion was also observed at the Southern Pacific Building during a nuclear testing event in 1968 (11). There was no observable 
resonant peak on the basement spectrum due to the interaction effect. Similar spectral properties of several basement motions were again observed during the 1971 San Fernando earthquake when the basement spectra were compared with the spectra of the higher elevation structural motions.

In conclusion, to realistically analyze the soil-structure interaction by the method of modal superposition, the interaction modes must be properly suppressed to avoid erroneous resonant response. Appropriately computed modal damping values (e.g., by the technique illustrated in the Bechtel Seismic Topical), dynamic test data and actual earthquake observations all support this conclusion. 